Aus dem Institut für Anatomie und Zellbiologie

(Prof. Dr. rer. nat. J. Wilting) im Zentrum Anatomie

der Medizinischen Fakultät der Universität Göttingen

\title{
Untersuchung spezifischer Inhibitoren der \\ PI3K-Signalkaskade zur Therapie des \\ Lymphangioms
}

\author{
INAUGURAL-DISSERTATION \\ zur Erlangung des Doktorgrades \\ für Zahnheilkunde \\ der Medizinischen Fakultät der \\ Georg-August-Universität zu Göttingen
}

vorgelegt von

Hannah Leonore Blesinger

aus

Wurmberg

Göttingen 2019 
Dekan:

\section{Betreuungsausschuss}

Betreuer/in:

Ko-Betreuer/in:

\section{Prüfungskommission}

Referent/in:

Ko-Referent/in:

Drittreferent/in:
Prof. Dr. rer. nat. H. K. Kroemer

Prof. Dr. rer. nat. J. Wilting

PD Dr. rer. nat. S. Kaulfuß
Prof. Dr. rer. nat. J. Wilting

Prof. Dr. med. P. Ströbel

Prof. Dr. med. dent. R. Mausberg

Datum der mündlichen Prüfung: 20.07.2020 
Hiermit erkläre ich, die Dissertation mit dem Titel "Untersuchung spezifischer Inhibitoren der PI3K-Signalkaskade zur Therapie des Lymphangioms" eigenständig angefertigt und keine anderen als die von mir angegebenen Quellen und Hilfsmittel verwendet zu haben.

Göttingen, den

(Unterschrift) 


\section{Inhaltsverzeichnis}

Abkürzungsverzeichnis................................................................................................. III

Tabellenverzeichnis .......................................................................................... V

Abbildungsverzeichnis .........................................................................................VI

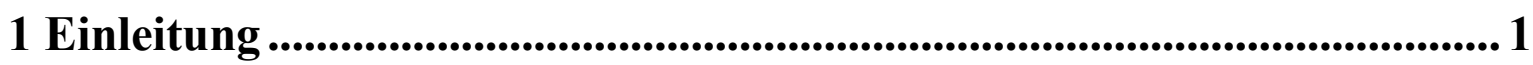

1.1 Das Lymphgefäßsystem .................................................................................

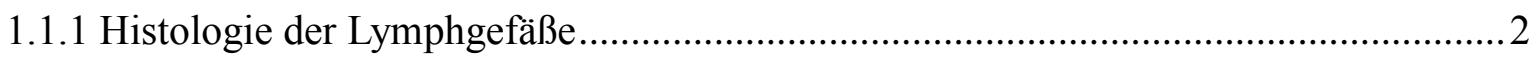

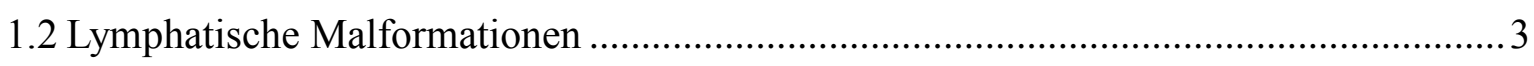

1.2.1 Diagnostik von lymphatischen Malformationen......................................................

1.2.2 Behandlungsmöglichkeiten von lymphatischen Malformationen ................................

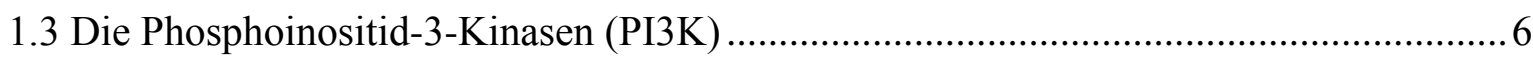

1.4 PI3K-AKT-mTOR-Signalkaskade..................................................................

1.5 Hypothesen und Ziele der Arbeit ................................................................................

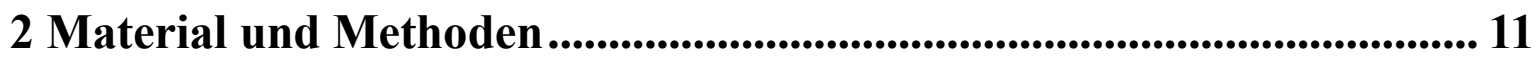

2.1 Geräte

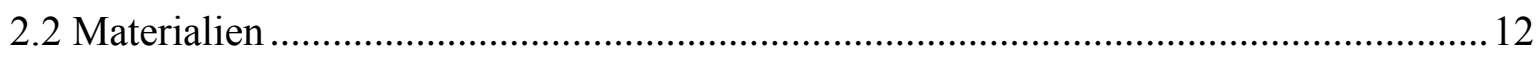

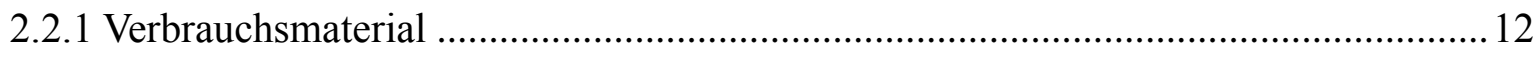

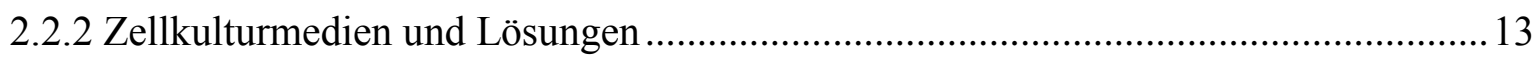

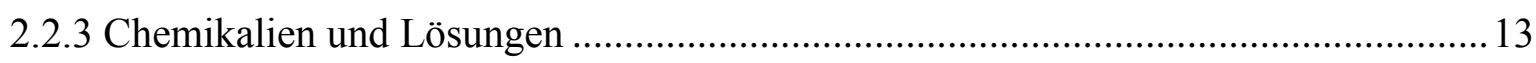

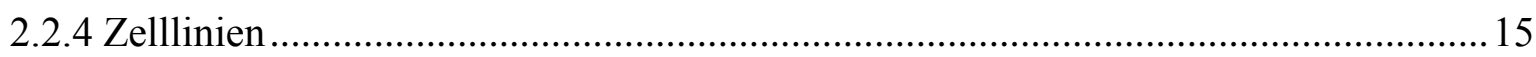

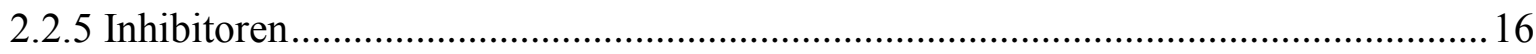

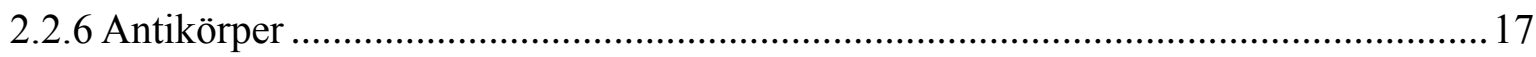

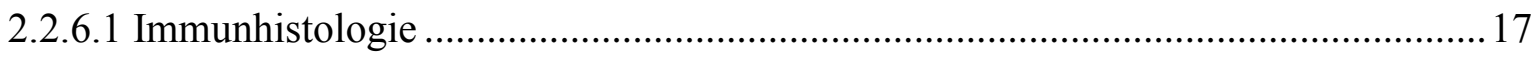

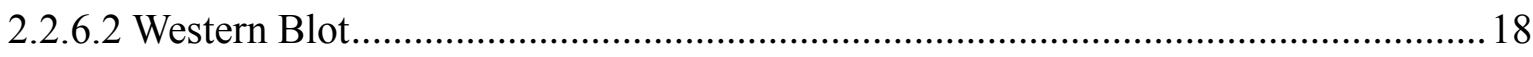

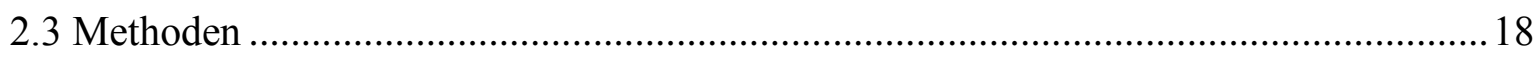

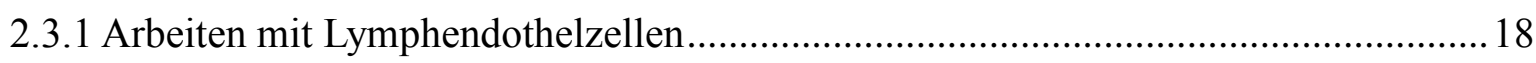

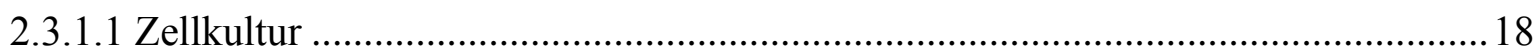

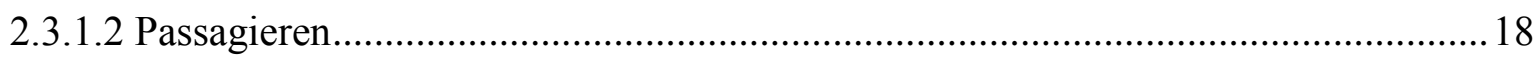

2.3.1.3 Einfrieren und Auftauen von Zellen ................................................................... 19

2.3.2 Zellzählung mittels Coulter-Counter Z1 ………….............................................. 19

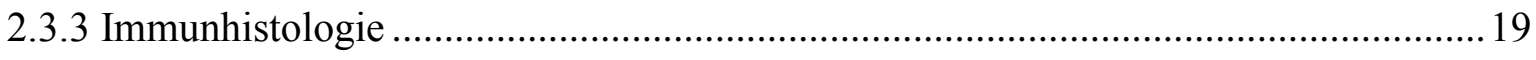

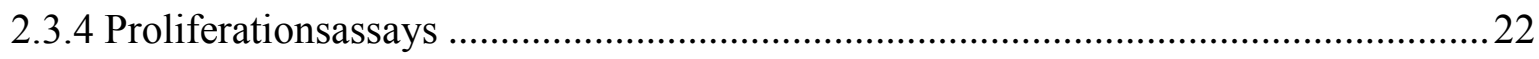

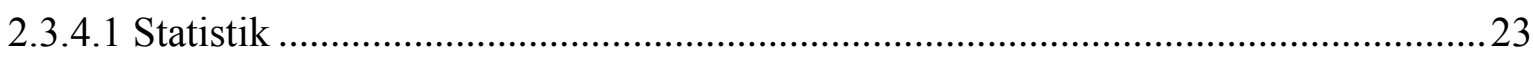

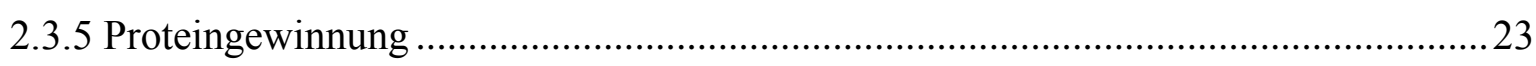

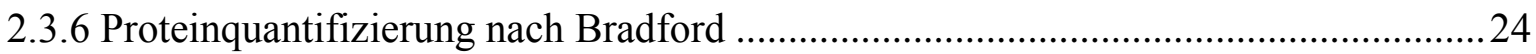

2.3.7 Natriumdodecylsulfat-Polyacrylamidgelelektrophorese (SDS-PAGE) ………….......2

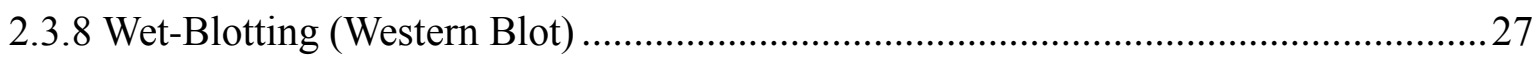




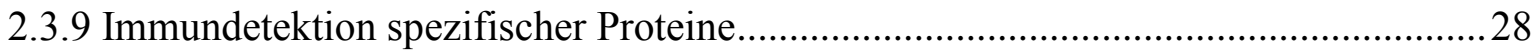

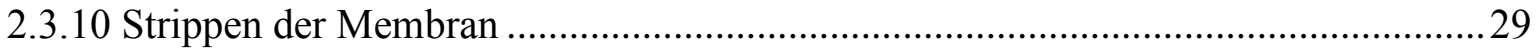

3 Ergebnisse ................................................................................ 30

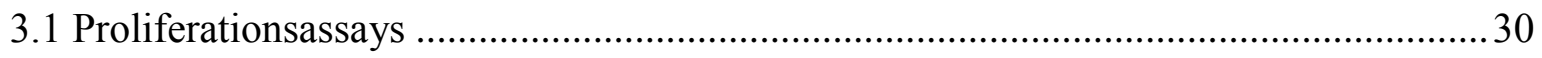

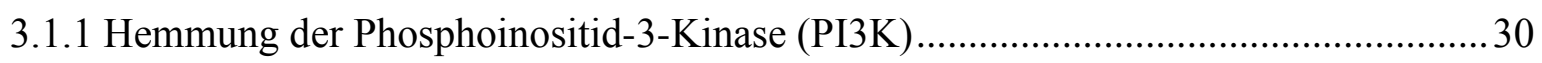

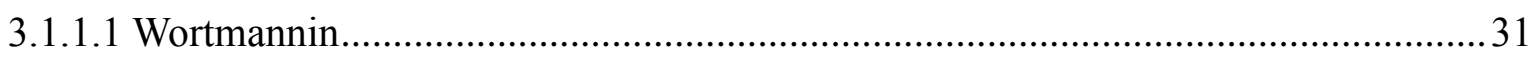

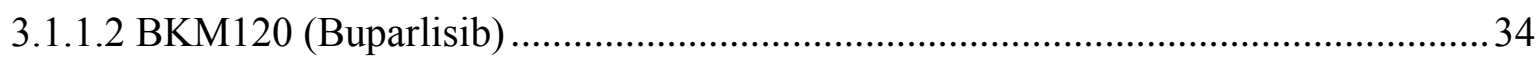

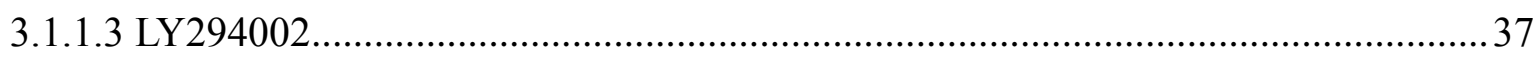

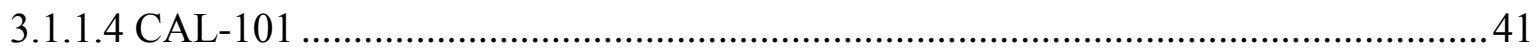

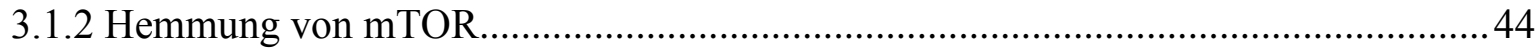

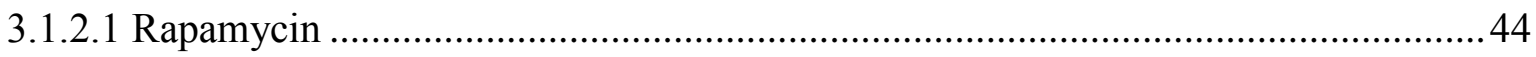

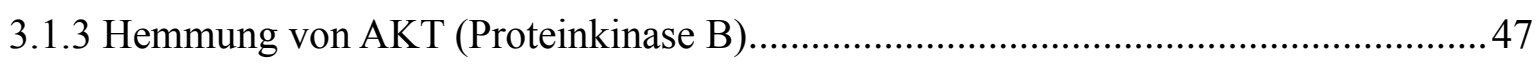

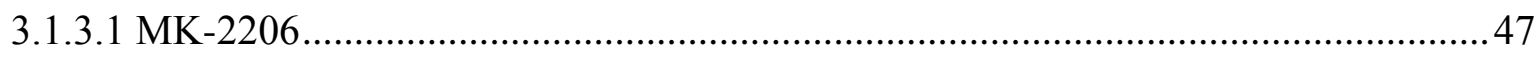

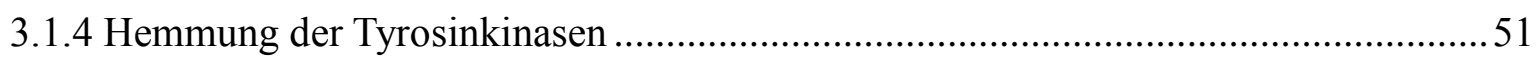

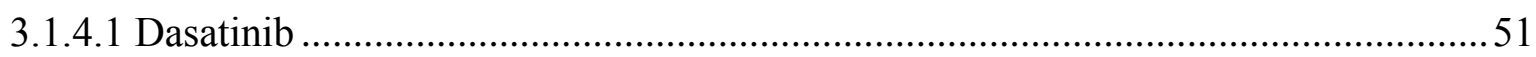

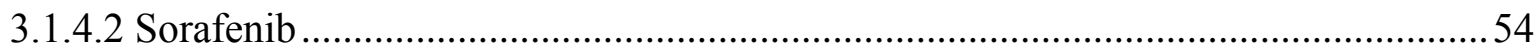

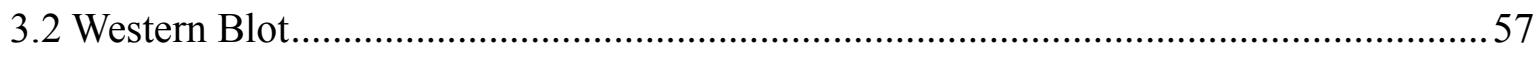

4 Diskussion .............................................................................................5 59

4.1 Aktivierende PIK3CA-Mutationen in LECs bei LM und Tumoren .............................59

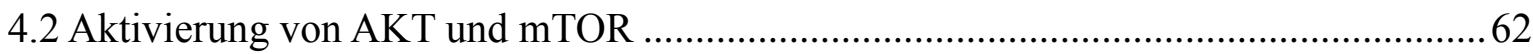

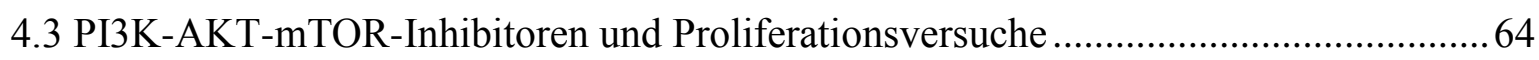

4.3.1 Hemmung der PI3K durch Wortmannin, BKM120, LY294002 und CAL-101 ..........65

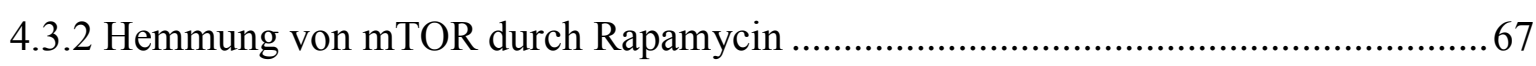

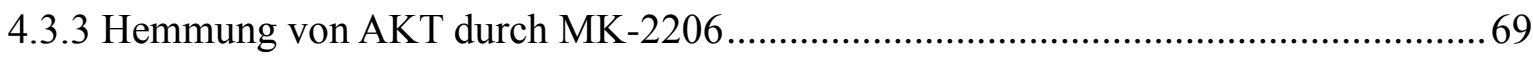

4.3.4 Hemmung der Tyrosinkinasen durch Dasatinib und Sorafenib ...................................69

4.4 Western Blot-Versuche zur Darstellung der Aktivierung von AKT .............................. 71

4.5 Ausblick der In-vitro-Daten auf eine klinische Therapie............................................ 71

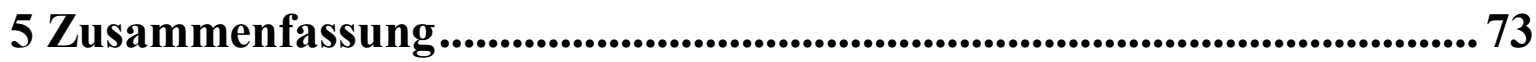

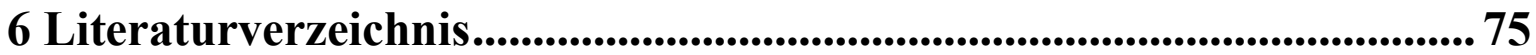




\section{Abkürzungsverzeichnis}

ATM

BSA

CD

CLOVES

$\mathrm{CO}_{2}$

DAPI

DMSO

ED

ELISA

FAVA

FCS

FOXC2

FRAP

GAB

GTP

HRP

LECs

LM

LYVE-1

mSIN1

PBS

PDK1

PDPN

PFA

$\mathrm{PH}$

PI3K

PIK3CA

PIP2

PIP3

PRAS40

PROX1

PTEN

RAFT1

Raptor

Ras

Rictor

SDS

SEP

SFK

$\mathrm{SH} 2$

UE

VEGF ataxia telangiectasia mutated

bovines Serumalbumin

cluster of differentiation

congenital lipomatous overgrowth, vascular malformations, epidermal nevi and spinal/skeletal anomalies

Kohlendioxid

4',6-Diamidin-2-phenylindol

Dimethylsulfoxid

embryonic day

enzyme-linked immunosorbent assay

fibro-adipose vascular anomaly

fetal calf serum (fetales Kälberserum)

forkhead box $C 2$

FKBP12-rapamycin-associated protein

GTPase-activating proteins

Guanosintriphosphat

horseradish peroxidase (Meerrettichperoxidase)

lymphatic endothelial cells (Lymphendothelzellen)

lymphatische Malformation

Lymphgefäß-Hyaluronsäure-Rezeptor-1

mammalian stress-activated protein kinase-interacting protein 1

phosphate buffered saline (phosphatgepufferte Salzlösung)

phosphoinositide-dependent kinase-1

Podoplanin

Paraformaldehyd

pleckstrin homology

Phosphoinositid-3-Kinase

phosphatidylinositol-4,5-bisphosphate-3-kinase catalytic subunit alpha

Phosphatidylinositol-4,5-bisphosphat

Phosphatidylinositol-3,4,5-trisphosphat

proline-rich akt substrate $40 \mathrm{kDa}$

prospero homeobox protein 1

phosphatase and tensing homolog

rapamycin and FKBP12 target

regulatory associated protein of $m T O R$

rat sarcoma

rapamycin insensitive companion of $m T O R$

Sodium-Dodecyl-Sulfat (Natriumlaurylsulfat)

sirolimus effector protein

src family kinase

src homology 2

Untereinheit

vascular endothelial growth factor 
VEGFR-2 vascular endothelial growth factor receptor-2

VEGFR-3 vascular endothelial growth factor receptor-3 


\section{Tabellenverzeichnis}

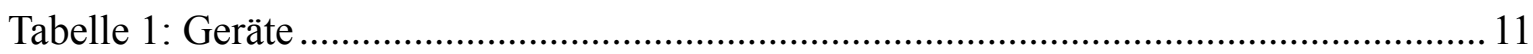

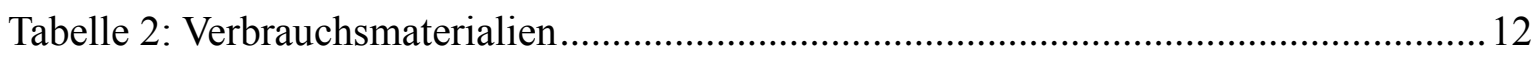

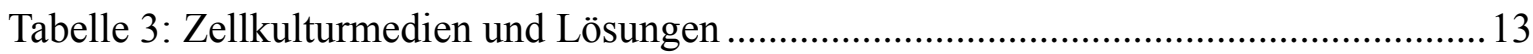

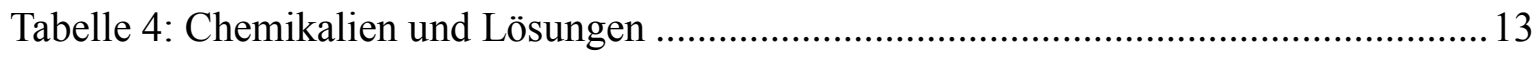

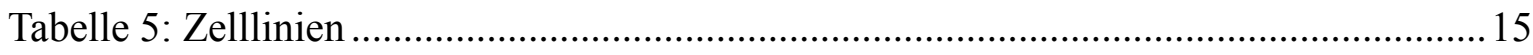

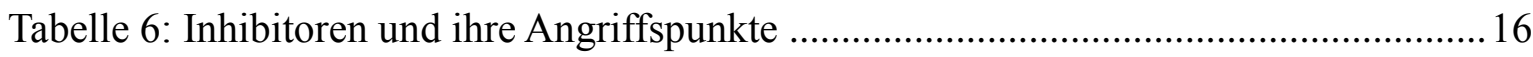

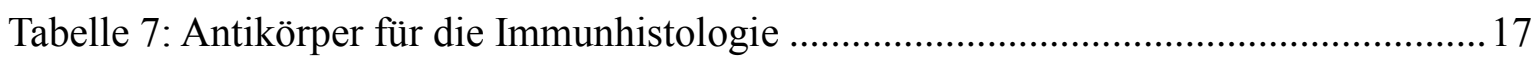

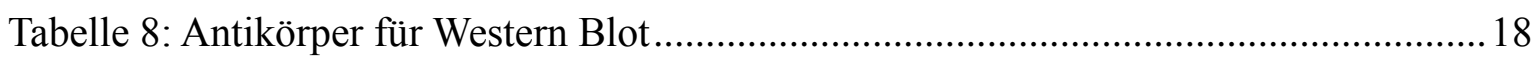

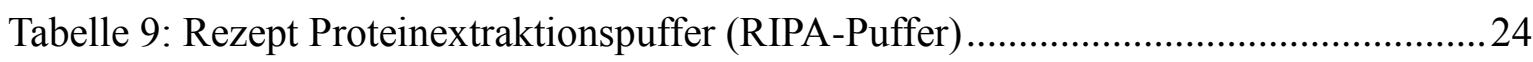

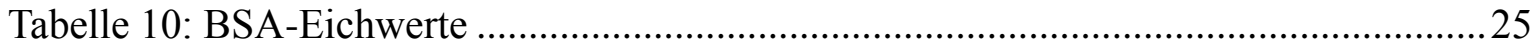

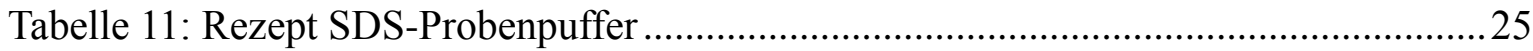

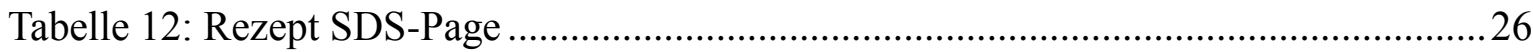

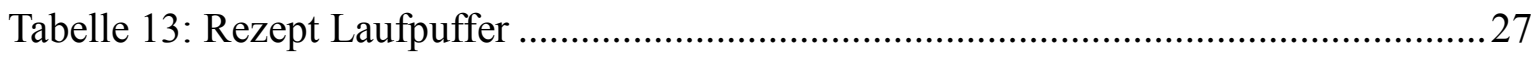

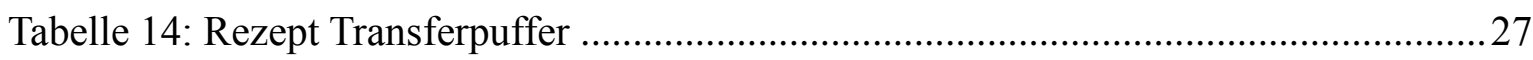




\section{Abbildungsverzeichnis}

Abbildung 1: Foto und MRT-Bild eines Säuglings mit LM im Brust- und Armbereich ....... 4

Abbildung 2: Die PI3K-AKT-mTOR-Signalkaskade.................................................. 8

Abbildung 3: Immunhistologische Bilder zur Identifizierung von Lymphendothelzellen. . 21

Abbildung 4: Eichkurve mit Bradford-Lösung und BSA als Standardprotein .24

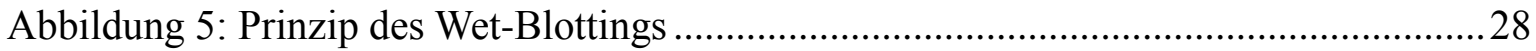

Abbildung 6: Proliferationsassays mit PI3K-Inhibitor Wortmannin .................................... 31

Abbildung 7: Proliferationsassays mit PI3K-Inhibitor BKM120 (Buparlisib).................... 34

Abbildung 8: Proliferationsassays mit PI3K-Inhibitor LY294002 .................................... 37

Abbildung 9: Proliferationsassays mit PI3K-Inhibitor CAL-101 ....................................... 41

Abbildung 10: Proliferationsassays mit mTOR-Inhibitor Rapamycin ............................. 44

Abbildung 11: Proliferationsassays mit Proteinkinase B(AKT)-Inhibitor MK-2206.......... 47

Abbildung 12: Proliferationsassays mit Tyrosinkinase-Inhibitor Dasatinib ........................ 51

Abbildung 13: Proliferationsassays mit Tyrosinkinase-Inhibitor Sorafenib........................54

Abbildung 14: Nachweis von pAKT Serin473, tAKT und alpha-Tubulin ..........................57

Abbildung 15: PI3K-AKT-mTOR-Signalkaskade mit den getesteten Inhibitoren.............. 64 


\section{Einleitung}

\subsection{Das Lymphgefäßsystem}

Das Lymphgefäßsystem ist essenziell für die Homöostase des Flüssigkeitshaushaltes, die immunologische Abwehrfunktion und spielt eine wichtige Rolle im Lipidstoffwechsel (Butler et al. 2009; Norrmén et al. 2011).

Zum lymphatischen System gehören neben den Lymphgefäßen die primären und die sekundären lymphatischen Organe. Die primären lymphatischen Organe umfassen das Knochenmark und den Thymus, hier findet die Bildung, Reifung und Prägung der Immunzellen ( $\mathrm{T}$ - und B-Zellen) statt. $\mathrm{Zu}$ den sekundären lymphatischen Organen gehören die Lymphknoten, die Milz, die Tonsillen des lymphatischen Rachenrings und das MALT (mucosa-associated lymphoid tissue). Sie dienen der spezifischen Immunabwehr (Rengier 2009; Aumüller et al. 2010).

Die Lymphgefäße dienen der Aufnahme und dem Abtransport der Gewebeflüssigkeit (Interstitialflüssigkeit). Die Lymphgefäße bestehen dabei aus Leitungsbahnen, welche in das venöse Blutgefäßsystem führen und als Hauptverbindungssystem zwischen den Organen fungiert (Wilting et al. 2003a). Im Gegensatz zum kardiovaskulären System handelt es sich bei den Lymphgefäßen um keinen geschlossenen Kreislauf (Jeltsch et al. 2003; Aumüller et al. 2010). Lymphgefäße sind in allen vaskularisierten Geweben zu finden, außer in Knochenmark, ZNS, Parenchym der Milz und der Plazenta (Tammela und Alitalo 2010; Wilting et al. 2003b).

Das Lymphsystem beginnt mit Lymphkapillaren im Interstitium und vereinigt sich zu immer größer werdenden Lymphgefäßen. Das Einbahngefäßsystem mündet dabei herznah als Ductus thoracicus in den linken Venenwinkel und als Ductus lymphaticus dexter in den rechten Venenwinkel. Dabei beinhaltet der Ductus thoracicus, das größte lymphatische Gefäß, die Lymphe der linken Seite des Körpers, des Abdomens und der unteren Extremitäten. Der Ductus lymphaticus dexter führt die Lymphe vom rechten Arm, Thorax und der Kopfregion (Tammela und Alitalo 2010). 
1.1.1 Histologie der Lymphgefäße

Die Lymphkapillaren bilden mit einem Durchmesser von 10-50 $\mu \mathrm{m}$ den kleinsten Abschnitt des Lymphgefäßsystems. Sie ergeben ein dichtes Netz im interstitiellen Bindegewebe der Organe und in der Dermis. Die Wand der Lymphkapillaren besteht aus einer platten Epithelzellschicht (Endothel), ähnlich der Blutkapillaren (Saharinen et al. 2004; Albuquerque et al. 2009).

Lymphkapillaren gehen in Lymphkollektoren über, deren Wände $(150-600 \mu \mathrm{m})$ charakterisiert sind durch glatte Muskelzellen in der Tunica media (Maby-El Hajjami und Petrova 2008). Zudem besitzen sie eine Tunica interna und Tunica externa (Adventitia). Lymphendothelzellen (LECs) der Lymphkollektoren exprimieren endotheliale Stickstoffmonoxid-Synthase (eNOS), welche wichtig für die Dilatation der Gefäße ist (Hasselhof et al. 2016).

Die Weiterleitung der Lymphe in den Kollektoren wird durch die Kontraktion der Tunica media ausgelöst, zudem durch die Pumpfunktion der Bewegungsmuskulatur, die Pulswelle in den Arterien und die Pumpwirkung bei der Atmung. Die Kollektoren führen die Lymphe dann weiter zu regionalen Lymphknoten, Sammellymphknoten und schließlich zu den großen Lymphstämmen (Trunci lymphatici), welche sich dann $\mathrm{zu}$ den zwei Lymphhauptstämmen vereinigen. Die Lymphe wird schließlich in die Mündungsstellen der Vena subclavia und Vena jugularis interna geleitet (Rengier 2009; Bazigou et al. 2009; Aumüller et al. 2010).

Von den LECs werden typische Endothelzellmarker wie PROX1, VEGF-C, VEGF-D, VEGFR-3, LYVE-1, PDPN und CD31/PECAM-1 exprimiert (Saharinen et al. 2004; Albuquerque et al. 2009; Tammela und Alitalo 2010; Rössler et al. 2014; Wick et al. 2007). Im weiteren Verlauf wird auf drei wichtige Endothelzellmarker eingegangen:

LYVE-1 ist einer der spezifischsten und gebräuchlichsten Lymphendothelzellmarker, welcher ein Homolog zum Hyaluronsäurerezeptor CD44 darstellt (Banerji et al. 1999; Alitalo et al. 2005; Wilting et al. 2003a). LYVE-1 transportiert Metaboliten der Hyaluronsäure durch das lymphatische Endothel in die Lymphe (Jeltsch et al. 2003).

Das früheste Ereignis in der Entwicklung des lymphatischen Gefäßsystems ist die „polarisierte Expression“ des Transkriptionsfaktors PROX1. Studien zeigten, dass PROX1 ein hochspezifischer Marker für LECs im gesunden bzw. erkrankten Gewebe ist (Wilting et al. 2002). In den LECs wird PROX1 mit CD31 und VEGFR-3 koexprimiert. Bei Mäusen 
wird an ED 9,5 das Gen PROX1 von Endothelzellen in einigen embryonalen Venen unter dem Einfluss eines noch nicht bekannten Signals exprimiert. Eine Absenz von PROX1 führt unweigerlich zum Stopp der physiologischen Entwicklung des lymphatischen Gefäßsystems (Wilting et al. 2006). PROX1 knock-out-Mäuse besitzen weder Lymphsäcke noch Lymphgefäße (Schacht et al. 2003; Tammela et al. 2005).

Der Tyrosinkinaserezeptor VEGFR-3 ist einer der früh entdeckten Lymphendothelzellmarker. VEGFR-3 wird durch VEGF-C und VEGF-D (Mitglieder der VEGF-Familie der Wachstumsfaktoren) aktiviert (Petrova et al. 2002). VEGFR-3 ist in allen Endothelien während der frühen Embryonalentwicklung vorhanden und dadurch ein spezifischer Rezeptor des Lymphendothels (Joukov et al. 1997; Wilting et al. 2003b). VEGFR-3 knockout-Mäuse sterben nach ED 10,5 aufgrund von Defekten bei der Entwicklung des kardiovaskulären Systems (Tammela und Alitalo 2010; Kärpänen et al. 2006). In einer Studie konnte eine Hochregulierung von VEGFR-2 und VEGFR-3 in LECs mit lymphatischen Malformationen (Kapitel 1.2) nachgewiesen werden (Norgall et al. 2007).

\subsection{Lymphatische Malformationen}

Lymphatische Malformationen (LM; früher: Lymphangiome) werden durch somatische Mutationen verursacht. Hereditäre Fälle wurden bis jetzt noch nicht verzeichnet (Clemens et al. 2015a). Es handelt sich dabei um eine kongenitale gutartige Fehlbildungsstörung des Lymphgefäßsystems. Die LM machen ca. 5,6 \% der gutartigen Läsionen im Säuglings- und Kleinkindalter aus und sind dabei weder von Geschlecht noch Ethnie beeinflusst (Zadvinskis et al. 1992).

Die LM zeigt sich als zystische Lymphgefäßerweiterung, wobei man je nach Ausprägung zwischen der mikrozystischen $(<2 \mathrm{~cm})$, makrozystischen $(\geq 2 \mathrm{~cm})$ und der gemischten Form unterscheidet (Rössler et al. 2014; Buckmiller et al. 2010; Samedi und Elsharkawy 2017; Albuquerque et al. 2009). Zudem werden Sonderformen der LM unterschieden. Die Zysten imponieren als ein- oder mehrkammerige, mit Lymphflüssigkeit gefüllte Räume. Dabei wachsen die LM proportional zum Wachstum des Kindes (Ardelean et al. 2008).

Nach Wegener werden drei Formen der LM unterschieden (Fritz-Niggli et al. 1966; Miceli und Stewart 2017; Limaye und Vikkula 2015):

Das Lymphangioma simplex (kapilläres Lymphangiom, Lymphangioma circumscriptum) erscheint als multiple, gruppierend oder vereinzelte, transluzente oder hämorrhagische bläschenförmige Papeln. Es handelt sich hierbei um kleinzystische, solide erscheinende 
Läsionen, welche infiltrierend in benachbarte Strukturen einwachsen können. Der Durchmesser der Zysten ist unter einem Zentimeter (Stadler et al. 2010; Ardelean et al. 2008).

Das Lymphangioma cavernosum (kavernöses Lymphangiom) kommt typischerweise in der Kindheit als schmerzfreie, unklare subkutane Schwellung vor. Diese Form zeichnet sich durch große Zysten mit einer verdickten Wand aus. Die darüber liegende Cutis kann eine bläuliche Verfärbung aufweisen. Die Zysten können nach einer Infektion oder Einblutung an Größe zunehmen und dadurch eine Verdrängung und Kompression von benachbarten Strukturen verursachen.

Das Lymphangioma cysticum, das auch als zystisches Hygrom, zystisches Lymphangiom, Hygroma colli oder Hygroma cysticum benannt wird, tritt in $90 \%$ der Fälle in der Hals- und Nackenregion auf (Grasso et al. 2008). Es kann aber auch in der Achsel- und Leistenregion lokalisiert sein und erscheint weich und in unterschiedlicher Größe und Form.

$\mathrm{Zu}$ den Sonderformen gehören das Hämangiolymphangiom (zusätzliche hämangiomatöse Anteile) und einige tumorartige Überwucherungen in Verbindung mit Syndromen wie das Klippel-Trenauney-Syndrom (KTS), Proteus-Syndrom, CLOVES-Syndrom, FAVA und das Gorham-Stout-Syndrom (Ardelean et al. 2008; Luks et al. 2015).

Über $95 \%$ der LM treten im Weichgewebe des Kopfes, Hals oder der Achselhöhlen auf. Weniger als 5 \% manifestieren sich in der Region der Bauchhöhle (Norgall et al. 2007). Im Kopf-Hals-Bereich können LM schwerwiegende Symptome wie Atembehinderungen, Sprachentwicklungs- oder Wachstumsstörungen verursachen (Rössler et al. 2014).
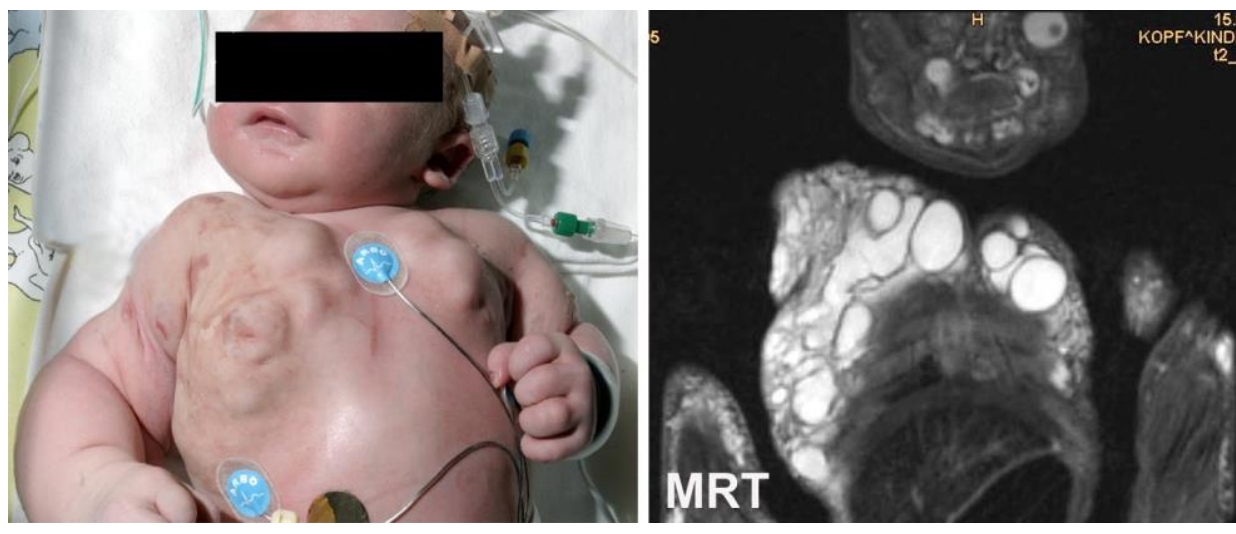

Abbildung 1: Foto und MRT-Bild eines Säuglings mit LM im Brust- und Armbereich Quelle: Mit freundlicher Genehmigung von Prof. Dr. Jochen Rössler, Universität Freiburg (jetzt: Inselspital Bern) 
1.2.1 Diagnostik von lymphatischen Malformationen

In den meisten Fällen kann eine korrekte Diagnose einer LM schon nach einer Patientenanamnese und einer körperlichen Untersuchung gestellt werden. Es können auch zunehmend pränatal Diagnosen zu vaskulären Erkrankungen mittels Sonographie gestellt werden (Croonen et al. 2013; Grasso et al. 2008).

Zu der klinischen Untersuchung gehört die Palpation der Schwellung, die Sonographie bzw. die farbcodierte Doppler-Sonographie.

Das MRT erlaubt, wie die Sonographie, eine nicht-invasive und nicht-ionisierende Untersuchung, wobei Ausdehnung und Angrenzung zu benachbarten Strukturen bestimmt werden können.

Eine weitere Untersuchungsmöglichkeit ist die Schnittbildtechnik der Computertomographie (CT), wobei allerdings eine relativ hohe Strahlenexposition besteht (Abernethy 2003). Eine Biopsie wird nur bei klinisch und radiologisch unklarer Situation benötigt (Clemens et al. 2015a, 2015b; Rössler 2015).

\subsubsection{Behandlungsmöglichkeiten von lymphatischen Malformationen}

Das Ziel einer Behandlung von LM ist die Wiederherstellung bzw. Erhaltung von anatomisch wichtigen Strukturen und der Ästhetik. Alle Behandlungen sollten auf einer gründlichen vorherigen Diagnostik mit einer Einschätzung des Schweregrades an funktionaler und/oder ästhetischer Beeinträchtigung basieren. Dabei ist die Erhaltung von lebensnotwendigen Strukturen von oberster Priorität (Perkins et al. 2010).

Die Behandlungstherapie sollte zudem aufgrund der Größe der Läsion, anatomischer Lokalisation und möglichen Komplikationen gewählt werden (Ha et al. 2014). LM in kleiner Dimension ohne funktionelle oder ästhetische Beeinträchtigung müssen nicht zwangsläufig behandelt werden (Perkins et al. 2010). Spontane Regressionen bei LM sind allerdings selten (Rautio et al. 2003).

Die Therapie der Wahl bei LM ist die chirurgische Entfernung (Rössler et al. 2014; Grasso et al. 2008; Manning und Perkins 2013). Jedoch sind häufig mehrere Operationen nötig, da eine Totalresektion bei Erhaltung von lebensnotwendigen Strukturen nur in den seltensten Fällen möglich ist (Ogita et al. 1994). Eine Totalresektion ist bei ca. 18-50 \% der Fälle möglich (Rautio et al. 2003). Gelingt diese, ist mit hoher Wahrscheinlichkeit eine langfristige Beschwerdefreiheit möglich (Rezidivrate von 0-27\%). Allerdings kann 
aufgrund von angrenzenden lebensnotwendigen anatomischen Strukturen oftmals nur eine Teilresektion bzw. Größenreduktion erzielt werden. Bei Teilresektionen beträgt die Rezidivrate 53-100 \% (Rössler et al. 2014).

Eine weitere Therapiemöglichkeit ist die Sklerosierung (Verödung), welche vor allem bei makrozystischen LM Anwendung findet (Menendez-Castro et al. 2017). Laserbehandlungen können bei LM im Bereich der Atemwege sowie bei vesikulären Ausschlägen auf Schleimhautoberflächen angewendet werden (Clemens et al. 2015a, 2015b).

Eine anerkannte kausale Behandlungsmöglichkeit gibt es allerdings nicht. Jedoch konnte in kürzlich durchgeführten Studien gezeigt werden, dass sich in Proben von LM-Gewebe aktivierende Mutationen in der katalytischen $\alpha$-Untereinheit der Phosphoinositid-3-Kinase (PI3K) befinden (Luks et al. 2015). Dies ermöglicht zum ersten Mal einen Ansatz für eine medikamentöse Therapie durch Hemmung dieser aktivierten Mutation. Im weiteren Verlauf werden die Mutation in der Phosphoinositid-3-Kinase und die Ziele dieser Arbeit genauer erläutert.

\subsection{Die Phosphoinositid-3-Kinasen (PI3K)}

Die PI3K, welche in den 1980ern entdeckt wurden, sind Lipidkinasen (Enzyme), welche eine Schlüsselfunktion bei der Regulierung von zellulären Vorgängen wie Zellüberleben, Wachstum und Differenzierung übernehmen (Liu et al. 2009). Sie spielen eine wichtige Rolle bei Adhäsion, Zelltod, Motilität und Invasivität von Zellen (Samuels et al. 2004; Broderick et al. 2004; Bachman et al. 2004; Samuels und Velculescu 2004). Aufgrund ihrer biochemischen Eigenschaften und Struktur kann die PI3K-Familie mit acht katalytischen Isoformen in drei funktionelle Gruppen eingeteilt werden (Liu et al. 2009; Vanhaesebroeck et al. 2010):

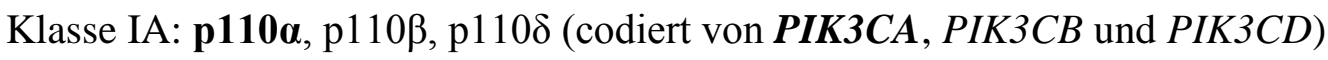

Klasse IB: p110

Klasse II: PI3K-C2 $\alpha$, PI3K-C2 $\beta$, PI3K-C2 $\gamma$

Klasse III: Vps34

Alle Klassen werden in spezifischer Weise von humanen Zellen exprimiert (Fruman et al. 2017). Die Klasse II produziert 3,4-Bisphosphate und 3-Monophosphate der Inositollipide, während die Klasse III 3-Monophosphate erzeugen (Zhao und Vogt 2008). Diese beiden Enzymklassen sind in der vorliegenden Arbeit nicht untersucht worden. 
Eine besondere Rolle bei den vaskulären Anomalien spielt die Gruppe IA (Castillo et al. 2016a). PI3K der Klasse IA sind Heterodimere, welche eine katalytische und eine jeweils dazugehörige regulatorische p85 (p85 $\alpha, \mathrm{p} 85 \beta, \mathrm{p} 85 \gamma, \mathrm{p} 50 \alpha$, und $\mathrm{p} 55 \alpha$ ) Untereinheit (UE) besitzen. Die regulatorische UE vermittelt die Bindung an einen Rezeptor z. B. Rezeptortyrosinkinasen (RTK) oder G-Protein-gekoppelte-Rezeptoren (GPCR) durch deren SH2Domäne und zudem die Aktivierung und Lokalisation des Enzyms. Die katalytische UE besitzt verschiedene Domänen, wie eine C2-Domäne, RAS-Bindedomäne, PIK-Homologie (helikale Domäne), Kinasedomäne und eine Adapterbindedomäne (Vanhaesebroeck und Waterfield 1999; Vanhaesebroeck et al. 1997).

Die p85-regulatorische UE hält den heterodimeren p85-p110-Komplex in einem inaktiven zytosolischen Zustand (Castillo et al. 2016a). Wird die Klasse IA aktiviert, konvertiert die katalytische UE PIP2 zu PIP3, welches in der Signalkaskade weitere Aktivitäten bewirkt (Abb. 2). Die Proteine der Klasse I p110 $\alpha$ und p110 $\beta$ werden ubiquitär exprimiert, während

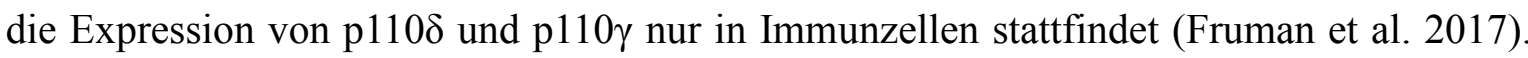
Mutationen von PIK3CA (p110 $\alpha)$ sind in verschiedenen humanen Krebsarten zu finden (Bachman et al. 2004; Samuels et al. 2004). Bei Karzinomen, Immunschwäche und Erkrankungen mit Gewebewucherungen konnten aktivierende PI3K-Mutationen verzeichnet werden (Fruman et al. 2017). Ein Zusammenhang von PIK3CA-somatische Mutationen und CLOVES bzw. Krebs mit einer Hyperaktivierung von AKT und einem erhöhten Zellwachstum wurde untersucht (Osborn et al. 2015). Der in der Abbildung 2 aufgeführte PI3K-AKT-mTOR-Signalweg ist häufig in malignen Erkrankungen aktiviert (Massacesi et al. 2016). 


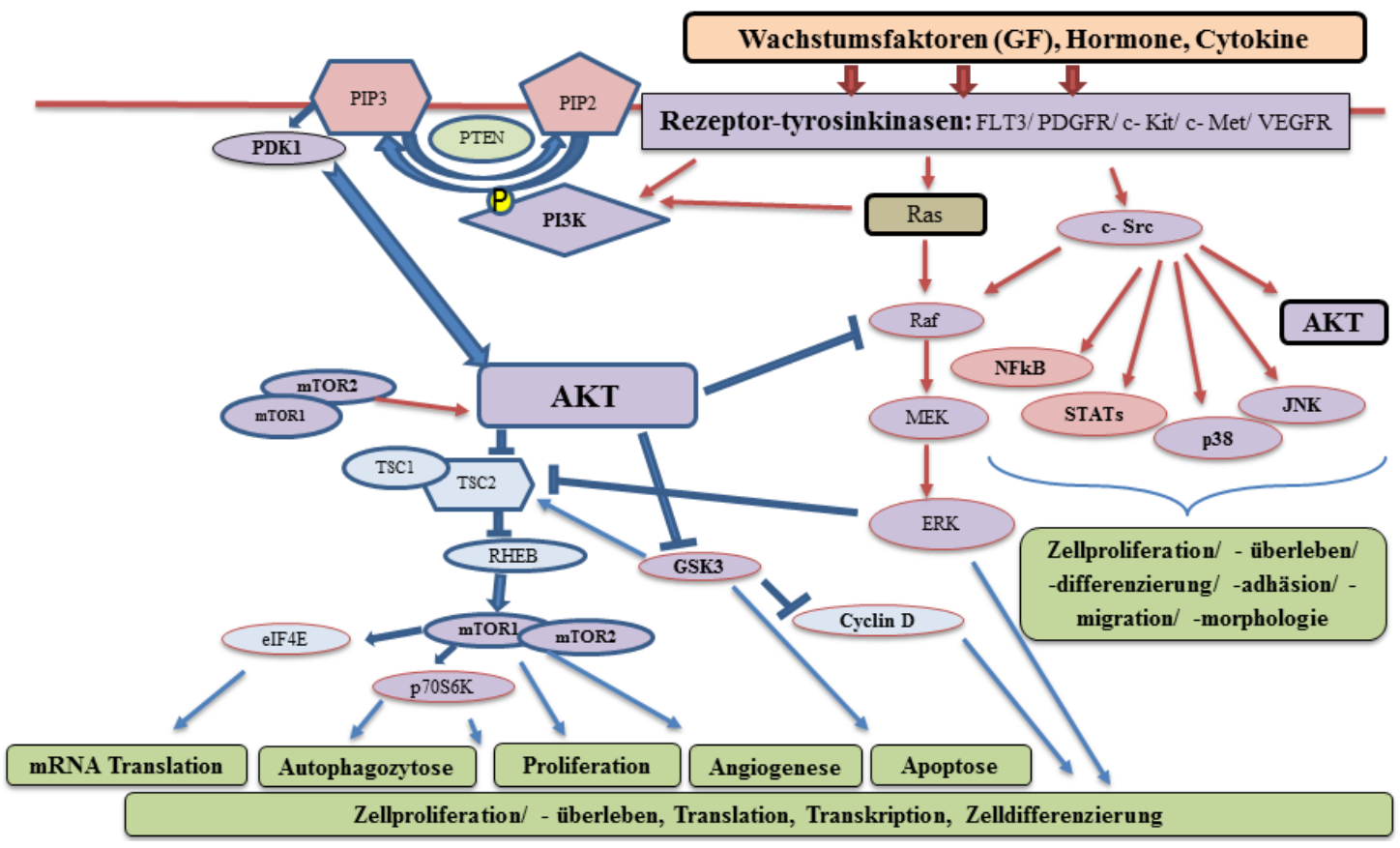

Abbildung 2: Die PI3K-AKT-mTOR-Signalkaskade

Modifiziert nach Selleck Chemicals LLC (Selleck Chemicals 2013), Cell Signaling Technology (Cell Signaling Technology 2008) und Cisbio (Cisbio 2016). Abbildung in Zusammenarbeit mit Rieke Werner erstellt.

Bei der Weiterleitung von Wachstumssignalen in eukaryotischen Zellen ist der PI3K-AKTmTOR-Signalweg (Abb. 2) von großer Bedeutung. Er reguliert viele zelluläre Prozesse wie Zellüberleben, Zellwachstum, Proliferation, Angiogenese, Metabolismus und Migration (Manning und Cantley 2007; Castellano und Downward 2011). Im Weiteren wird die PI3K-AKT-mTOR-Signalkaskade in den wichtigsten Schritten beschrieben (Castellano und Downward 2011; Liu et al. 2009):

Wachstumsfaktoren, z.B. VEGF, binden an membranständige Rezeptortyrosinkinasen (RTKs), wodurch eine Dimerisierung und Autophosphorylierung der RTKs initiiert wird. Durch die Konformationsänderung werden Bindungsstellen für Proteine frei, welche eine SH2-Domäne besitzen und die PI3K aktivieren. Dies geschieht auf drei verschiedenen Wegen: zum einen direkt, durch die regulatorische UE p85 und deren SH2-Domäne, wodurch es zu einer Aktivierung der katalytischen p110-UE kommt. Zum anderen indirekt, indem GRB2 mit seiner SH2-Domäne an das Protein GAB bindet, welches nun an die regulatorische p85-UE binden kann und somit die katalytische p110-UE aktiviert. Zudem kann die PI3K über das G-Protein RAS aktiviert werden. Dazu dockt GRB2 an SOS (Son of Sevenless), welches an RAS bindet und unabhängig von der regulatorischen p85-UE die 
katalytische p110-UE von PI3K aktiviert. Bisher ist unbekannt welcher Weg der PI3KAktivierung überwiegt. Bei der Aktivierung kommt es $\mathrm{zu}$ einer Rekrutierung der regulatorischen p85-UE an die Zellmembran, worauf die katalytische p110-UE PIP2 an der dritten Stelle des Inositolrings zu PIP3 phosphoryliert wird (Liu et al. 2009; Zhao und Vogt 2008). Der Tumorsuppressor PTEN kann diesen Schritt durch Dephosphorylierung revidieren und so die Wirkung von PI3K zumindest teilweise aufheben (Manning und Cantley 2007). Das Phospholipid PIP3 spielt eine Schlüsselrolle als sekundärer Botenstoff und rekrutiert bzw. aktiviert Proteine mit einer PH-Domäne, wie AKT (Proteinkinase B) und die PDK1 (Zhao und Vogt 2008; Scheid und Woodgett 2003). PDK1 aktiviert die Serin-/Threoninkinase AKT durch Phosphorylierung an der Threonin308-Bindungsstelle und die Serin-/Threoninkinase mTORC2, die zusammen mit mTORC1 den Proteinkomplex mTOR bildet. MTOR phosphoryliert AKT an seiner zweiten Bindungsstelle Serin473. Auch PDK2 und AKT können den Serin473-Rest phosphorylieren. Beide Phosphorylierungen von AKT sind erforderlich, um eine vollständige Aktivierung $\mathrm{zu}$ erzielen (Anderson et al. 1998). Durch die aktivierte Proteinkinase B (pAKT) werden Zielproteine phosphoryliert, wodurch diese aktiviert oder inhibitiert werden (Abb. 2). Dadurch kommt es zu einer Hemmung der Apoptose bzw. einer Förderung der Translation, Autophagozytose, Proliferation und Angiogenese.

\subsection{Hypothesen und Ziele der Arbeit}

Lymphatische Malformationen, ob isoliert oder in Kombination mit Syndromen, werden vor allem durch aktivierende Mutationen im PIK3CA-Gen verursacht (Luks et al. 2015). In einer Untersuchungsgruppe des Seattle Children's Hospital konnte bei $74 \%$ der 31 isolierten LM eine aktivierende PIK3CA-Mutation gefunden werden. In einer weiteren Untersuchungsgruppe des Boston Children's Hospital wurden sogar bei $>90 \%$ (16 von 17) der LM-Patienten somatische Mosaike für aktivierende PIK3CA-Mutationen entdeckt. Bei der Mehrzahl $(\sim 80 \%)$ der Patienten handelte es sich um eine der fünf am häufigsten vorkommenden Mutationen: p.C420R, p.E542K, p.E545K, p.H1047R und p.H1047L.

Die PI3K-AKT-mTOR-Signalkaskade spielt eine wichtige Rolle bei der Weiterleitung von Wachstumssignalen in eukaryotischen Zellen. Dabei finden viele zelluläre Prozesse wie Zellüberleben, Zellwachstum, Proliferation, Angiogenese, Metabolismus und Migration statt (Manning und Cantley 2007; Castellano und Downward 2011). 
Die Hemmung dieser durch aktivierende PI3K-Mutationen verursachten Prozesse durch spezifische Medikamente könnte ein Ansatz zur nicht-invasiven Therapie oder zur Unterstützung invasiver Behandlungsmethoden von LM sein.

Ziel der vorliegenden Arbeit war es zu untersuchen, welche Substanzen (small molecules) und Angriffsziele (drug targets) geeignet sein könnten, um das Wachstum der LECs zu hemmen.

Es gibt verschiedene Angriffspunkte für die Inhibition der PI3K-AKT-mTORSignalkaskade. Dazu gehören die downstream liegende Proteinkinase B und mTOR, sowie die PI3K selbst. In der vorliegenden Arbeit wurden acht verschiedene Inhibitoren In-vitro mittels Proliferationsversuchen bei gesunden und erkrankten Lymphendothelzellen getestet. Bei den LM Lymphendothelzellen wurden von Frau Dr. S. Kaulfuß (Humangenetik der UMG) aktivierende PIK3CA-Mutationen in den Exons 2, 8, 10 und 21 nachgewiesen. Bei den LECs von gesunden Spendern waren solche Mutationen nicht nachweisbar. Zudem wurden in Western Blot-Analysen die Phosphorylierung von AKT (pAKT) in unterschiedlichen Lymphendothelzelllinien untersucht.

Ziel ist es, einen effektiven Inhibitor des PI3K-AKT-mTOR-Signalweges spezifisch für LECs der LM zu identifizieren, mit dem Fernziel einer kausalen medikamentösen Therapie der LM. 


\section{Material und Methoden}

\subsection{Geräte}

In der nachfolgenden Tabelle 1 wird aufgeführt, welche Geräte für die Versuche verwendet wurden.

Tabelle 1: Geräte

\begin{tabular}{|c|c|}
\hline Geräte & Hersteller \\
\hline Autoklav Systec VE-65 & Systec; Wettenberg \\
\hline Biophotometer & Eppendorf; Hamburg \\
\hline Chemidoc Touch Imaging System & Bio-Rad Laboratories; München \\
\hline Laborwaage und Feinwaage & Sartorius; Göttingen \\
\hline Gelelektrophoresekammer Mini-Protean II & Bio-Rad Laboratories; München \\
\hline IKA Ret Control/t Magnetrührer & IKA-Werke GmbH und Co.; Staufen \\
\hline Minicentrifuge & LMS Co., LTD; Japan \\
\hline $\begin{array}{l}\text { Niederspannungs Power Supplies, } \\
\text { Standard power pack } 25\end{array}$ & Analytikjena; Jena \\
\hline Phasenkontrastmikroskop & Nikon; Japan \\
\hline Pipettierhilfe accu-jet pro & Brand; Wertheim \\
\hline Pipettierhilfe $(10,20100,200,1000 \mu 1)$ & Eppendorf; Hamburg \\
\hline Pipetus & Hirschmann; Eberstadt \\
\hline Rollenmischer CAT RM5 & Fröbel Labortechnik GmbH; Lindau \\
\hline Semi-Dry Western Blot-Apparatur & Biometra; Göttingen \\
\hline Sterilbank Steril Gard III Advance & The Baker Company; USA \\
\hline Thermomixer compact & Eppendorf; Hamburg \\
\hline Vortex neolab7-2020 & neoLab Migge; Heidelberg \\
\hline Wasserbad & GFL; Großburgwedel \\
\hline
\end{tabular}




\begin{tabular}{|l|l|}
\hline Wippschüttler Shaker DRS-12 & ELMI Skyline; Lettland \\
\hline Zellzähler „Coulter-Counter“ Z1 & Beckman Coulter; Krefeld \\
\hline Zentrifuge Rotina 380R & Andreas Hettich; Tuttlingen \\
\hline Zentrifuge 5415D & Eppendorf; Hamburg \\
\hline Zentrifuge 5417R & Eppendorf; Hamburg \\
\hline
\end{tabular}

\subsection{Materialien}

\subsubsection{Verbrauchsmaterial}

Tabelle 2: Verbrauchsmaterialien

\begin{tabular}{|l|l|}
\hline Verbrauchsmaterial & Hersteller \\
\hline 96-Well-Platten & Sarstedt; Nümbrecht \\
\hline 12-channel-basins (5 ml Channel) & Argos technologies; USA \\
\hline 15-ml-Röhrchen, 50-ml-Röhrchen & Sarstedt; Nümbrecht \\
\hline Mikro-Schraubröhre (Mikro tube) 1,5 ml & Sarstedt; Nümberg \\
\hline Pasteurpipetten aus Glas (150 mm) & Brand; Wertheim \\
\hline Pipettenaufsatz Combitips advanced 5 ml & Eppendorf; Hamburg \\
\hline Pipettenspitzen 10, 200, 1000 $\mu 1$ & Sarstedt; Nümbrecht \\
\hline Pipetting Reservoir 25 ml & Argos technologies; USA \\
\hline PVDF-Membran & Roth; Karlsruhe \\
\hline Reagenzgefäß 1,5 ml & Sarstedt; Nümbrecht \\
\hline Serologische Pipetten 1, 2, 5, 10, 25 ml & Sarstedt; Nümbrecht \\
\hline Zellkulturflaschen & Sarstedt; Nümbrecht \\
\hline Zellkultur Petrischalen (ZK-Schale 100, & Sarstedt; Nümbrecht \\
\hline Zell+) & Sarstedt; Nümbrecht \\
\hline
\end{tabular}


2.2.2 Zellkulturmedien und Lösungen

Tabelle 3: Zellkulturmedien und Lösungen

\begin{tabular}{|l|l|}
\hline Zellkulturmedien/Lösungen & Hersteller \\
\hline Dimethylsulfoxid (DMSO) & Sigma-Aldrich; Steinheim \\
\hline $\begin{array}{l}\text { Dulbecco`s Phosphate-Buffered Saline } \\
\text { (DPBS) }\end{array}$ & Pan Biotech; Aidenbach \\
\hline EDTA Trypsin & Lonza, Basel; Schweiz \\
\hline $\begin{array}{l}\text { Endothelial Cell GM MV2 + } \\
\text { MV2 + FCS 25 ml }\end{array}$ & PromoCell; Heidelberg \\
\hline RPMI 1640 mit L-Glutamin & Lonza, Basel; Schweiz \\
\hline
\end{tabular}

Das SupplementPack Endothelial Cell GM MV2 besteht aus Endothelial Cell GM MV2Medium (Basal-Medium), zugefügtem FCS und weiteren wachstumsfördernden Zusätzen wie hEGF (human epidermal growth factor), HC (Hydrocortison), VEGF-A (vascular endothelial growth factor A), hbFGF (human basic fibroblast growth factor), R3 IGF (insulin-like growth factor) und AA (Ascorbinsäure). Die genauen Mengenangaben sind Betriebsgeheimnis des Herstellers.

RPMI 1640 mit L-Glutamin wird vor der Verwendung mit $10 \%$ (v/v) FBS sowie mit 100 $\mu \mathrm{g} \mathrm{ml}{ }^{-1}$ des Aminoglycosid-Antibiotikums Streptomycin und $100 \mathrm{U} \mathrm{ml}^{-1}$ des BLactamantibiotikums Penicillin (zum Schutz vor grampositiven und gramnegativen Bakterien) angereichert. Die Kulturmedien und Lösungen wurden im Kühlschrank bei $4{ }^{\circ} \mathrm{C}$ aufbewahrt.

\subsubsection{Chemikalien und Lösungen}

Tabelle 4: Chemikalien und Lösungen

\begin{tabular}{|l|l|}
\hline Material & Hersteller \\
\hline DAPI & Invitrogen; USA \\
\hline Acrylamid-Lösung & PanReac Applichem; Darmstadt \\
\hline
\end{tabular}




\begin{tabular}{|c|c|}
\hline Alexa Fluor 488, 594 & Invitrogen; USA \\
\hline Ammoniumpersulfat (APS) & Sigma-Aldrich; Steinheim \\
\hline Aqua B. Braun & B. Braun; Melsungen \\
\hline Bovines Serum-Albumin (BSA) & PanReac Applichem; Darmstadt \\
\hline Coomassie-Brillant-Blau G250 & Thermo Fisher Scientific; USA \\
\hline Coulter Isoton II Diluent Lösung & Beckman Coulter; Krefeld \\
\hline Dimethylsulfoxid (DMSO) & Sigma-Aldrich; Steinheim \\
\hline Essigsäure 99,8 \% & Merck GmbH; Darmstadt \\
\hline Flow Clean Cleaning Agent & Beckman Coulter; Krefeld \\
\hline Fluoromount-G & Thermo Fisher Scientific; USA \\
\hline Glutaraldehyd $25 \%$ & Serva Electrophoresis GmbH; Heidelberg \\
\hline Isopropanol, $\geq 99,5 \%$ & Roth; Karlsruhe \\
\hline Kristallviolett rein & Serva Electrophoresis GmbH; Heidelberg \\
\hline Methanol $\left(\mathrm{CH}_{3} \mathrm{OH}\right), \geq 99,9 \%$ & Roth; Karlsruhe \\
\hline Natriumchlorid $(\mathrm{NaCl})$ & Roth; Karlsruhe \\
\hline Natrium-Dodecylsulfat (SDS) & Roth; Karlsruhe \\
\hline Natriumorthovanadat $\left(\mathrm{NaVO}_{3}\right)$ & Sigma-Aldrich; Steinheim \\
\hline PageRuler Plus Protein (Größenmarker) & Thermo Fisher Scientific; USA \\
\hline Paraformaldehyd (PFA) & Roth; Karlsruhe \\
\hline Ponceau-Rot & Roth; Karlsruhe \\
\hline Roti-Quant Bradford-Lösung & Roth; Karlsruhe \\
\hline Tetramethylethylendiamin (TEMED) & Roth; Karlsruhe \\
\hline Tris hydrochlorid & Roth; Karlsruhe \\
\hline Tween 20 & Sigma-Aldrich; München \\
\hline
\end{tabular}


2.2.4 Zelllinien

Tabelle 5: Zelllinien

\begin{tabular}{|c|c|c|c|}
\hline Zelllinie & Mutation (PIK3CA) & Geschlecht & Alter \\
\hline Ly-LEC1 (LEC-A, LEC-1) & Exon 8: c.1258T $>$ C (p.C420R) & M & Kind \\
\hline Ly-F-1 & Keine Mutation in Exon 8, 10, 21 & & \\
\hline Ly-LEC2 (LEC-B, LEC-2) & Exon 2: Glu109del & M & Kind \\
\hline Ly-F-2 & Keine Mutation in Exon 2, 8, 10, 21 & & \\
\hline Ly-LEC10 & Exon 10: c.1636G>A (p.Q546K) & $\mathrm{W}$ & Kind \\
\hline Ly-F-10 & Keine Mutation in Exon 8, 10, 21 & & \\
\hline Ly-LEC12 & Exon 10: c.1633G>A (p.E545K) & $\mathrm{W}$ & Kind \\
\hline Ly-F-12 & Keine Mutation in Exon 8, 10, 21 & & \\
\hline Ly-LEC14 & Exon 21: c.3140A>T (p.H1047L) & $\mathrm{W}$ & Erwachsener \\
\hline Ly-F-14 & Keine Mutation in Exon 8, 10, 21 & & \\
\hline HD-LEC C2 & Keine Mutation in Exon 8, 10, 21 & M & Kind \\
\hline HD-LEC C3 & Keine Mutation in Exon 8, 10, 21 & M & Kind \\
\hline HD-LEC C4 & Keine Mutation in Exon 8, 10, 21 & M & Kind \\
\hline
\end{tabular}

Die Lymphendothelzellen Ly-LEC1 und Ly-LEC2 stammen von männlichen Kleinkindern aus der Universitätsklinik Freiburg. Ly-LEC10, Ly-LEC12 und Ly-LEC14 stammen von weiblichen Patienten aus dem Universitätsklinikum Regensburg. Die Zellen wurden im Institut für Anatomie und Zellbiologie der UMG (Universitätsmedizin Göttingen) mittels der cell-sweeping-Methode isoliert. Im Institut für Humangenetik der UMG wurden die Zelllinien von Frau Dr. S. Kaulfuß auf bestehende Mutationen in den Exons 8, 10 und 21 geprüft. Es wurden keine Mutationen in den dazugehörigen Fibroblasten (Ly-F) gefunden. Die Lymphendothelzellen HD-LEC C2 (Lot Nr. 4051204), HD-LEC C3 (Lot Nr. 4051204) und HD-LEC C4 (Lot Nr. 30516023) stammen von Vorhäuten juveniler Spender und wurden bei PromoCell, Heidelberg gekauft. 
2.2.5 Inhibitoren

Tabelle 6: Inhibitoren und ihre Angriffspunkte

\begin{tabular}{|c|c|c|c|}
\hline Inhibitor & Hersteller & Angriffspunkt & $\begin{array}{c}\text { Verwendete } \\
\text { Konzentrationen }\end{array}$ \\
\hline Wortmannin (KY 12420) & InvivoGen; USA & $\begin{array}{c}P I K 3 C A(\mathrm{p} 110 \alpha, \mathrm{pH}> \\
\text { 8,5: } 110 \alpha / \mathrm{p} 85 \alpha)\end{array}$ & $10 / 50 \mu \mathrm{M}$ \\
\hline $\begin{array}{l}\text { BKM120 (Buparlisib, NVP- } \\
\text { BKM120) }\end{array}$ & ChemTek; USA & $\begin{array}{c}\text { PI3K Klasse } \mathrm{I}(\mathrm{p} 110 \alpha, \\
\beta, \delta, \gamma)\end{array}$ & $0,2 / 1 \mu \mathrm{M}$ \\
\hline Rapamycin (Sirolimus) & ChemTek; USA & mTOR (mTORC1) & $1 / 10 \mathrm{nM}$ \\
\hline $\begin{array}{l}\text { LY294002 (SF 1101, NSC } \\
697286)\end{array}$ & $\begin{array}{l}\text { Selleckchem; } \\
\text { München }\end{array}$ & $\begin{array}{l}\text { PI3K Klasse IA } \\
\quad(\mathrm{p} 110 \alpha, \beta, \delta)\end{array}$ & $0,5 / 5 \mu \mathrm{M}$ \\
\hline MK-2206 2HCI & $\begin{array}{l}\text { Selleckchem; } \\
\text { München }\end{array}$ & AKT $1 / 2 / 3$ & $10 / 25 \mu \mathrm{M}$ \\
\hline CAL-101 (Idelalisib, GS-1101) & $\begin{array}{l}\text { Selleckchem; } \\
\text { München }\end{array}$ & $\begin{array}{c}\text { PI3K Klasse I } \\
(\mathrm{p} 110 \delta)\end{array}$ & $5 / 50 \mu \mathrm{M}$ \\
\hline Dasatinib (BMS-354825) & $\begin{array}{l}\text { Selleckchem; } \\
\text { München }\end{array}$ & Src, Abl, c-Kit & $1 \mu \mathrm{M}$ \\
\hline Sorafenib (BAY 43-9006) & $\begin{array}{l}\text { Selleckchem; } \\
\text { München }\end{array}$ & $\begin{array}{c}\text { Raf-1, B-Raf, } \\
\text { VEGFR-2 }\end{array}$ & $1 / 5 \mu \mathrm{M}$ \\
\hline
\end{tabular}

Wortmannin, benannt nach dem Mykologen Julius Wortmann, wird aus einer Vielzahl fadenförmiger Pilze, wie z.B. Penicillium funiculosum gewonnen. Wortmannin ist ein

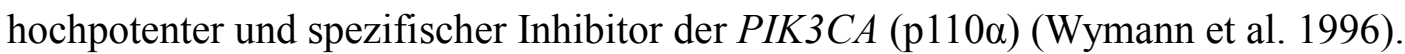

Buparlisib (BKM120), ein oral verfügbares 2,6-Dimorpholinopyrimidinderivat, ist ein potenter selektiver Pan-PI3K-Klasse I-Inhibitor (Janku 2017).

LY294002 ist der erste synthetisch hergestellte reversible PI3K-Inhibitor, der sich von dem natürlich vorkommenden Bioflavonoid Quercetin ableitet (El-Kholy et al. 2003; Vlahos et al. 1994). LY294002 hemmt die Klasse IA (p110 $\alpha, \beta$, $\delta)$ der PI3K (Wagener und Müller 2010).

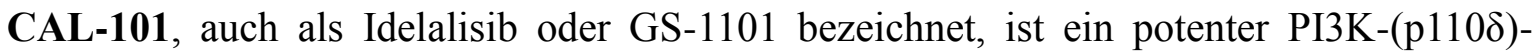
Inhibitor (Brown et al. 2014). 
Rapamycin wurde als erster mTOR-Inhibitor bei einer Erdbodenstichprobe auf den Osterinseln (Rapa Nui) entdeckt. Es ist ein makrozyklisches Lacton (Makrolid), welches von Streptomyces hygroscopicus produziert wird. Rapamycin hemmt mTORC1 aus dem Komplex mTOR (Hosoi et al. 1998).

MK-2206 ist ein oralverträglicher AKT-Inhibitor, welcher alle drei menschlichen AKTIsoformen (AKT 1, 2, und 3) mit einem jeweiligen IC50-Wert von 8, 12 und $65 \mathrm{nM}$ inhibiert (Wilson et al. 2014).

Dasatinib (BMS-354825) wurde ursprünglich als Inhibitor der SFKs synthetisch hergestellt (Lombardo et al. 2004). Es wurde zudem eine Wirksamkeit als BCR-ABL Kinase-Inhibitor entdeckt (Shah et al. 2004; Dorsey et al. 2000).

Sorafenib ist ein oral verfügbarer Multikinaseinhibitor mit antiproliferativer und antiangiogener Wirkung. Studien zeigten, dass Sorafenib Raf, PDGF, VEGF, FLT3, c-Kit und den MAPK-Signalweg blockiert (Hahn und Stadler 2006).

\subsubsection{Antikörper}

\subsubsection{Immunhistologie}

Tabelle 7: Antikörper für die Immunhistologie

\begin{tabular}{|l|l|l|}
\hline Antikörper & Verdünnung & Hersteller \\
\hline mouse-anti-human-CD-31 & $1: 100(1 \%$ BSA in PBS $)$ & BD; Heidelberg \\
\hline rabbit-anti-human-Prox1 & $1: 200(1 \%$ BSA in PBS $)$ & ReliaTech; Wolfenbüttel \\
\hline goat-anti-rabbit-Alexa594 & $1: 200(1 \%$ BSA in PBS $)$ & $\begin{array}{l}\text { ThermoFisherScientific; } \\
\text { USA }\end{array}$ \\
\hline goat-anti-mouse-Alexa488 & $1: 200(1 \%$ BSA in PBS $)$ & $\begin{array}{l}\text { ThermoFisherScientific; } \\
\text { USA }\end{array}$ \\
\hline
\end{tabular}




\subsubsection{Western Blot}

Tabelle 8: Antikörper für Western Blot

\begin{tabular}{|l|l|l|}
\hline Antikörper & Verdünnung & Hersteller \\
\hline pAkt Serin 473 (rabbit) & $1: 500(5 \%$ BSA in TBS $)$ & Cell Signaling; Cambridge \\
\hline goat-anti-rabbit IgG HRP & $1: 2000(5 \%$ BSA in TBS $)$ & Santa Cruz; USA \\
\hline tAkt (5 \% BSA in TBS) (rabbit) & $1: 1000(5 \%$ BSA in TBS) & Cell Signaling; Cambridge \\
\hline goat-anti-mouse IgG & $\begin{array}{l}1: 10000 \quad(5 \% \text { BSA in } \\
\text { TBS })\end{array}$ & Santa Cruz; USA \\
\hline$\alpha$-tubulin & $1: 2000(5 \%$ BSA in TBS $)$ & Abcam; USA \\
\hline
\end{tabular}

\subsection{Methoden}

\subsubsection{Arbeiten mit Lymphendothelzellen}

\subsubsection{Zellkultur}

Alle Arbeiten an den Zellkulturen wurden unter einer Sterilbank durchgeführt. Die Lymphendothelzellen wurden in Endothelial Cell GM MV2-Medium auf Zellkulturschalen (100x20 mm), mit einer Wachstumsfläche von $58 \mathrm{~cm}^{2}$, bei $37{ }^{\circ} \mathrm{C}, 95 \%$ Luftfeuchtigkeit und $5 \%-\mathrm{CO}_{2}$-Atmosphäre im Wärmeschrank inkubiert. Ein Mediumwechsel wurde dreimal pro Woche durchgeführt. Die Medien, DPBS und Trypsin wurden bei $4{ }^{\circ} \mathrm{C}$ im Kühlschrank gelagert und vor Verwendung im Wasserbad auf $37{ }^{\circ} \mathrm{C}$ erwärmt.

\subsubsection{Passagieren}

Je nach Wachstumsstatus, aber in der Regel einmal in der Woche, wurden die Lymphendothelzellen auf neue ZK-Schalen umgesetzt. Dabei wurden die Zellen je nach Proliferationsgeschwindigkeit entweder 1:2 oder 1:3 gesplittet. Hierzu wurde das alte Medium mit einer Glaspipette abgesaugt und die Zellen mit $5 \mathrm{ml}$ DPBS zweimal gewaschen. Anschließend wurden die Zellen mit $2 \mathrm{ml}$ Trypsin für ca. 2-5 Minuten behandelt. Trypsin verdaut Adhäsionsmoleküle an der Zelloberfläche und löst so adhärente Zellen von der Schale. Diese Reaktion wurde mit $3 \mathrm{ml}$ RPMI640 Medium gestoppt. Durch Suspendieren der Zellen erfolgte eine vollständige Ablösung. Daraufhin wurde die 
Zellsuspension für 5 Minuten bei 20800 x g zentrifugiert. Je nach Verwendung wurden die Zellen auf eine neue Kulturschale mit $5 \mathrm{ml}$ Endothelial Cell GM MV2-Medium gesetzt oder für Versuche verwendet.

\subsubsection{Einfrieren und Auftauen von Zellen}

Um Zellen langfristig zu sichern, wurden Zellen nach der Trypsinierung und Zentrifugation in einem Einfriermedium (bestehend aus 90 \% FCS und $10 \%$ DMSO) resuspendiert und in Kyroröhrchen überführt. Die Röhrchen wurden in einem Kunststoffgefäß mit Isopropanol bei $-80{ }^{\circ} \mathrm{C}$ langsam heruntergekühlt. Nach 48 Stunden wurden die Röhrchen dann in einen Flüssigstickstofftank $\left(-196^{\circ} \mathrm{C}\right)$ zur Dauerlagerung überführt.

Zur Reaktivierung der Zellen wurden die benötigten Kryoröhrchen aus dem Flüssigstickstofftank entnommen und kurz im Wasserbad bei $37{ }^{\circ} \mathrm{C}$ aufgetaut. Anschließend wurde die Zellsuspension mit kaltem RPMI1640 Medium in ein Zentrifugierröhrchen überführt und dann bei 20800 x g für 5 Minuten zentrifugiert. Daraufhin wurde das Zellpellet in Wachstumsmedium $(5 \mathrm{ml})$ resuspendiert, auf eine Zellkulturschale ausplattiert und im Wärmeschrank inkubiert.

\subsubsection{Zellzählung mittels Coulter-Counter Z1}

Für alle Versuche wurde die Zellzahl mittels Coulter-Counter Z1 bestimmt und auf die gewünschte Zellzahl eingestellt (bei Proliferationsassays 5.000 Zellen/Vertiefung und zur Proteingewinnung 500.000 Zellen/Vertiefung). Das Prinzip der Zellzählung des CoulterCounter Z1 beruht auf der Impedanz-Messung (Widerstandsmessung von durchfließenden Partikeln zwischen zwei Elektroden, die durch einen Glaskolben mit einer kleinen Öffnung, durch die die Zellen gesaugt werden, getrennt sind). Hierfür wurden $100 \mu 1$ trypsinierte Zellen 1:100 mit einer Isotonlösung verdünnt und gemessen.

\subsubsection{Immunhistologie}

Die Immunhistologie wurde angewendet, um durch Antikörper spezifische Antigene in Lymphendothelzellen $\mathrm{zu}$ markieren und fluoreszenzmikroskopisch darzustellen. So sind

z. B. der Lymphendothelspezifische Transkriptionsfaktor PROX1 (prospero homeobox protein 1) und das panendotheliale Oberflächenprotein CD-31/PECAM1 (platelet endothelial cell adhesion molecule 1) geeignet, um Lymphendothelzellen zu identifizieren 
(Abb. 3). Bei der Durchführung wurden die zu untersuchenden Zellen auf einen Objektträger in einzelnen Kammern kultiviert und bei Erreichen der geeigneten Zelldichte (80- $90 \%$ Konfluenz) mit $500 \mu 14 \%$-igen Paraformaldehyd für 5 Minuten fixiert. Anschließend wurden die Zellen mit $500 \mu$ PBS zweimal gespült und dann mit $1 \%$-igem BSA in PBS für 30 Minuten inkubiert. BSA wird verwendet, um unspezifische Bindungen der Antikörper an freien Oberflächen zu verhindern. Nach dem Entfernen der BSA-Lösung erfolgte die Permeabilisierung der (Kern-)Membran für die Antikörper mit 0,05 \%-igem Tween 20 in PBS für eine Minute. Nun wurden pro Vertiefung $300 \mu l$ des Primärantikörpers hinzugefügt (CD-31; 1:100 in PBS und PROX1; 1:200 in PBS) und für eine Stunde inkubiert. Anschließend wurden die ungebundenen Primärantikörper entfernt und die Kammern zweimal mit $500 \mu$ PBS gespült. Je Kammer wurden dann $300 \mu 1$ 0,1 \% BSA in PBS mit fluoreszenzmarkierten Sekundärantikörpern pipettiert; goat-anti-mouse 1:200 und goat-anti-rabbit 1:200 (Farbstoff: Alexa Fluor 488 und Alexa Fluor 594). Zudem wurde der DNA-bindende Farbstoff DAPI (1:100) zur Zellkerndarstellung in die Kammern pipettiert. Nach einer Stunde Inkubation wurde die Lösung entfernt und die Kammern zweimal mit je $500 \mu 1$ PBS gespült. Das Kammergerüst wurde entfernt und die Zellen mit Fluoromount-G eingedeckt. 

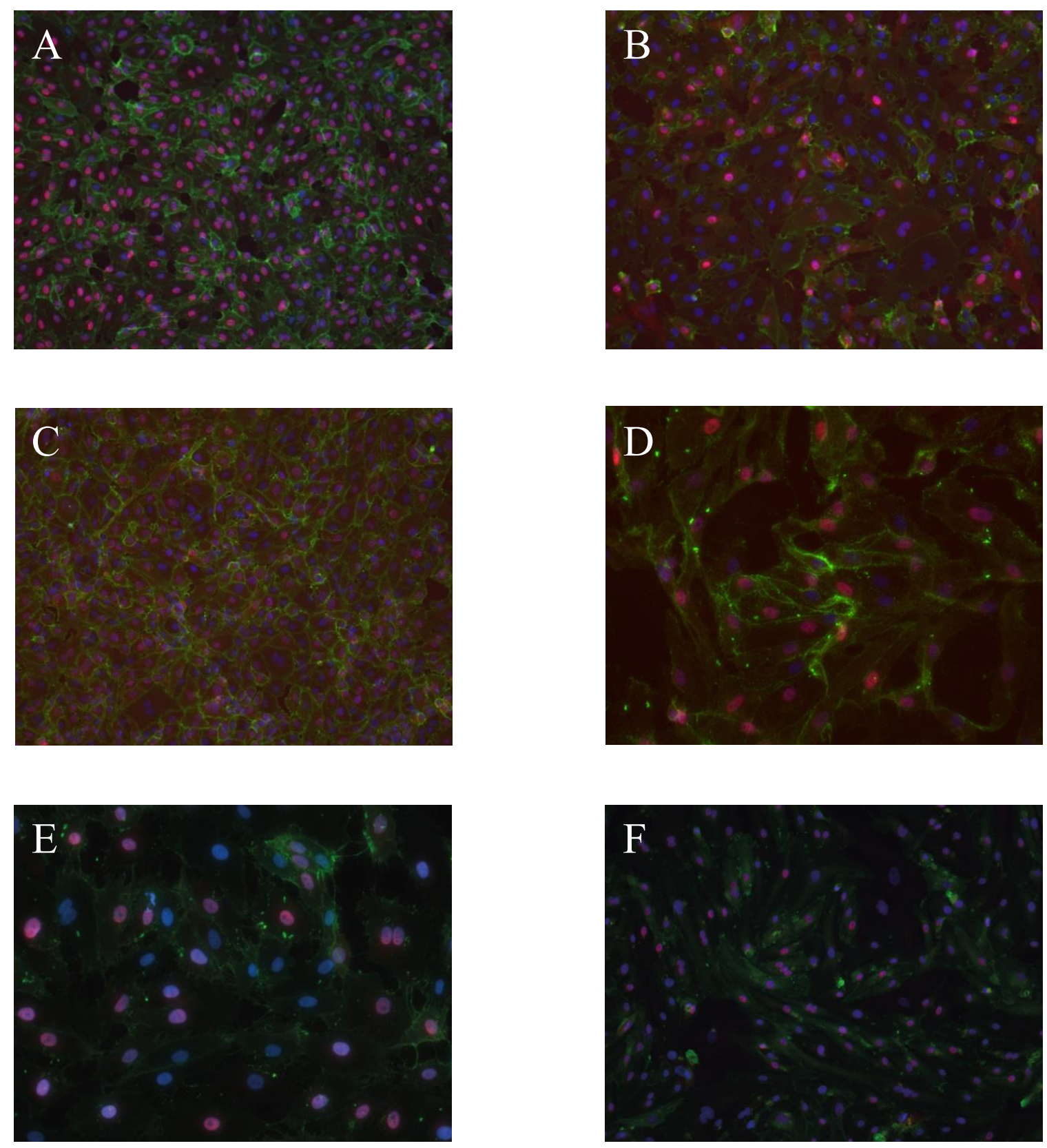

Abbildung 3: Immunhistologische Bilder zur Identifizierung von Lymphendothelzellen (A) HD-LEC C2, Vergrößerung: 10x, (B) HD-LEC C3, Vergrößerung: 10x, (C) HD-LEC C4, Vergrößerung: 10x, (D) Ly-LEC1, Vergrößerung: 20x, (E) Ly-LEC2, Vergrößerung: 20x, (F) Ly-LEC12, Vergrößerung: 10x. Zellkernfärbung mittels DAPI (blau). Fluoreszierender Reaktivfarbstoff (fluorescent dye) Alexa Fluor 549 (Bindung an Prox1Antikörper mit der Färbung in rot) und Alexa Fluor 488 (Bindung an CD31-Antikörper mit der Färbung in grün). 


\subsubsection{Proliferationsassays}

Proliferationsassays dienen der Bestimmung der Vermehrungsrate von Zellen. Dafür wurden 5000 Zellen/Vertiefung in Zellkulturplatten mit $100 \mu$ 1 Endothelial Cell GM MV2Medium ausplattiert und bei $37^{\circ} \mathrm{C}$ vier Stunden bis zur vollständigen Adhäsion am Boden inkubiert.

Danach wurden die Inhibitoren in entsprechenden Konzentrationen gelöst in je $100 \mu 1$ Endothelial Cell GM MV2-Medium zugegeben. Als Kontrolle diente die Zugabe von 100 $\mu 1$ reinem Medium sowie einer Lösungsmittelkontrolle mit der jeweils höchsten DMSOKonzentration. Zum Zeitpunkt der Inhibitorzugabe $(\mathrm{t}=0)$ sowie nach 24, 48 und 72 Stunden wurden die Zellen mit je $50 \mu 15 \%$-igen Glutaraldehyd für 15 Minuten auf einen Kippschüttler bei Raumtemperatur fixiert. Anschließend wurden die Platten zweimal gewaschen und dann unter einem Abzug getrocknet. Zur Färbung der Zellkerne wurden 50 $\mu 1$ pro Vertiefung Kristallviolett $(0,1 \%$ in Aqua dest.) für 15 Minuten hinzugefügt und überschüssiger Farbstoff wurde ausgewaschen. Die Zellkulturplatten trockneten wieder mind. 24 Stunden unter dem Abzug. Zur Messung der optischen Dichte wurde der in den Zellkernen gebundene Farbstoff mit je $100 \mu 1 \quad 10 \%$-iger Essigsäure gelöst und die Extinktion bei einer Wellenlänge von $570 \mathrm{~nm}$ im Thermo Max Microplate Reader (ElisaReader) gemessen. Die Menge an gelöstem Farbstoff ist dabei proportional zur DNAMenge, also zur Anzahl der Zellkerne und damit zur Anzahl der Zellen. Die gemessene Extinktion kann nach dem Lambert-Beer’schen Gesetz direkt als Maß für die Menge vorhandener Zellen genutzt werden.

Dabei besagt das Lambert-Beer'sche Gesetz (Harms 2000), dass die durch die Extinktion $\left(E_{\lambda}\right)$ gemessene Absorptionsintensität bei einer bestimmten Wellenlänge $(\lambda)$ der durchstrahlten Schichtdicke $(d)$ und der molaren Konzentration $(c)$ der Probe proportional ist. Die Extinktion $\left(E_{\lambda}\right)$ ist dabei die frequenz- bzw. stoffabhängige Abschwächung der Intensität einer Lichtstrahlung durch Absorption, Streuung und Reflexion in der zu untersuchenden Lösung.

Lambert-Beer`sches Gesetz: $E_{\lambda}=\log _{10} \frac{I 0}{I}=\varepsilon_{\lambda} \cdot c \cdot d$

$I_{0}$ : Intensität des Lichtes vor dem Durchgang durch die Lösung (Einheit: $\mathrm{W} \cdot \mathrm{m}^{-2}$ )

I: Intensität des Lichtes nach dem Durchgang durch die Lösung (Einheit: $\mathrm{W} \cdot \mathrm{m}^{-2}$ ) 
$\varepsilon_{\lambda}$ : Absorptionskoeffizient bzw. Extinktionskoeffizient bei einer bestimmten Wellenlänge $(\lambda)$. Dieser ist eine für die absorbierende Substanz spezifische Größe, die auch vom pHWert oder dem Lösungsmittel beeinflusst werden kann (Einheit in $\mathrm{m}^{2} \cdot \mathrm{mol}^{-1}$ )

c: Stoffmengenkonzentration der absorbierenden Substanz in der Flüssigkeit (Einheit: $\left.\mathrm{mol} \cdot 1^{-1}\right)$

$d$ : Schichtdicke (Einheit: m)

\subsubsection{Statistik}

Die statistische Auswertung der Proliferationsversuche wurde mittels der ein- und zweifaktoriellen Varianzanalyse (One-/Two-way-ANOVA) mit der Statistiksoftware STATISTICA durchgeführt. Die abhängige Variable ist in beiden Varianzanalysen die prozentuale Zellzahl. In der One-Way-ANOVA ist der kategoriale Faktor die zugegebene Lösung (Kontrollgruppen oder Inhibitor). Die gemessenen Zeitpunkte wurden in den einzelnen Tests berücksichtigt. Bei der Two-Way-ANOVA sind Faktor A die gemessenen Inkubationszeiten (24, 48 und 72 Stunden) und Faktor B die zugegebene Lösung. Vor der Durchführung der Analysen wurden die Werte auf Normalverteilung geprüft. In den Diagrammen werden signifikante Ergebnisse $(p \leq 5 \%)$ mit $\left[{ }^{*}\right]$, sehr signifikante Ergebnisse $(\mathrm{p} \leq 1 \%)$ mit $[* *]$ und hoch signifikante Ergebnisse $(\mathrm{p} \leq 0,1 \%)$ mit $[* * *]$ dargestellt.

\subsubsection{Proteingewinnung}

Um Versuche wie das Western Blotting durchführen zu können, müssen zuerst Proteine von den zu untersuchenden Zelllinien gewonnen werden. Dazu wurden je 500.000 Lymphendothelzellen pro Vertiefung in $2 \mathrm{ml}$ Medium auf 6-Well-Platten ausplattiert. Nach zwölf Stunden wurden die Zellen mit je $5 \mathrm{ml}$ DPBS $+1 \mathrm{mM}$ Natriumorthovanadat zweimal gewaschen und dann mit $200 \mu$ l RIPA-Puffer (Alcaraz et al. 1990) (Rezept siehe Tab. 9) für 10 Minuten auf Eis lysiert. Daraufhin wurden die lysierten Zellen mittels Zellschaber von den Platten in ein Mikroreaktionsgefäß (E-Cup) überführt und nochmals für 20 Minuten auf Eis inkubiert, um möglichst alle Proteine zu lösen. Danach wurden die E-Cups in einer vorgekühlten Zentrifuge bei $4{ }^{\circ} \mathrm{C}$ und bei $20800 \mathrm{x}$ g für 15 Minuten zentrifugiert. Anschließend wurde das Zelllysat in ein neues E-Cup überführt und durch die Bradford-Messung die Proteinkonzentration bestimmt, oder zur Lagerung bei $-20^{\circ} \mathrm{C}$ eingefroren. 
Tabelle 9: Rezept Proteinextraktionspuffer (RIPA-Puffer)

\begin{tabular}{|l|l|}
\hline Tris & $30 \mathrm{mM}$ \\
\hline $\mathrm{NaCl}$ & $150 \mathrm{mM}$ \\
\hline EDTA & $1 \mathrm{mM}$ \\
\hline Triton X-100 & $1 \%$ \\
\hline
\end{tabular}

\subsubsection{Proteinquantifizierung nach Bradford}

Bei der Proteinquantifizierung nach der Bradford-Methode (Bradford 1976) wird mit Hilfe des Triphenylmethanfarbstoffes Coomassie-Brillant-Blau G250 die Extinktion (siehe Lambert-Beer`sches Gesetz, Kapitel 2.3.4) des zu untersuchenden Proteinlysats bestimmt. Dazu wurden $3 \mu 1$ des Proteinlysats mit $27 \mu 1$ Aqua dest. vermischt und mit $200 \mu 1$ der Bradfordlösung Roti-Quant (Bradfordreagenz 1:5 in Aqua dest. verdünnt) versetzt (5 Minuten Inkubationszeit). Coomassie-Brillant-Blau G250 bildet mit Proteinen Komplexe, und dadurch ändert sich der Ladungszustand von kationisch zu anionisch. Zudem verschiebt sich das Absorptionsspektrum von ca. $470 \mathrm{~nm}$ zu $595 \mathrm{~nm}$. Da diese Absorptionsänderung direkt proportional zur Proteinkonzentration ist, lässt sich mit Hilfe einer Standardeichkurve (Abb. 4, Tab. 10) die Proteinmenge einer Lösung bestimmen. Die Proteine wurden daraufhin bei $-20^{\circ} \mathrm{C}$ gelagert.

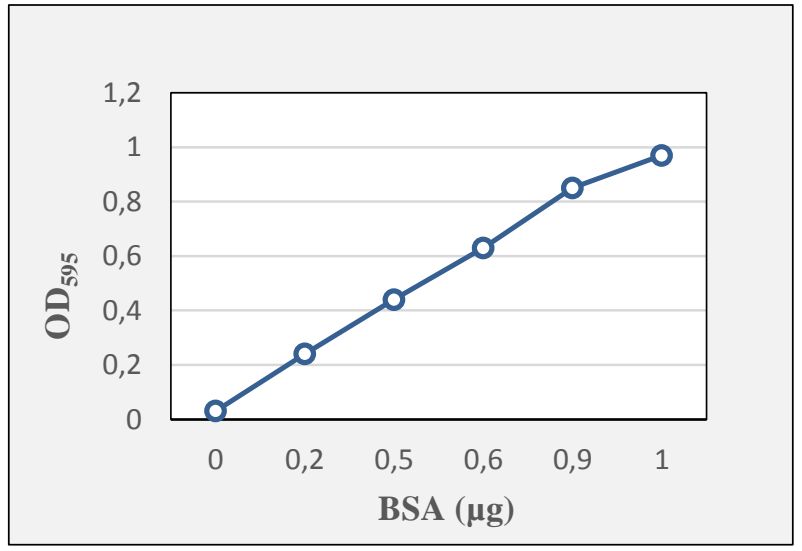

Abbildung 4: Eichkurve mit Bradford-Lösung und BSA als Standardprotein 
Tabelle 10: BSA-Eichwerte

\begin{tabular}{|c|c|}
\hline BSA $(\boldsymbol{\mu g})$ & gemessene OD-Werte $\left(\mathbf{O D}_{\mathbf{5 9 5}}\right)$ \\
\hline 0 & 0,03 \\
\hline 0,2 & 0,24 \\
\hline 0,5 & 0,44 \\
\hline 0,6 & 0,63 \\
\hline 0,9 & 0,85 \\
\hline 1 & 0,97 \\
\hline
\end{tabular}

\subsubsection{Natriumdodecylsulfat-Polyacrylamidgelelektrophorese (SDS-PAGE)}

SDS-PAGE ist eine Methode, die erlaubt, Proteine in einem elektrischen Feld mittels eines Acrylamidgels nach ihrer Molekularmasse zu trennen (Laemmli 1970). Dazu wurden die Proteinlysate mit einem 6-fachen SDS-Ladepuffer (PAP) versehen und anschließend für 5 Minuten bei $92{ }^{\circ} \mathrm{C}$ denaturiert. Sodium-Dodecyl-Sulfat (SDS) ist ein anionisches Detergens, welches die Eigenladung der Proteine mit einer gleichmäßigen negativen Ladung überdeckt. Durch die so entstandene gleichmäßige negative Ladung wird die Auftrennung der Proteine im Polyacrylamidgel nur noch durch die Kettenlänge, welche proportional zur Molekularmasse ist, bestimmt.

Tabelle 11: Rezept SDS-Probenpuffer

\begin{tabular}{|l|l|}
\hline Tris/HCL $(\mathrm{pH} 6,8)$ & $350 \mathrm{mM}$ \\
\hline SDS & $10 \%$ \\
\hline Glycerin & $36 \%$ \\
\hline Dithiothreitol (DTT) & $9,3 \%$ \\
\hline Bromphenolblau & $0,015 \%$ \\
\hline
\end{tabular}

Für die Herstellung des Polyacrylamidgels wurde zunächst das Trenngel gegossen, welches feinporig ist (12\% Acrylamidkonzentration). Im Anschluss wurde das Sammelgel hergestellt und auf das Trenngel gegossen. Das Sammelgel ist grobporiger (5\% Acrylamidkonzentration) und dient dazu, die Proteine zu Beginn der Auftrennung auf einer Bande zu fokussieren. Außerdem bildet man hier die Taschen, in die später die Proteine aufgetragen werden. Das Herstellungsrezept für die Gele wurde nach Harlow und Lane (1988) modifiziert: 
Tabelle 12: Rezept SDS-Page

\begin{tabular}{|l|l|l|}
\hline & Trenngel (12 \%) & Sammelgel (5 \%) \\
\hline Aqua dest. & $3,4 \mathrm{ml}$ & $2,2 \mathrm{ml}$ \\
\hline $\begin{array}{l}30 \% \text { Acrylamid (AA)-Lösung } \\
(30 \% \text { AA, } 0,8 \% \text { Bis-AA) }\end{array}$ & $4,0 \mathrm{ml}$ & $370 \mu \mathrm{l}$ \\
\hline 1,5 M Tris (pH 8,8) & $2,5 \mathrm{ml}$ & - \\
\hline 0,5 M Tris (pH 6,8) & - & $1,0 \mathrm{ml}$ \\
\hline $\begin{array}{l}20 \% \text { Natriumlaurylsulfat (SDS)- } \\
\text { Lösung in Aqua dest. }\end{array}$ & $50 \mu \mathrm{l}$ & $50 \mu \mathrm{l}$ \\
\hline $\begin{array}{l}10 \% \text { Ammoniumpersulfat (APS)- } \\
\text { Lösung in Aqua dest. }\end{array}$ & $100 \mu \mathrm{l}$ & $50 \mu \mathrm{l}$ \\
\hline $\begin{array}{l}\text { 99 \% Tetramethylethylendiamin } \\
\text { (TEMED) }\end{array}$ & $5 \mu \mathrm{l}$ & $5 \mu 1$ \\
\hline
\end{tabular}

Das Trenngel wurde zwischen zwei Glasplatten (1 mm Abstand) gegossen und mit $600 \mu 1$ Isopropanol überschichtet. Isopropanol verschließt das Trenngel zur Luft und glättet deren Kontaktoberfläche. Nach vollständiger Polymerisierung des Trenngels wurde das Sammelgel hergestellt und nach Dekantieren des Isopropanols vorsichtig auf das Trenngel pipettiert. Schließlich wurde ein Kamm auf das Sammelgel gesetzt, um Aussparungen für die Probentaschen zu erhalten. Das auspolymerisierte Gel wurde in die ElektrophoreseApparatur eingespannt und mit 1x Laufpuffer umgossen. Die Proteinproben wurden mit RIPA-Puffer so verdünnt, dass alle Proben ein einheitliches Ladevolumen für $50 \mu \mathrm{g}$ Gesamtprotein aufwiesen. Dann wurde der 6x SDS-Ladepuffer zugegeben, die Proben im Heizblock bei $95^{\circ} \mathrm{C}$ für 5 Minuten denaturiert, kurz abzentrifugiert und anschließend in die Probentaschen des Sammelgels aufgetragen. Um den Fortschritt der Auftrennung verfolgen zu können, wurde zusammen mit den Proben ein farbiger Größenmarker aufgetragen. Zunächst erfolgte die Fokussierung der Proben im Sammelgel bei 100V, beim Eintritt ins Trenngel wurde die Spannung dann auf 200V erhöht. Dabei wandern die negativ geladenen Proteine Richtung Anode (Pluspol) und werden entsprechend ihrer unterschiedlichen Molekularmasse aufgetrennt. Kleinere Proteine wandern dabei schneller durch die Poren des Polyacrylamidgels als größere Proteine. 
Tabelle 13: Rezept Laufpuffer

\begin{tabular}{|l|l|}
\hline Tris & $0,250 \mathrm{M}=30,28 \mathrm{~g} / \mathrm{l}$ \\
\hline Glycin & $2,5 \mathrm{M}=187,68 \mathrm{~g} / \mathrm{l}$ \\
\hline SDS & $0,5 \%=10 \mathrm{~g} / \mathrm{l}$ (in Aqua dest, $\mathrm{pH} 8,3)$ \\
\hline
\end{tabular}

\subsubsection{Wet-Blotting (Western Blot)}

Die im Polyacrylamidgel aufgetrennten Proteine werden beim Western Blot auf eine PVDF-Membran transferiert, um anschließend Proteine mit spezifischen Antikörpern nachzuweisen. Dazu wird das proteinbeladene Polyacrylamidgel aus den zwei umgebenen Glasplatten herausgelöst und in die Blot-Vorrichtung (Abb. 5) eingesetzt. Die hydrophobe PVDF-Membran wird zuvor für 15 Sekunden in Methanol eingelegt, damit sie in wässrigen Lösungen benetzbar wird. Die verwendeten Filterpapiere und Schwämme werden kurz im Transferpuffer getränkt. Nach Befüllung des Tanks mit Transferpuffer (Tab. 14; Aufbewahrung im Kühlschrank) wird ein elektrischer Strom angelegt $(2,5$ $\mathrm{mA} / \mathrm{cm}^{2}$ Membranfläche), mit dem die negativ geladenen Proteine aus dem Gel wandern und dann von der PVDF Membran gebunden werden. Der Blot-Vorgang dauerte in den Versuchen eine Stunde und musste je nach Größe der zu untersuchenden Proteine angepasst werden.

Tabelle 14: Rezept Transferpuffer

\begin{tabular}{|l|l|}
\hline Tris & $48 \mathrm{mM}=5,81 \mathrm{~g} / 1$ \\
\hline Glycin & $39 \mathrm{mM}=2,93 \mathrm{~g} / 1$ \\
\hline Methanol & $20 \%$ \\
\hline SDS & $0,05 \%$ \\
\hline Aqua dest. & auf $1000 \mathrm{ml}$ auffüllen \\
\hline
\end{tabular}

Die PVDF-Membran wurde danach vorsichtig aus der Apparatur herausgelöst, beschriftet und in TBST $(0,1 \%$ Tween20) gewaschen. Danach wurde die PVDF-Membran kurz getrocknet und konnte dann zur Kontrolle mit Ponceaurot eingefärbt werden (optional). Dann wurde diese wieder mit TBST $(0,1 \%$ Tween20) gewaschen und anschließend mit 
einem Blockpuffer (5 \% BSA in TBST 0,1\%) auf den Rollenmischer für eine Stunde inkubiert. Dabei werden auf der Membran freie Proteinbindungsstellen gesättigt, damit es nicht zu unspezifischen Bindungen von Antikörpern kommt.

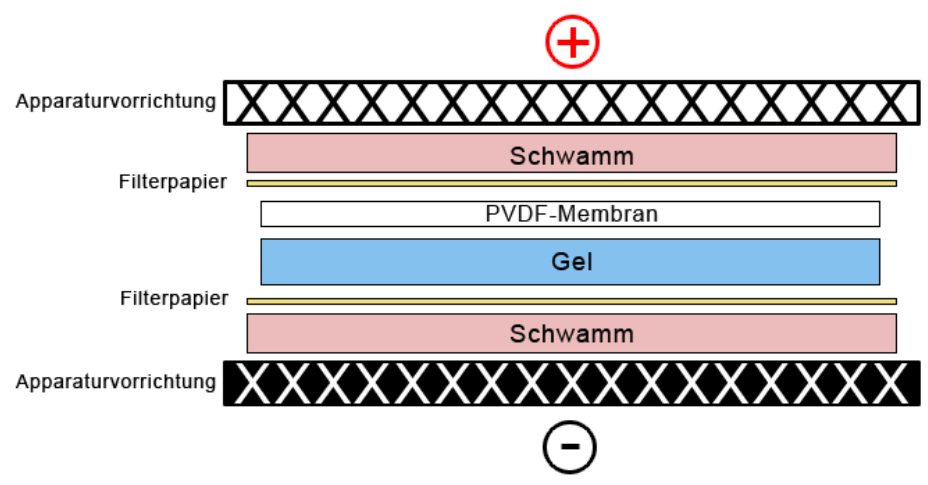

Abbildung 5: Prinzip des Wet-Blottings.

Modifiziert nach Novus Biologicals (Novus Biologicals 2019).

\subsubsection{Immundetektion spezifischer Proteine}

Um spezifische Proteine auf der Membran nachweisen zu können, werden Primär- und Sekundärantikörper verwendet. Die Primärantikörper binden spezifisch das passende Antigen und bilden einen Antigen-Antikörper-Komplex. Die Sekundärantikörper sind mit einem Enzym für die Detektion gekoppelt, hier Meerrettich-Peroxidase (HRP), und binden an die Fc-Region des Primärantikörpers. Mit Hilfe der HRP können in einer Chemilumineszenzreaktion die gesuchten Proteine sichtbar gemacht werden.

Nach Inkubation mit der Blockierlösung wurde dieser verworfen und der primäre Antikörper $(5 \mathrm{ml})$ hinzugegeben um über Nacht bei $4{ }^{\circ} \mathrm{C}$ im Kühlschrank auf einem Rollmischer zu inkubieren. Am nächsten Morgen wurde der Primärantikörper entfernt und die PVDF-Membran in drei Waschdurchläufen mit TBST $(0,1 \%$ Tween 20$)$ für jeweils 10 Minuten gewaschen. Danach wurde der Sekundärantikörper $(5 \mathrm{ml})$ hinzugefügt und für eine Stunde auf dem Rollmischer inkubiert. Dieser wurde nach Inkubation entfernt und die PVDF-Membran anschließend wieder dreimal mit TBST (0,1\% Tween20) gewaschen.

Unter Chemilumineszenz versteht man die Emission von Licht (Lumineszenz) aufgrund einer chemischen Reaktion. Dabei katalysiert die Meerretichperoxidase, welche an den Sekundärantikörper gekoppelt ist, die Oxidation von Luminol in einer alkalischen Lösung durch Wasserstoffperoxid, unter Abgabe von Stickstoff (NO). Dabei wird Energie in Form von Licht frei. 
Die Wellenlängen sind meistens im sichtbaren Bereich (400-700 nm). Die Temperatur liegt deutlich unterhalb der Glühtemperatur der beteiligten Substanzen, weshalb man auch von „kaltem Licht" spricht. Die Lichtemission wurde mit einem „Chemidoc Imaging System“ der Fa. BioRad detektiert und dokumentiert.

Zusammensetzung der Chemilumineszenz-Lösung:

$1000 \mu \mathrm{l}$ : $\quad$ Lösung A: $50 \mathrm{mg}$ Luminol in $200 \mathrm{ml} \mathrm{0,1}$ M TRIS-HCL (pH 8,6)

$100 \mu \mathrm{l}$ : $\quad$ Lösung B: $11 \mathrm{mg}$ para-Hydroxycoumarinsäure in $10 \mathrm{ml}$ DMSO

$2 \mu \mathrm{l}: \quad \mathrm{H}_{2} \mathrm{O}_{2}(30 \%)$

\subsubsection{Strippen der Membran}

Um Primär- und Sekundärantikörper von der PVDF-Membran für einen weiteren Proteinnachweis zu entfernen, wird die Membran „gestrippt“. Dazu wird die PVDFMembran mit TBST (0,1\% Tween20) gespült, anschließend für 10 Minuten in eine 0,1 M $\mathrm{NaOH}-L o ̈ s u n g$ auf den Wippschüttler gestellt und dann zweimal für 15 Minuten mit TBST $(0,1 \%$ Tween 20$)$ gewaschen. Danach kann die PVDF-Membran getrocknet und für einen nächsten Proteinnachweis verwendet werden. 


\section{Ergebnisse}

\subsection{Proliferationsassays}

In diesem Kapitel werden die Ergebnisse der Proliferationsversuche in Abhängigkeit von der Wirkung der verwendeten Inhibitoren in der PI3K-Signalkaskade aufgeführt. Die Versuche wurden an drei Lymphangiomzelllinien (Ly-LEC1, Ly-LEC2 und Ly-LEC12) und an drei Lymphendothelzelllinien (HD-LEC C2, HD-LEC C3 und HD-LEC C4) von gesunden Spendern durchgeführt. Die Versuche wurden für sämtliche Zelllinien mindestens dreimal unabhängig voneinander mit je 6 Replikaten durchgeführt. Die gemessenen OD-Werte wurden in prozentuale Mittelwerte umgerechnet. Mit dem Statistikprogramm STATISTICA, wie in Kapitel 2.3.4.1 beschrieben, wurden die prozentualen Zuwachsraten der mit Inhibitoren behandelten Ansätze mit den DMSObehandelten und unbehandelten Kontrollen verglichen und auf signifikante Unterschiede geprüft. Bei jedem Ergebnis wird der Standardfehler ( \pm SEM) graphisch dargestellt.

\subsubsection{Hemmung der Phosphoinositid-3-Kinase (PI3K)}

Im Folgenden werden die Ergebnisse mit den Inhibitoren dargestellt, welche auf die Phosphoinositid-3-Kinase (PI3K) wirken. Hierfür wurden Wortmannin, BKM120, LY294002 und CAL-101 verwendet. 
3.1.1.1 Wortmannin

Die Abbildung 6 zeigt die Ergebnisse der sechs untersuchten Lymphendothelzelllinien mit dem PI3K-Inhibitor Wortmannin, in den Konzentrationen von $10 \mu \mathrm{M}$ und $50 \mu \mathrm{M}$. Wie bei allen nachfolgenden Abbildungen sind die erkrankten LECs in der linken, die gesunden LECs in der rechten Spalte dargestellt.

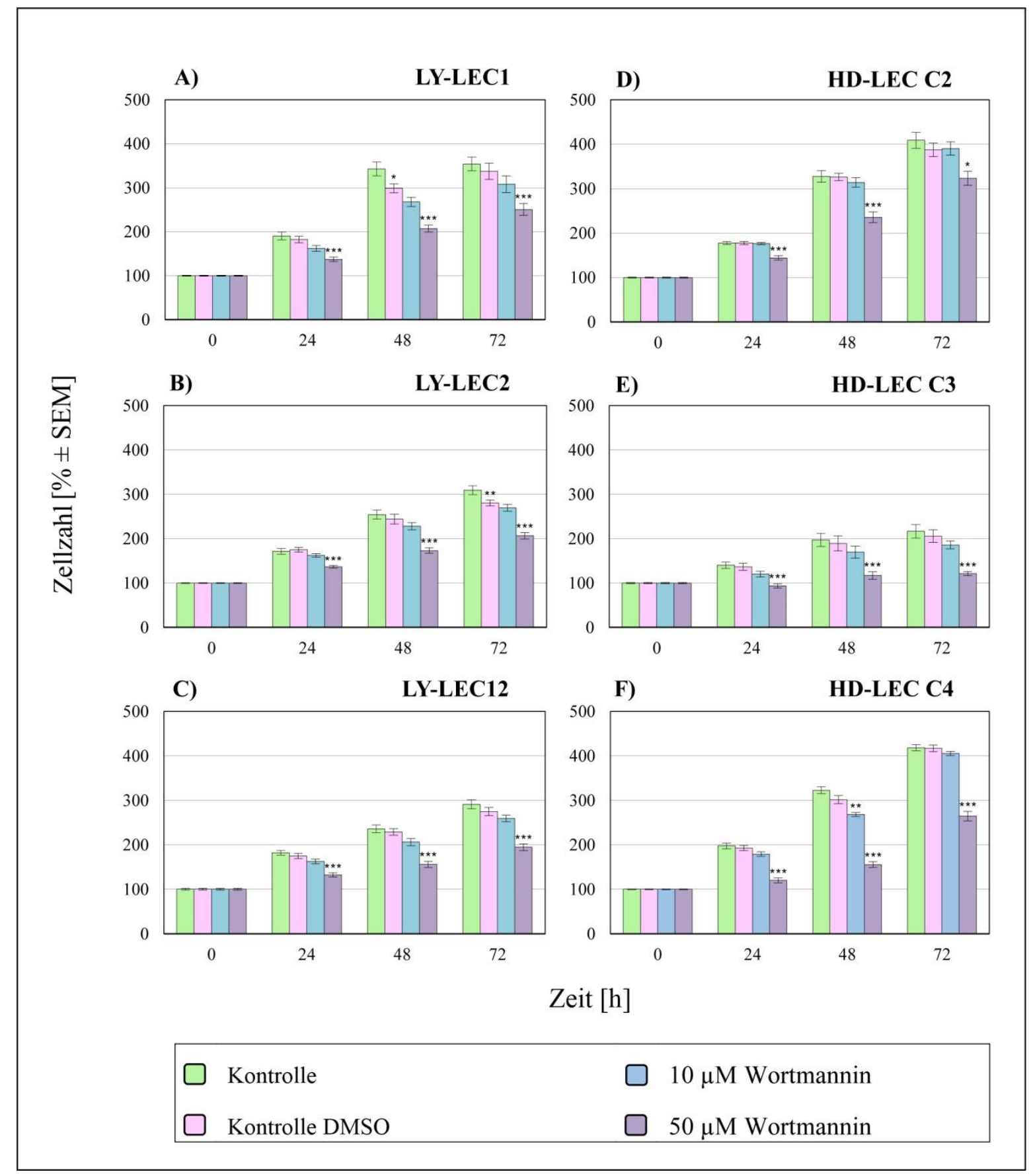

Abbildung 6: Proliferationsassays mit PI3K-Inhibitor Wortmannin

Für Ly-LEC1 stieg die Zellzahl der Medium-Kontrolle nach 24 h von $100 \%$ auf den Wert 190,5 \%, nach 48 h auf 343,0 \% und nach 72 h auf 354,2 \%. Dies entsprach einer Zunahme 
innerhalb der ersten $24 \mathrm{~h}$ von $+90,0 \%$, nach weiteren $24 \mathrm{~h}$ von $+80,0 \%$ und einem weiteren Zuwachs von $+3,2 \%$. Die Zellzahl bei DMSO-Behandlung stieg ähnlich wie bei den Medium-Ansätzen an $(24 \mathrm{~h}$; DMSO $=182,2 \%)$, zeigte jedoch bei $48 \mathrm{~h}(\mathrm{DMSO}=$ 298,9 \%) einen signifikanten Unterschied ( $\left.\mathrm{p} \leq 0,05\left[^{*}\right]\right)$ zur Medium-Kontrolle. Bei $72 \mathrm{~h}$ ergab sich ein Zellzahlwert von 337,6 \%. Der PI3K-Inhibitor Wortmannin zeigte in der Konzentration von $10 \mu \mathrm{M}$ bei allen Zeitpunkten keinen signifikanten Unterschied zur DMSO-Kontrolle. Hoch signifikante Werte ( $\leq \leq 0,001[* * *])$ wurden bei Wortmannin 50 $\mu \mathrm{M}$ gegenüber der DMSO-Kontrolle bei allen drei Inkubationszeitpunkten gemessen. Wortmannin: $50 \mu \mathrm{M}=137,3 \%(24 \mathrm{~h}), 207,3 \%$ (48 h) und 250,6 \% (72 h) (Abbildung $6 \mathrm{~A})$.

Für Ly-LEC2 wuchs die Zellzahl der Medium-Kontrolle in den ersten $24 \mathrm{~h}$ von aufsteigend $100 \%$ auf $171,4 \%(\hat{=}+71,4 \%), 254,2 \%(\hat{=}+48,5 \%)$ und $309,3 \%(\hat{=}+21,6 \%)$. Die Zellzahl der DMSO-Kontrolle stieg in den ersten $24 \mathrm{~h}$ von $100 \%$ auf 175,2 \% $(\hat{=}+$ $75,3 \%)$ an, dann auf $244,1 \%(\hat{=}+39,3 \%)$ und bei $72 \mathrm{~h}$ auf $280,6 \%(\hat{=}+14,7 \%)$. Es zeigte sich hierbei ein sehr signifikanter Unterschied ( $\mathrm{p} \leq 0,01$ [**] zwischen MediumKontrolle und DMSO-Kontrolle zum Zeitpunkt $t=72$ h. Bei der Konzentration von $10 \mu \mathrm{M}$ Wortmannin fanden sich zu keinem Zeitpunkt signifikante Unterschiede gegenüber der DMSO-Kontrolle. Bei der Konzentration von $50 \mu \mathrm{M}$ Wortmannin ergaben sich bei allen drei Inkubationszeitpunkten hoch signifikante Unterschiede $(\mathrm{p} \leq 0,001[* * *])$ gegenüber der DMSO-Kontrolle. Wortmannin; $50 \mu \mathrm{M}=136,6 \%$ (24 h), 173,2 \% (48 h) und 206,5 \% (72 h) (Abbildung 6B).

Die Zellzahl der Zelllinie Ly-LEC12 erhöhte sich in der Medium-Kontrolle in den ersten $24 \mathrm{~h}$ von $100 \%$ auf den Wert 182,0 \% (스 $+82,0 \%)$, nach $48 \mathrm{~h}$ auf $235,8 \%(\hat{=}+29,5 \%)$ und nach $72 \mathrm{~h}$ auf 291,1 \% (^ $+23,4 \%$ ). Die Zellzahl der DMSO-Kontrolle wuchs ähnlich wie bei der Medium-Kontrolle, es wurden keine signifikanten Unterschiede gemessen. Die prozentualen Zellzahlwerte lagen zum Zeitpunkt $0 \mathrm{~h}$ bei 100,0\%, dann aufsteigend bei $174,8 \%$, bei $228,8 \%$ und bei $274,8 \%$. Wortmannin in der Konzentration von $10 \mu \mathrm{M}$ besaß ebenfalls eine ansteigende Wachstumskurve ohne signifikanten Unterschied zur DMSO-Kontrolle. Hoch signifikante Unterschiede $(p \leq 0,001 \quad[* * *])$ wurden bei Wortmannin $50 \mu \mathrm{M}$ gegenüber der DMSO-Kontrolle zu allen drei Zeitpunkten gemessen. Wortmannin; $50 \mu \mathrm{M}=132,3 \%$ (24 h), 155,9\% (48 h) und 194,6 \% (72 h) (Abbildung 6C).

Für HD-LEC C2 erhöhte sich die Zellzahl der Medium-Kontrolle nach 24 h von 100 \% auf den Wert $177,9 \%(\hat{=}+77,9 \%)$, nach $48 \mathrm{~h}$ auf $327,8 \%(\hat{=}+84,2 \%)$ und nach $72 \mathrm{~h}$ auf 
409,1 \% (^ $+24,8 \%)$. Die Zellzahl der DMSO-Kontrolle stieg ähnlich wie bei der Medium-Kontrolle an. Es können keine signifikanten Unterschiede zur Medium-Kontrolle gefunden werden. DMSO = 177,7 \% (24 h), 326,2 \% (48 h), 387,6 \% (72 h). Zwischen der Zellzahl der Wortmannin $10 \mu \mathrm{M}$-Ansätze und der Zellzahl der DMSO-Kontrolle traten keine signifikanten Unterschiede auf. Bei den Wortmannin-Ansätzen in der Konzentration von $50 \mu \mathrm{M}$ wurden allerdings bei $\mathrm{t}=24 \mathrm{~h}$ und bei $\mathrm{t}=48 \mathrm{~h}$ ein hoch signifikanter Unterschied $\left(\mathrm{p} \leq 0,001\left[{ }^{* * *}\right]\right)$ und bei $\mathrm{t}=72 \mathrm{~h}$ ein signifikanter Unterschied $\left(\mathrm{p} \leq 0,05\left[{ }^{*}\right]\right)$ verzeichnet. Wortmannin: $50 \mu \mathrm{M}=144,3 \%(24 \mathrm{~h}), 235,7 \%(48 \mathrm{~h}), 323,5 \%$ (72 h) (Abbildung 6D).

Die Zellzahl der Zelllinie HD-LEC C3 wuchs in der Medium-Kontrolle von $100 \%$ auf $140,1 \%(\hat{=}+40,1 \%)$, nach $48 \mathrm{~h}$ auf $197,2 \%(\hat{=}+40,7 \%)$ und bei $72 \mathrm{~h}$ hat sie $216,7 \%(\hat{=}$ +9,8 \%) betragen. Zwischen der Medium-Kontrolle und der DMSO-Kontrolle wurden keine signifikanten Unterschiede verzeichnet. Die Zellzahl der DMSO-Kontrolle stieg in den Intervallen von $0 \mathrm{~h}$ auf $72 \mathrm{~h}$ von $100 \%$ auf 136,7 \%, 189,2\% und 205,6\%. Die Wachstumskurve der Ansätze Wortmannin $10 \mu \mathrm{M}$ stieg kontinuierlich an ohne signifikante Unterschiede zu der DMSO-Kontrolle. Die Zellzahlwerte lagen aufsteigend bei $100 \%$, $120 \%, 169,6 \%$ und 185,8 \%. Hoch signifikante Unterschiede ( $\leq 0,001$ [***]) wurden bei Wortmannin in der Konzentration von $50 \mu \mathrm{M}$ gegenüber der DMSO-Kontrolle zu allen drei Inkubationszeitpunkten gemessen. Wortmannin: $50 \mu \mathrm{M}=93,3 \%$ (24 h), 116,9 \% (48 h) und 121,4\% (72 h) (Abbildung 6E).

Für HD-LEC C4 stieg die Zellzahl der Medium-Kontrolle nach $24 \mathrm{~h}$ von $100 \%$ auf den Wert $197,7 \%(\hat{=}+97,7 \%)$, nach $48 \mathrm{~h}$ auf $322,6 \%(\hat{=}+63,1 \%)$ und nach $72 \mathrm{~h}$ auf $418,0 \%(\hat{=}+29,5 \%)$. Zwischen der Medium-Kontrolle und der DMSO-Kontrolle ergaben sich keine signifikanten Unterschiede. Die Zellzahl der DMSO-Kontrolle wuchs in den Intervallen von $0 \mathrm{~h}$ auf $72 \mathrm{~h}$ von $100 \%$ auf $192,6 \%, 301,6 \%$ und $417,0 \%$ an. Der PI3KInhibitor Wortmannin zeigte in der Konzentration von $10 \mu \mathrm{M}$ bei Zeitpunkt $48 \mathrm{~h}$ einen sehr signifikanten Unterschied ( $\mathrm{p} \leq 0,01[* *])$ zur DMSO-Kontrolle $(\mathrm{WM}=286,0 \%)$. Bei den anderen Zeitpunkten konnten keine signifikanten Unterschiede zur DMSO-Kontrolle festgestellt werden. Bei Wortmannin $50 \mu \mathrm{M}$ fanden sich hoch signifikante Unterschiede (p $\left.\leq 0,001\left[{ }^{* *}\right]\right)$ gegenüber der DMSO-Kontrolle bei Zeitpunkt $\mathrm{t}=24 \mathrm{~h}(\mathrm{WM}=120,0 \%), \mathrm{t}=$ $48 \mathrm{~h}(\mathrm{WM}=155,5 \%)$ und $\mathrm{t}=72 \mathrm{~h}(\mathrm{WM}=264,4 \%)($ Abbildung $6 \mathrm{~F})$. 


\subsubsection{BKM120 (Buparlisib)}

Nachfolgend werden im Einzelnen die Ergebnisse der sechs untersuchten Lymphendothelzelllinien bei Hinzugabe des Inhibitors BKM120, in der Konzentration von 0,2 und $1 \mu \mathrm{M}$, aufgeführt (Abb. 7).

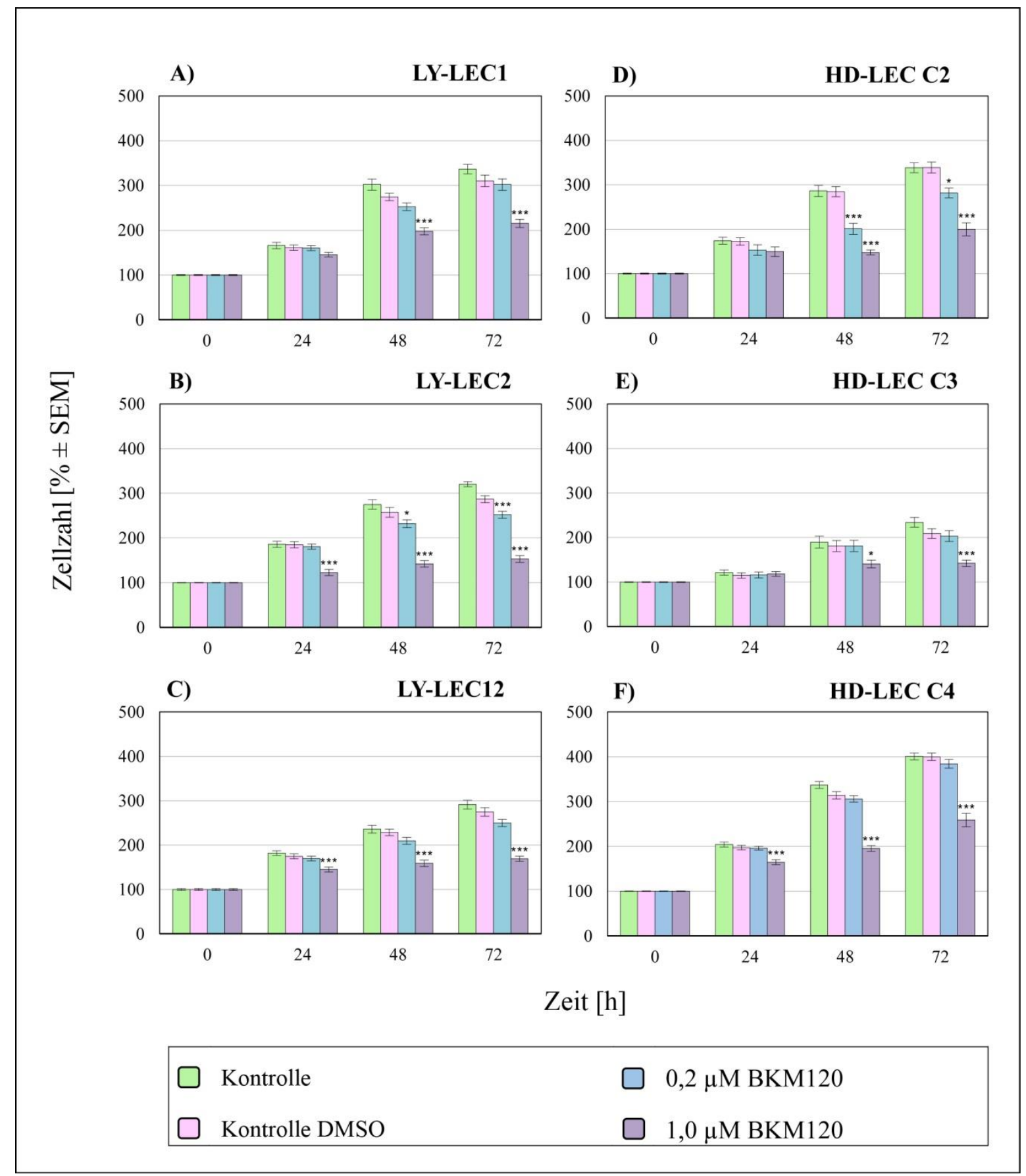

Abbildung 7: Proliferationsassays mit PI3K-Inhibitor BKM120 (Buparlisib)

Die Zellzahl von Ly-LEC1 hat sich in der Medium-Kontrolle nach $24 \mathrm{~h}$ von $100 \%$ auf den Wert $166,1 \%(\hat{=}+66,1 \%)$, nach $48 \mathrm{~h}$ auf $302,2 \%(\hat{=}+81,9 \%)$ und nach $72 \mathrm{~h}$ auf $336,6 \%(\hat{=}+11,3 \%)$ erhöht. Zwischen der Medium-Kontrolle und der DMSO-Kontrolle 
ergaben sich keine signifikanten Unterschiede. Die Zellzahl der DMSO-Kontrolle wuchs in den Intervallen von $0 \mathrm{~h}$ auf $72 \mathrm{~h}$ von $100 \%$ auf 161,3\%, 274,5\% und 310,4\% an. Der PI3K-Inhibitor BKM120 zeigte in der Konzentration von 0,2 $\mu \mathrm{M}$ bei keinem Zeitpunkt einen signifikanten Unterschied zur DMSO-Kontrolle. BKM120: 0,2 $\mu \mathrm{M}=160,3 \%$ (24 h), 252,8 \% (48 h), 302,1 \% (72 h). Bei BKM120 konnte in der Konzentration von $1 \mu \mathrm{M}$ zum Zeitpunkt $\mathrm{t}=24 \mathrm{~h}$ keine Signifikanz notiert werden. Bei den Zeitpunkten $\mathrm{t}=48 \mathrm{~h}$ und $\mathrm{t}=72 \mathrm{~h}$ wurden hoch signifikante Unterschiede $(\mathrm{p} \leq 0,001[* * *]$ gegenüber der DMSOKontrolle festgestellt. BKM120: 1,0 $\mu \mathrm{M}=145,7 \%$ (24 h), 197,7 \% (48 h) und 215,4 \% (72 h) (Abbildung 7A).

Für Ly-LEC2 wuchs die Zellzahl der Medium-Kontrolle in den ersten $24 \mathrm{~h}$ um $+85,8 \%$, in den weiteren $24 \mathrm{~h}$ um $+48,0 \%$ und bis $72 \mathrm{~h}$ nochmal um $+16,4 \%$. Zwischen der MediumKontrolle und der DMSO-Kontrolle ergaben sich keine signifikanten Unterschiede. Die Zellzahl der DMSO-Kontrolle wuchs in den Intervallen von $0 \mathrm{~h}$ auf $72 \mathrm{~h}$ von $100 \%$ auf $184,8 \%, 257,5 \%$ und 287,0 \% an. BKM120 zeigte in der Konzentration von 0,2 $\mu \mathrm{M}$ bei Zeitpunkt $\mathrm{t}=24 \mathrm{~h}$ keinen signifikanten Unterschied zur DMSO-Kontrolle. Allerdings

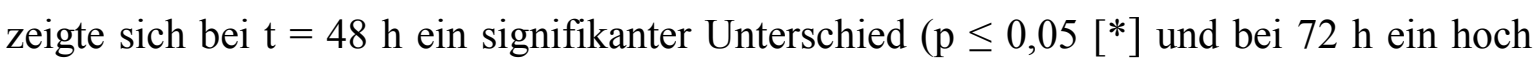
signifikanter Unterschied ( $\mathrm{p} \leq 0,001$ [***]. BKM120: 0,2 $\mu \mathrm{M}=180,7 \%$ (24 h), 232,0\% (48 h) und 252,2 \% (72 h). In der Konzentration von $1 \mu \mathrm{M}$ konnten bei BKM120 zu allen Inkubationszeitpunkten hoch signifikante Unterschiede $(\mathrm{p} \leq 0,001[* * *])$ gegenüber der DMSO-Kontrolle gemessen werden. BKM120: 1,0 $\mu \mathrm{M}=122,6 \%$ (24 h), 142,2 \% (48 h) und 153,0\% (72 h) (Abbildung 7B).

Die Zellzahl der Medium-Kontrolle von Ly-LEC12 erhöhte sich nach 24 h von $100 \%$ auf den Wert 182,0 \% $(\hat{=}+82,0 \%)$, nach $48 \mathrm{~h}$ auf 235,8 \% $(\hat{=}+29,5 \%)$ und nach $72 \mathrm{~h}$ auf $291,1 \%(\hat{=}+23,4 \%)$. Zwischen Medium-Kontrolle und DMSO-Kontrolle ergaben sich keine signifikanten Unterschiede. Die Zellzahl der DMSO-Kontrolle wuchs in den Intervallen von $0 \mathrm{~h}$ auf $72 \mathrm{~h}$ von $100 \%$ auf $174,8 \%, 228,8 \%$ und 274,8 \% an. BKM120 $0,2 \mu \mathrm{M}$ zeigte $\mathrm{zu}$ keinem Inkubationszeitpunkt einen signifikanten Unterschied zur DMSO-Kontrolle. BKM120: 0,2 $\mu \mathrm{M}=169,6 \%$ (24 h), 209,7 \% (48 h) und 249,9 \% (72 h). In der Konzentration von $1 \mu \mathrm{M}$ konnte bei BKM120 zu allen Messpunkten ein hoch signifikanter Unterschied ( $\mathrm{p} \leq 0,001[* * *])$ gegenüber der DMSO-Kontrolle gemessen werden. BKM120: 1,0 $\mu \mathrm{M}=145,2 \%$ (24 h), 159,0\% (48 h) und 169,2\% (72 h) (Abbildung 7C). 
Die Zellzahl von HD-LEC C2 der Medium-Kontrolle erhöhte sich nach 24 h von $100 \%$ auf den Wert 174,2 \% ( $\hat{=}+74,2 \%)$, nach $48 \mathrm{~h}$ auf $286,3 \%(\hat{=}+64,3 \%)$ und nach $72 \mathrm{~h}$ auf $338,3 \%(\hat{=}+18,1 \%)$. Zwischen der Medium-Kontrolle und der DMSO-Kontrolle ergaben sich zu keinem Inkubationszeitpunkt signifikante Unterschiede. Die Zellzahl der DMSOKontrolle wuchs in den Intervallen von $0 \mathrm{~h}$ auf $72 \mathrm{~h}$ von $100 \%$ auf 172,4 \%, 284,4 \% und $338,8 \%$ an. Der PI3K-Inhibitor BKM120 zeigte in der Konzentration von 0,2 $\mu \mathrm{M}$ bei $\mathrm{t}=$ 24 h keinen signifikanten Unterschied zur DMSO-Kontrolle. Allerdings wurde bei dem Zeitpunkt $\mathrm{t}=48 \mathrm{~h}$ ein hoch signifikanter Unterschied $(\mathrm{p} \leq 0,001[* * *])$ und bei dem Zeitpunkt $\mathrm{t}=72 \mathrm{~h}$ ein signifikanter Unterschied $\left(\mathrm{p} \leq 0,05\left[^{*}\right]\right)$ festgestellt. BKM120: 0,2 $\mu \mathrm{M}=153,0 \%$ (24 h), 201,1 \% (48 h) und 281,7\% (72 h). Bei BKM120 konnten bei der Konzentration von $1 \mu \mathrm{M}$ bei dem Zeitpunkt $\mathrm{t}=24 \mathrm{~h}$ kein signifikanter Unterschied notiert werden. Bei den Zeitpunkten $\mathrm{t}=48 \mathrm{~h}$ und $\mathrm{t}=72 \mathrm{~h}$ konnten allerdings hoch signifikante Unterschiede $(\mathrm{p} \leq 0,001[* * *])$ gegenüber der DMSO-Kontrolle festgestellt werden. BKM120: 1,0 $\mu \mathrm{M}=149,6 \%$ (24 h), 147,8 \% (48 h) und 199,9 \% (72 h) (Abbildung 7D).

Die Zellzahl der Medium-Kontrolle von HD-LEC C3 wuchs in den ersten $24 \mathrm{~h}$ um $+21,2 \%$, in den weiteren $24 \mathrm{~h}$ um $+56,5 \%$ und bis $72 \mathrm{~h}$ nochmal um $+23,3 \%$. Zwischen der Medium-Kontrolle und der DMSO-Kontrolle ergaben sich keine signifikanten Unterschiede. Die Zellzahl der DMSO-Kontrolle wuchs in den Intervallen von $24 \mathrm{~h}$ um $+14,7 \%$, dann um $+58,5 \%$ und schließlich um $+15,4 \%$. BKM120 zeigte in der Konzentration von 0,2 $\mu \mathrm{M}$ keine signifikanten Unterschiede zur DMSO-Kontrolle. BKM120: 0,2 $\mu \mathrm{M}=115,8 \%$ (24 h), 181,0\% (48 h) und 203,3\% (72 h). In der Konzentration von $1 \mu \mathrm{M}$ konnte bei BKM120 allerdings bei $\mathrm{t}=48$ ein signifikanter Unterschied $\left(\mathrm{p} \leq 0,05\left[^{*}\right]\right)$ und bei $72 \mathrm{~h}$ ein hoch signifikanter Unterschied ( $\left.\leq 0,001\left[{ }^{* * *}\right]\right)$ im Vergleich zur DMSOKontrolle gemessen werden. BKM120: 1,0 $\mu \mathrm{M}=118,0 \%(24 \mathrm{~h}), 140,6 \%$ (48 h) und 142,3\% (72 h) (Abbildung 7E).

Für HD-LEC C4 stieg die Zellzahl der Medium-Kontrolle nach $24 \mathrm{~h}$ von $100 \%$ auf den Wert 204,3\% $(\hat{=}+104,3 \%)$, nach $48 \mathrm{~h}$ auf $337,1 \%(\hat{=}+65,0 \%)$ und nach $72 \mathrm{~h}$ auf $400,7 \%(\hat{=}+18,8 \%)$. Zwischen der Medium-Kontrolle und der DMSO-Kontrolle ergaben sich keine signifikanten Unterschiede. Die Zellzahl der DMSO-Kontrolle wuchs in den Intervallen von $24 \mathrm{~h}$ um $+97,2 \%, \quad+59,1 \%$ und bei $72 \mathrm{~h}$ um $+27,5 \%$. In der Konzentration von $0,2 \mu \mathrm{M}$ konnte bei BKM120 bei keinen Inkubationszeitpunkt ein signifikanter Unterschied gegenüber der DMSO-Kontrolle gemessen werden. BKM120: $0,2 \mu \mathrm{M}=196,0 \%(24 \mathrm{~h}), 306,1 \%(48 \mathrm{~h})$ und 384,2\% (72 h). Allerdings konnte in der 
Konzentration von $1 \mu \mathrm{M}$ BKM120 zu allen Messungsintervallen ein hoch signifikanter Unterschied $(\mathrm{p} \leq 0,001[* * *])$ gegenüber der DMSO-Kontrolle verzeichnet werden. BKM120: 1,0 $\mu \mathrm{M}=164,6 \%$ (24 h), 195,3 \% (48 h) und 258,8 \% (72 h) (Abbildung 7F).

\subsubsection{LY294002}

Die nachfolgende Abbildung 8 zeigt die Ergebnisse der sechs untersuchten Lymphendothelzelllinien mit dem PI3K-Inhibitor LY294002 in der Konzentration von 0,5 $\mu \mathrm{M}$ und $5 \mu \mathrm{M}$.

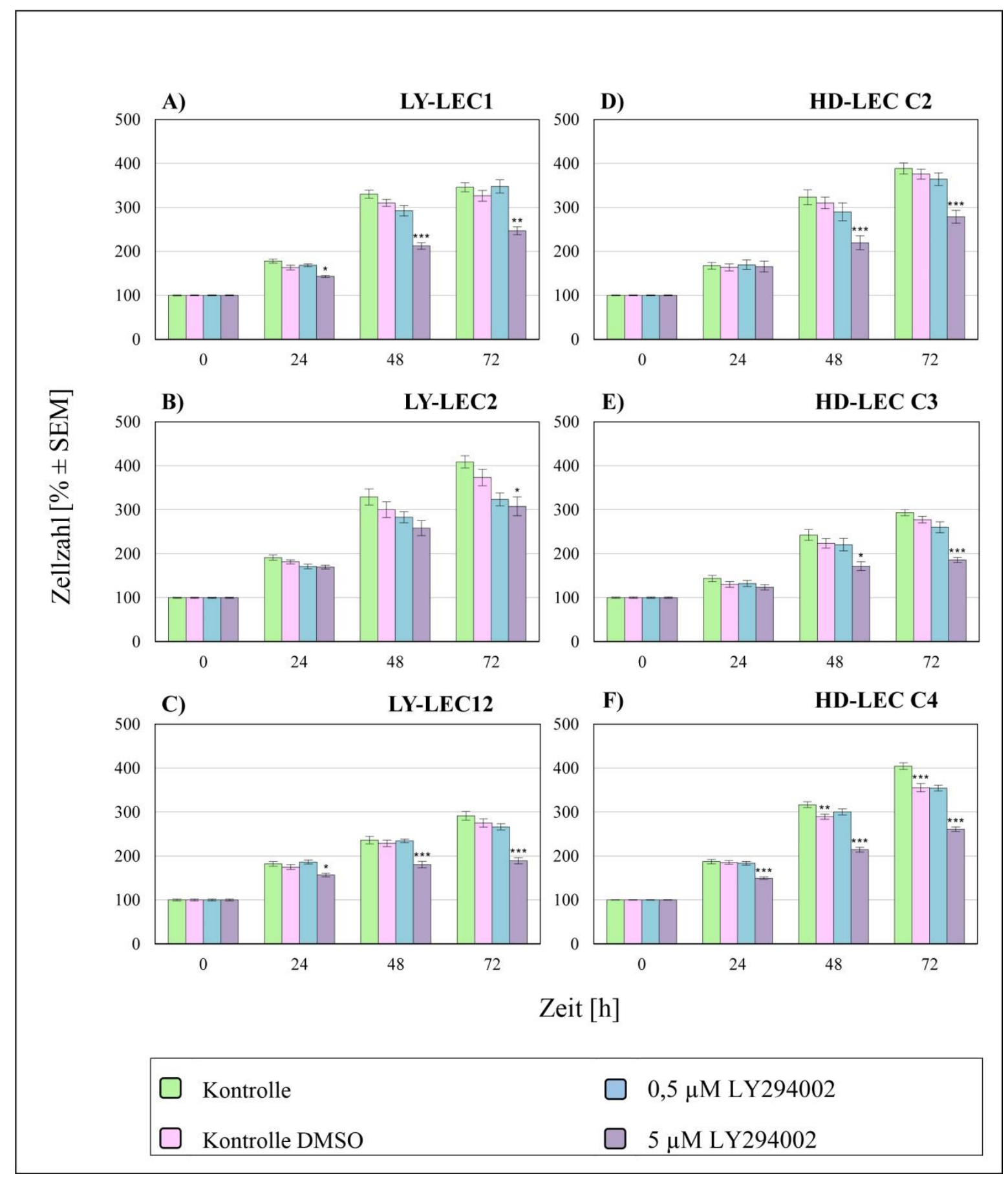

Abbildung 8: Proliferationsassays mit PI3K-Inhibitor LY294002 
Für Ly-LEC1 stieg die Zellzahl der Medium-Kontrolle nach $24 \mathrm{~h}$ von $100 \%$ auf den Wert $177,8 \%(\hat{=}+77,8 \%)$, nach $48 \mathrm{~h}$ auf $330,1 \%(\hat{=}+85,6 \%)$ und nach $72 \mathrm{~h}$ auf $345,7 \%(\hat{=}$ $+4,7 \%$ ). Die Zellzahl bei DMSO-Kontrolle stieg ähnlich wie bei der Medium-Kontrolle

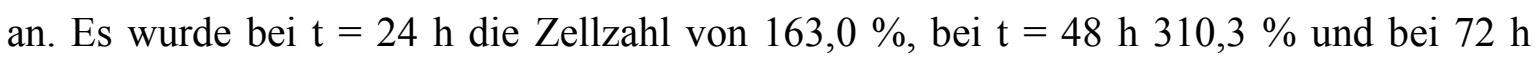
$326,4 \%$ gemessen. Es wurde kein signifikanter Unterschied zur Medium-Kontrolle festgestellt. Der PI3K-Inhibitor LY294002 zeigte in der Konzentration von 0,5 $\mu \mathrm{M}$ bei allen Messpunkten keinen signifikanten Unterschied zur DMSO-Kontrolle. LY294002: 0,5 $\mu \mathrm{M}=168,4 \%$ (24 h), 292,4\% (48 h) und 347,8 \% (72 h). In der Konzentration von $5 \mu \mathrm{M}$ konnte allerdings bei $\mathrm{t}=24 \mathrm{~h}$ ein signifikanter Unterschied $\left(\mathrm{p} \leq 0,05\left[{ }^{*}\right]\right)$, bei $\mathrm{t}=48 \mathrm{~h}$ ein hoch signifikanter Unterschied $(\mathrm{p} \leq 0,001[* * *])$ und bei $\mathrm{t}=72 \mathrm{~h}$ ein sehr signifikanter Unterschied ( $\left.\mathrm{p} \leq 0,01{ }^{* *}\right]$ zur DMSO-Kontrolle gemessen werden. LY294002: 5,0 $\mu \mathrm{M}=$ $143,0 \%(24 \mathrm{~h}), 212,3 \%$ (48 h) und 246,7 \% (72 h) (Abbildung 8A).

Für Ly-LEC2 wuchs die Zellzahl der Medium-Kontrolle in den ersten $24 \mathrm{~h}$ um $+91,0$ \%, in den weiteren $24 \mathrm{~h}$ um $+72,3 \%$ und bis 72 h nochmal um $+24,1 \%$. Dies entsprach einer Zellzahl von aufsteigend $100 \%$, 191,0 \%, 329,1\% und 408,5 \%. Die Zellzahl der DMSOKontrolle stieg in den ersten $24 \mathrm{~h}$ um $+81,2 \%$ an, dann um $+65,6 \%$ und bei $72 \mathrm{~h}$ um $+24,3 \%$. Es zeigte sich hierbei keine signifikanten Unterschiede zur Medium-Kontrolle. In der Konzentration von 0,5 $\mu \mathrm{M}$ LY294002 fanden sich zu keinem Zeitpunkt signifikante Unterschiede zur DMSO-Kontrolle. LY294002: 0,5 $\mu \mathrm{M}=170,9 \%$ (24 h), 282,8 \% (48 h) und 323,4 \% (72 h). In der Konzentration von $5 \mu$ M LY294002 ergab sich nach 72 h ein signifikanter Unterschiede ( $\left.\mathrm{p} \leq 0,05\left[{ }^{*}\right]\right)$ zur DMSO-Kontrolle. Vorher wurden keine signifikanten Unterschiede zur DMSO-Kontrolle gemessen. LY294002: 5,0 $\mu \mathrm{M}=169,6$ \% (24 h), 258,1 \% (48 h) und 307,7 \% (72 h) (Abbildung 8B).

Die prozentualen Zellzahlwerte der Medium-Kontrolle von Ly-LEC12 erhöhten sich von $100 \%$ auf 182,0 \%, nach $48 \mathrm{~h}$ auf 235,8 \% und nach $72 \mathrm{~h}$ auf 291,1\%. Die Zellzahl der DMSO-Kontrolle wuchs von 100,0 \% aufsteigend auf 174,8 \%, dann auf 228,8 \% und bei $72 \mathrm{~h}$ auf $274,8 \%$. Signifikante Unterschiede zur Medium-Kontrolle wurden nicht festgestellt. LY294002 in der Konzentration von 0,5 $\mu \mathrm{M}$ zeigte ebenfalls eine ansteigende Wachstumskurve ohne signifikanten Unterschied zur DMSO-Kontrolle. LY294002: 0,5 $\mu \mathrm{M}=186,0 \%$ (24 h), 234,2 \% (48 h) und 266,1\% (72 h). In der Konzentration von $5 \mu \mathrm{M}$ LY294002 wurden signifikante Unterschiede $\left(\mathrm{p} \leq 0,05\left[{ }^{*}\right]\right)$ zum Zeitpunkt $\mathrm{t}=24 \mathrm{~h}$ festgestellt. $\mathrm{Zu}$ den Inkubationszeitpunkten $\mathrm{t}=48 \mathrm{~h}$ und $72 \mathrm{~h}$ wurden bei LY294002 gegenüber der DMSO-Kontrolle hoch signifikante Unterschiede $\left(\mathrm{p} \leq 0,001\left[{ }^{* * *}\right]\right)$ 
gemessen. LY294002: 5,0 $\mu \mathrm{M}=156,7 \%(24 \mathrm{~h}), 180,4 \%(48 \mathrm{~h})$ und 189,2 \% (72 h) (Abbildung 8C).

Die Zellzahl der Medium-Kontrolle von HD-LEC C2 erhöhte sich nach 24 h von $100 \%$ auf den Wert 167,2 \% (스 $+67,2 \%)$, nach $48 \mathrm{~h}$ auf 323,1\% $(\hat{=}+93,2 \%)$ und nach $72 \mathrm{~h}$ auf $388,6 \%(\hat{=}+20,2 \%)$. Die Zellzahl der DMSO-Kontrolle stieg ähnlich wie bei der Medium-Kontrolle an. Es konnten keine signifikanten Unterschiede zur Medium-Kontrolle gefunden werden. DMSO = 163,5\% (24 h), 310,4\% (48 h) und 375,7 \% (72 h). In der Konzentration von 0,5 $\mu \mathrm{M}$ LY294002 wurden keine signifikanten Unterschiede zu der DMSO-Kontrolle gemessen. LY294002: 0,5 $\mu \mathrm{M}=169,7 \%$ (24 h), 289,8 \% (48 h) und $364,3 \%$ (72 h). In der Konzentration von $5 \mu \mathrm{M}$ LY294002 konnten bei $\mathrm{t}=24 \mathrm{~h}$ keine signifikanten Unterschiede, allerdings bei $\mathrm{t}=48 \mathrm{~h}$ und bei $\mathrm{t}=72 \mathrm{~h}$ hoch signifikante Unterschiede $(\mathrm{p} \leq 0,001[* * *])$ zur DMSO-Kontrolle verzeichnet werden. LY294002: 5,0 $\mu \mathrm{M}=165,3 \%$ (24 h), 219,4\% (48 h) und 278,8\% (72 h) (Abbildung 8D).

Die Zellzahl der Medium-Kontrolle von HD-LEC C3 wuchs von 100 \% auf 143,5 \% (슨 $+43,5 \%)$, nach $48 \mathrm{~h}$ auf 242,7\% $(\hat{=}+69,1 \%)$ und bei $72 \mathrm{~h}$ auf $293,2 \%(\hat{=}+20,8 \%)$. Zwischen der Medium-Kontrolle und der DMSO-Kontrolle wurden keine signifikanten Unterschiede verzeichnet. Die Zellzahl der DMSO-Kontrolle stieg in den Intervallen von 0 h bis 72 h von $100 \%$ auf 130,0 \%, 223,5\% und 277,2 \%. In den Ansätzen LY294002 0,5 $\mu \mathrm{M}$ ergab sich eine ansteigende Wachstumskurve ohne signifikanten Unterschied zu der DMSO-Kontrolle. LY294002: 0,5 $\mu \mathrm{M}=132,1 \%$ (24 h), 220,5 \% (48 h) und 260,1 \% (72 h). In den Ansätzen LY294002 $5 \mu \mathrm{M}$ konnten bei $\mathrm{t}=24 \mathrm{~h}$ keine signifikanten Unterschiede gegenüber der DMSO-Kontrolle gemessen werden. Allerdings wurden bei $\mathrm{t}=48 \mathrm{~h}$ signifikante Unterschiede $(\mathrm{p} \leq 0,05[*])$ und bei $\mathrm{t}=72 \mathrm{~h}$ hoch signifikante Unterschiede ( $\mathrm{p}$ $\leq 0,001[* * *])$ zur DMSO-Kontrolle gemessen. LY294002: 5,0 $\mu \mathrm{M}=123,4 \%(24 \mathrm{~h})$, $171,6 \%$ (48 h) und 185,7\% (72 h) (Abbildung 8E).

Für HD-LEC C4 stieg die Zellzahl der Medium-Kontrolle nach $24 \mathrm{~h}$ von $100 \%$ auf den Wert 186,9\% $(\hat{=}+86,9 \%)$, nach $48 \mathrm{~h}$ auf $316,6 \%(\hat{=}+69,3 \%)$ und nach $72 \mathrm{~h}$ auf $404,4 \%(\hat{=}+27,7 \%)$. Die prozentualen Zellzahlwerte der DMSO-Kontrolle stiegen ähnlich wie die Medium-Kontrolle an. Allerdings ergaben sich bei $\mathrm{t}=48 \mathrm{~h}$ sehr signifikante Unterschiede $(\mathrm{p} \leq 0,01[* *])$ und bei $\mathrm{t}=72 \mathrm{~h}$ ergaben sich hoch signifikante Unterschiede $(\mathrm{p} \leq 0,001[* * *])$ zur Medium-Kontrolle. DMSO = 185,0 \% (24 h), 189,3\% (48 h) und 355,3 \% (72 h). Der PI3K-Inhibitor LY294002 zeigte in der Konzentration von $0,5 \mu \mathrm{M}$ bei keinem Inkubationszeitpunkt einen signifikanten Unterschied zur DMSO- 
Kontrolle. LY294002: 0,5 $\mu \mathrm{M}=183,2 \%(24 \mathrm{~h}), 300,1 \%(48 \mathrm{~h})$ und 354,3 \% (72 h). In der Konzentration von $5 \mu \mathrm{M}$ LY294002 fanden sich zu allen drei Inkubationszeitpunkten hoch signifikante Unterschiede ( $\mathrm{p} \leq 0,001[* * *])$ gegenüber der DMSO-Kontrolle. LY294002: 5,0 $\mu \mathrm{M}=149,6 \%$ (24 h), 214,2 \% (48 h) und 260,7 \% (72 h) (Abbildung 8F). 


\subsubsection{CAL-101}

Die nachfolgende Abbildung 9 zeigt die Ergebnisse der sechs untersuchten Lymphendothelzelllinien mit dem PI3K-Inhibitor CAL-101 in der Konzentration von $5 \mu \mathrm{M}$ und $50 \mu \mathrm{M}$.

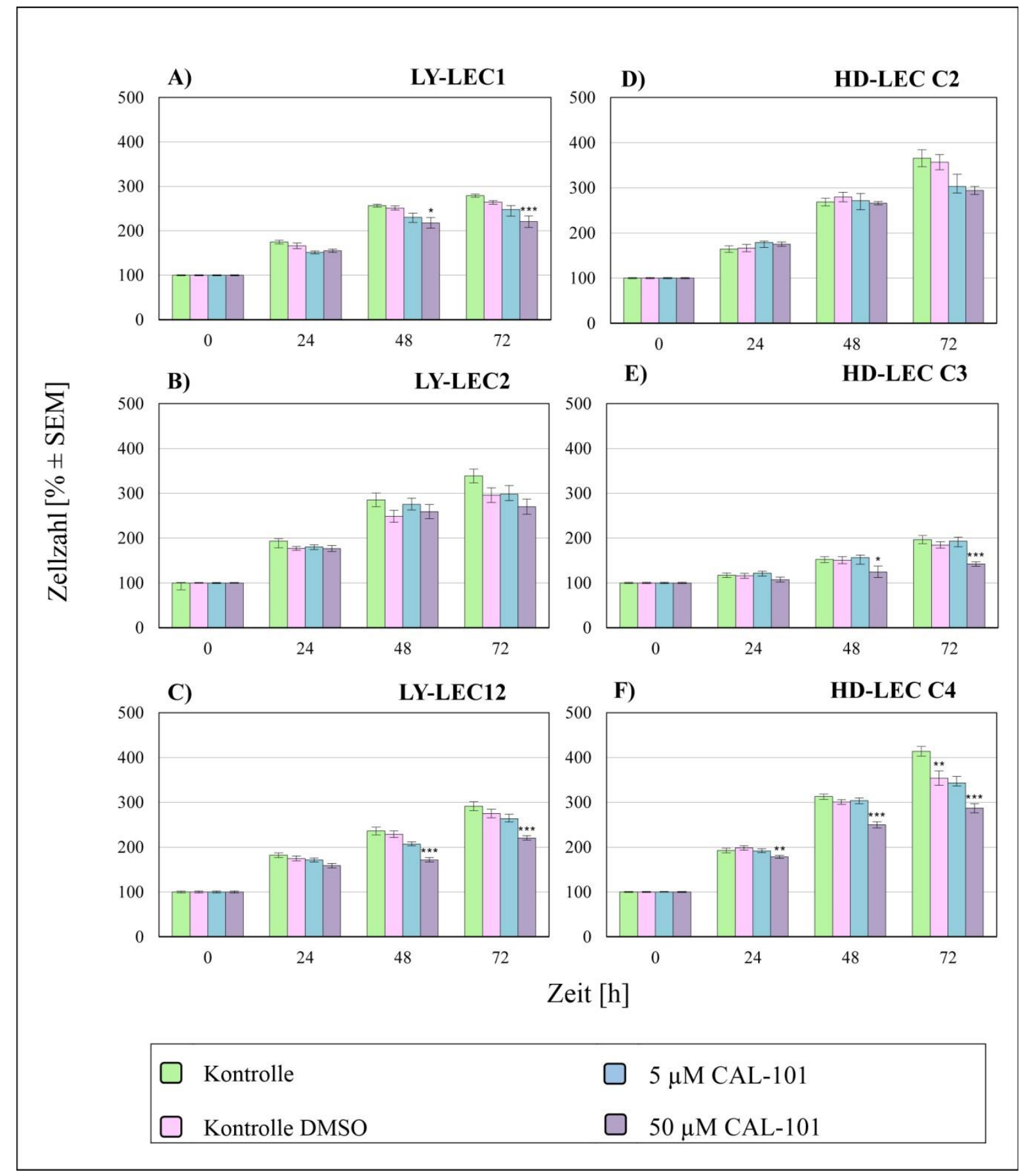

Abbildung 9: Proliferationsassays mit PI3K-Inhibitor CAL-101

Für die Zelllinie Ly-LEC1 stieg die Zellzahl der Medium-Kontrolle nach $24 \mathrm{~h}$ von $100 \%$ auf den Wert 174,4 \% (스 $+74,4 \%)$, nach $48 \mathrm{~h}$ auf 256,5\% $(\hat{=}+47,0 \%)$ und nach $72 \mathrm{~h}$ auf $279,0 \%(\hat{=}+8,7 \%)$. Die Zellzahl bei DMSO-Behandlung stieg ähnlich wie bei der 
Medium-Kontrolle an, nämlich in den ersten $24 \mathrm{~h}$ um $+66,2 \%$, in den weiteren $24 \mathrm{~h}$ um $+51,0 \%$ und danach um $+5,2 \%$. Ein signifikanter Unterschied zur Medium-Kontrolle konnte nicht registriert werden. Der PI3K-Inhibitor CAL-101 zeigte in der Konzentration von $5 \mu \mathrm{M}$ bei allen Inkubationsmesspunkten keinen signifikanten Unterschied zur DMSOKontrolle. Die Messwerte waren folgende: CAL-101: 5,0 $\mu \mathrm{M}=151,0 \%$ (24 h), 230,4 \% (48 h) und 247,7 \% (72 h). In der Konzentration von $50 \mu \mathrm{M}$ CAL-101 kann bei $\mathrm{t}=24 \mathrm{~h}$ kein signifikanter Unterschied gemessen werden. Allerdings konnte bei $\mathrm{t}=48 \mathrm{~h}$ ein signifikanter $\left(\mathrm{p} \leq 0,05\left[^{*}\right]\right)$ und bei $\mathrm{t}=72 \mathrm{~h}$ ein hoch signifikanter Unterschied $(\mathrm{p} \leq 0,001$ $[* * *])$ zur DMSO-Kontrolle verzeichnet werden. CAL-101: 50,0 $\mu \mathrm{M}=154,9 \%(24 \mathrm{~h})$, $217,6 \%$ (48 h) und 220,5\% (72 h) (Abbildung 9A).

Für Ly-LEC2 wuchs die Zellzahl der Medium-Kontrolle in den ersten $24 \mathrm{~h}$ um $+93,4 \%$, in den weiteren $24 \mathrm{~h}$ um $+47,5 \%$ und bis $72 \mathrm{~h}$ nochmal um $+18,6 \%$. Die Zellzahl der DMSO-Kontrolle stieg in den ersten $24 \mathrm{~h} \mathrm{um}+77,0 \%$ an, dann um $+40,3 \%$ und bei $72 \mathrm{~h}$ um $+18,9 \%$. Es zeigte sich hierbei kein signifikanter Unterschied zur Medium-Kontrolle. Auch in den Konzentrationen von 5 und $50 \mu \mathrm{M}$ CAL-101 fand sich zu keinem gemessenen Inkubationszeitpunkt ein signifikanter Unterschied gegenüber der DMSO-Kontrolle. CAL101: 5,0 $\mu \mathrm{M}=179,8 \%(24 \mathrm{~h}), 275,0 \%$ (48 h) und 289,0\% (72 h). CAL-101; 50,0 $\mu \mathrm{M}=$ $176,6 \%$ (24 h), 258,9\% (48 h) und 270,0\% (72 h) (Abbildung 9B).

Die Zellzahl der Medium-Kontrolle von Ly-LEC12 erhöhte sich in den ersten $24 \mathrm{~h}$ von $100 \%$ auf den Wert 182,0 \%, nach 48 h auf 235,8\% und nach 72 h auf 291,1\%. Die Zellzahl der DMSO-Kontrolle erhöhte sich von 100,0 \% auf 174,8 \%, dann auf 228,8 \% und bei $72 \mathrm{~h}$ liegt sie bei 274,8\%. CAL-101 zeigte bei $5 \mu \mathrm{M}$ zu keinem Inkubationszeitpunkt einen signifikanten Unterschied zur DMSO-Kontrolle. CAL-101: 5,0 $\mu \mathrm{M}=171,5 \%$ (24 h), 206,8 \% (48 h) und 263,2 \% (72 h). Bei CAL-101 mit $50 \mu \mathrm{M}$ konnte zum Zeitpunkt $\mathrm{t}=24 \mathrm{~h}$ ebenfalls kein signifikanter Unterschied zur DMSO-Kontrolle gemessen werden. Allerdings konnte bei den Inkubationszeitpunkten $\mathrm{t}=48 \mathrm{~h}$ und $\mathrm{t}=72 \mathrm{~h}$ ein hoch signifikanter Unterschied $(\mathrm{p} \leq 0,001[* * *])$ gemessen werden. CAL-101: 50,0 $\mu \mathrm{M}=158,7 \%$ (24 h), 171,5\% (48 h) und 220,5\% (72 h) (Abbildung 9C).

Für HD-LEC C2 erhöhte sich die Zellzahl der Medium-Kontrolle nach 24 h von $100 \%$ auf den Wert 164,2\% $(\hat{=}+64,2 \%)$, nach $48 \mathrm{~h}$ auf 268,4\% $(\hat{=}+63,4 \%)$ und nach $72 \mathrm{~h}$ auf $365,6 \%(\hat{=}+36,2 \%)$. Die Zellzahl der DMSO-Kontrolle stieg ähnlich wie bei der Medium-Kontrolle an. Es konnten keine signifikanten Unterschiede zur Medium-Kontrolle gefunden werden. DMSO = 166,6\% (24 h), 279,5\% (48 h) und 356,5\% (72 h). Zwischen 
der Zellzahl der CAL-101 $5 \mu \mathrm{M}$-Ansätze, sowie auch den CAL-101 $50 \mu \mathrm{M}$ - Ansätze und der Zellzahl der DMSO-Kontrolle traten bei allen Inkubationszeitpunkten kein signifikanter Unterschiede auf. CAL-101: 5,0 $\mu \mathrm{M}=178,8 \%$ (24 h), 271,8 \% (48 h) und $303,1 \%$ (72 h). CAL-101; 50,0 $\mu \mathrm{M}=175,4 \%$ (24 h), 265,9\% (48 h) und 294,2 \% (72 h) (Abbildung 9D).

Für HD-LEC C3 wuchs die Zellzahl der Medium-Kontrolle von $100 \%$ auf 117,1 \%, nach $48 \mathrm{~h}$ auf 152,0 \% und bei $72 \mathrm{~h}$ auf 196,5 \%. Die Zellzahl der DMSO-Kontrolle stieg in den Intervallen von $0 \mathrm{~h}$ auf $72 \mathrm{~h}$ von $100 \%$ auf $115,8 \%, 150,7 \%$ und 184,3\%. Zwischen der Medium-Kontrolle und der DMSO-Kontrolle wurden keine signifikanten Unterschiede verzeichnet. In den Ansätzen CAL-101 $5 \mu \mathrm{M}$ wurden keine signifikanten Unterschiede zu der DMSO-Kontrolle gemessen. CAL-101: 5,0 $\mu \mathrm{M}=121,7 \%$ (24 h), 156,2 \% (48 h), 193,1 \% (72 h). In den Ansätzen CAL-101 $50 \mu \mathrm{M}$ konnten allerdings zu Zeitpunkt $\mathrm{t}=48 \mathrm{~h}$ ein signifikanter Unterschied $\left(\mathrm{p} \leq 0,05\left[^{*}\right]\right)$ und bei Zeitpunkt $\mathrm{t}=72 \mathrm{~h}$ ein hoch signifikanter Unterschied ( $\mathrm{p} \leq 0,001\left[{ }^{* *}\right]$ ) zur DMSO-Kontrolle verzeichnet werden. CAL-101: 50,0 $\mu \mathrm{M}=107,2 \%$ (24 h), 124,6 \% (48 h), 142,0\% (72 h) (Abbildung 9E).

Die Zellzahl der Medium-Kontrolle der Zelllinie HD-LEC C4 stieg nach $24 \mathrm{~h}$ von $100 \%$ auf den Wert 192,2\% $(\hat{=}+92,2 \%)$, nach $48 \mathrm{~h}$ auf 312,6\% $(\hat{=}+62,6 \%)$ und nach $72 \mathrm{~h}$ auf $413,9 \%(\hat{=}+32,4 \%)$. Die Zellzahl der DMSO-Kontrolle wuchs in den Intervallen von $0 \mathrm{~h}$ auf $72 \mathrm{~h}$ von $100 \%$ auf 198,0 \%, 300,5\% und 353,8 \% an. Zum Zeitpunkt $\mathrm{t}=72 \mathrm{~h}$ ergab sich zwischen der Medium-Kontrolle und der DMSO-Kontrolle ein sehr signifikanter Unterschied ( $\left.\mathrm{p} \leq 0,001\left[{ }^{* * *}\right]\right)$. Der PI3K-Inhibitor CAL-101 zeigte in der Konzentration von $5 \mu \mathrm{M}$ bei allen drei Inkubationszeitpunkten keinen signifikanten Unterschied zur DMSO-Kontrolle. Die prozentualen Messwerte langen aufsteigend bei 191,5 \%, 304,0 \% und bei 343,2 \%. In der Konzentration von $50 \mu \mathrm{M}$ wurde allerdings bei $\mathrm{t}=24 \mathrm{~h}$ ein sehr signifikanter $(\mathrm{p} \leq 0,01[* *]$ und bei $\mathrm{t}=48 \mathrm{~h}$ und $\mathrm{t}=72 \mathrm{~h}$ ein hoch signifikanter Unterschied $(\mathrm{p} \leq 0,001$ [***] gemessen. CAL-101: 50,0 $\mu \mathrm{M}=178,4 \%$ (24 h), 249,9\% (48 h), 286,8\% (72 h) (Abbildung 9F). 
3.1.2 Hemmung von mTOR

3.1.2.1 Rapamycin

MTOR ist eine Serin/Threoninkinase und kommt in der PI3K-Signalkaskade downstream von der PI3K vor.

In der nachfolgenden Abbildung 10 werden die Ergebnisse der Proliferationsversuche mit mTOR-Inhibitor Rapamycin, in der Konzentration von $1 \mathrm{nM}$ und $10 \mathrm{nM}$, aufgeführt.

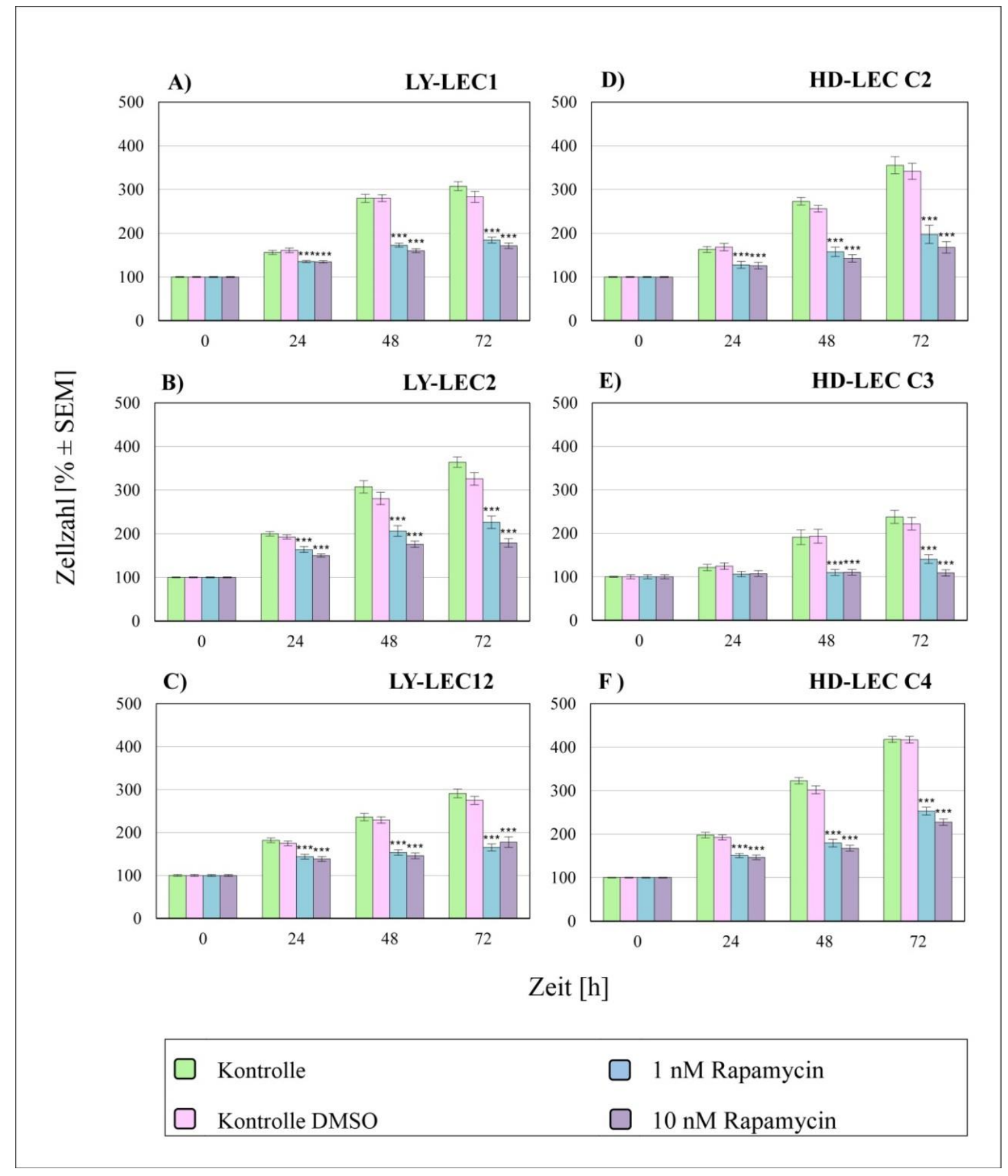

Abbildung 10: Proliferationsassays mit mTOR-Inhibitor Rapamycin 
Für Ly-LEC1 stieg die Zellzahl der Medium-Kontrolle nach $24 \mathrm{~h}$ von $100 \%$ auf den Wert $156,3 \%(\hat{=}+56,3 \%)$, nach $48 \mathrm{~h}$ auf $280,0 \%(\hat{=}+79,1 \%)$ und nach $72 \mathrm{~h}$ auf $307,6 \%(\hat{=}$ +9,8 \%). Die Zellzahl bei DMSO-Behandlung stieg ähnlich wie bei der Medium-Kontrolle an, nämlich in den ersten $24 \mathrm{~h}$ um $+60,9 \%$, in den weiteren $24 \mathrm{~h}$ um $+74,2 \%$ und danach um $+1,0 \%$. Ein signifikanter Unterschied zur Medium-Kontrolle wurde nicht registriert. DMSO = 160,9 \% (24 h), 280,3 \% (48 h), 283,3 \% (72 h). Der mTOR-Inhibitor Rapamycin zeigte in der Konzentration von $1 \mathrm{nM}$ bei allen Messpunkten einen hoch signifikanten Unterschied $\left(\mathrm{p} \leq 0,001\left[{ }^{* *}\right]\right)$ zur DMSO-Kontrolle. Die Messwerte waren folgende: Rapamycin: $1 \mathrm{nM}=135,4 \%(24 \mathrm{~h}), 172,7 \%$ (48 h), 184,5\% (72 h). Auch in der Konzentration von $10 \mathrm{nM}$ konnte bei allen Messwerten ein hoch signifikanter Unterschied $\left(\mathrm{p} \leq 0,001\left[{ }^{* * *}\right]\right)$ verzeichnet werden. Rapamycin: $10 \mathrm{nM}=134,8 \%(24 \mathrm{~h}), 160,0 \%$ (48 h), $171,7 \%$ (72 h) (Abbildung 10A).

Die Zellzahl der Medium-Kontrolle von Ly-LEC2 wuchs in den ersten $24 \mathrm{~h}$ um $+99,9 \%$, in den weiteren $24 \mathrm{~h}$ um $+53,7 \%$ und bis $72 \mathrm{~h}$ nochmal um $+18,4 \%$. Die Zellzahl der DMSO-Kontrolle stieg in den ersten $24 \mathrm{~h}$ um $+92,8 \%$ an, dann um $+45,5 \%$ und bei $72 \mathrm{~h}$ um $+16,0 \%$. Es zeigte sich hierbei kein signifikanter Unterschied zur Medium-Kontrolle. DMSO $=192,8 \%$ (24 h), 280,7 \% (48 h), 325,7 \% (72 h). In der Konzentration von $1 \mathrm{nM}$ Rapamycin fand sich zu allen gemessenen Inkubationszeitpunkten ein hoch signifikanter Unterschied $(\mathrm{p} \leq 0,001[* * *])$ gegenüber der DMSO-Kontrolle. Rapamycin: $1 \mathrm{nM}=$ $163,8 \%(24 \mathrm{~h}), 206,4 \%$ (48 h), 226,4 \% (72 h). In der Konzentration von $10 \mathrm{nM}$ Rapamycin ergaben sich auch hoch signifikante Unterschiede ( $\mathrm{p} \leq 0,001$ [***]) bei allen Messzeitpunkte gegenüber der DMSO-Kontrolle. Rapamycin: $10 \mathrm{nM}=150,1 \%(24 \mathrm{~h})$, $175,9 \%$ (48 h), 178,9 \% (72 h) (Abbildung 10B).

Für Ly-LEC12 erhöhte sich die Zellzahl der Medium-Kontrolle in den ersten $24 \mathrm{~h}$ von $100 \%$ auf den Wert 182,0\%, nach $48 \mathrm{~h}$ auf 235,8\% und nach $72 \mathrm{~h}$ auf 291,1\%. Die Zellzahl der DMSO-Kontrolle wuchs ähnlich wie bei der Medium-Kontrolle, es wurden keine signifikanten Unterschiede gemessen. Die prozentualen Zellzahlwerte lagen zum Zeitpunkt 0 h bei $100,0 \%$, dann aufsteigend bei $174,8 \%$, bei $228,8 \%$ und bei $274,8 \%$. Rapamycin zeigte auch bei Ly-LEC12 in den Konzentration von $1 \mathrm{nM}$ und $10 \mathrm{nM}$ bei allen Inkubationszeitpunkten einen hohen signifikanten Unterschied ( $\mathrm{p} \leq 0,001[* * *])$ zur DMSO-Kontrolle. Rapamycin: $1 \mathrm{nM}=143,6 \%$ (24 h), 153,4 \% (48 h), 274,8 \% (72 h). Rapamycin: $10 \mathrm{nM}=138,4$ \% (24 h), 145,7 \% (48 h), 177,6 \% (72 h) (Abbildung 10C). 
Die Zellzahl der Medium-Kontrolle von HD-LEC C2 erhöhte sich nach 24 h von $100 \%$ auf den Wert 163,1\% (스 $+63,1 \%)$, nach $48 \mathrm{~h}$ auf 272,9 \% $(\hat{=}+67,3 \%)$ und nach $72 \mathrm{~h}$ auf $355,6 \%(\hat{=}+30,3 \%)$. Die Zellzahl der DMSO-Kontrolle stieg ähnlich wie bei der Medium-Kontrolle an. Es konnten keine signifikanten Unterschiede zur Medium-Kontrolle gefunden werden. DMSO = 168,3 \% (24 h), 256,1 \% (48 h), 341,7 \% (72 h). Zwischen der Zellzahl der Rapamycin 1 nM-Ansätze, sowie den Rapamycin 10 nM- Ansätzen und der Zellzahl der DMSO-Kontrolle traten an allen Inkubationszeitpunkten hoch signifikante Unterschiede (p $\leq 0,001[* * *])$ auf. Rapamycin: $1 \mathrm{nM}=128,1 \%(24 \mathrm{~h}), 157,7 \%$ (48 h), 197,4 \% (72 h). Rapamycin: $10 \mathrm{nM}=125,9 \%$ (24 h), 142,6 \% (48 h), 167,8 \% (72 h) (Abbildung 10D).

Die Zellzahl der Medium-Kontrolle von HD-LEC C3 wuchs von $100 \%$ auf 121,4 \% nach $24 \mathrm{~h}(\hat{=}+21,4 \%)$, nach $48 \mathrm{~h}$ auf $191,3 \%(\hat{=}+57,5 \%)$ und nach $72 \mathrm{~h}$ auf $237,9 \%(\hat{=}$ $+24,3 \%$ ). Zwischen der Medium-Kontrolle und der DMSO-Kontrolle wurden keine signifikanten Unterschiede gefunden. Die Zellzahl der DMSO-Kontrolle stieg in den Intervallen von $0 \mathrm{~h}$ auf $72 \mathrm{~h}$ von $100 \%$ auf 124,5\%, 193,2\% und 221,8\%. In den Ansätzen Rapamycin $1 \mathrm{nM}$ und $10 \mathrm{nM}$ wurden in den ersten $24 \mathrm{~h}$ keine signifikanten Unterschiede zu der DMSO-Kontrolle gemessen. In den weiteren Inkubationszeitpunkten konnten allerdings hoch signifikante Unterschiede $(\mathrm{p} \leq 0,001[* * *])$ zur DMSO-Kontrolle verzeichnet werden. Rapamycin: $1 \mathrm{nM}=106,3 \%(24 \mathrm{~h}), 109,7 \%$ (48 h), 110,2 \% (72 h). Rapamycin: $10 \mathrm{nM}=107,3 \%$ (24 h), 140,5 \% (48 h), 109,1 \% (72 h) (Abbildung 10E).

Für die Zelllinie HD-LEC C4 stieg die Zellzahl der Medium-Kontrolle nach $24 \mathrm{~h}$ von $100 \%$ auf den Wert 197,7 \% $(\hat{=}+97,7 \%)$, nach $48 \mathrm{~h}$ auf $322,6 \%(\hat{=}+63,1 \%)$ und nach $72 \mathrm{~h}$ auf 418,0 \% (스 $+29,5 \%)$. Zwischen der Medium-Kontrolle und der DMSO-Kontrolle ergaben sich keine signifikanten Unterschiede. Die Zellzahl der DMSO-Kontrolle wuchs in den Intervallen von $0 \mathrm{~h}$ auf $72 \mathrm{~h}$ von $100 \%$ auf 192,6\%, 301,6\% und 417,0\% an. Der mTOR-Inhibitor Rapamycin zeigte in der Konzentration von $1 \mathrm{nM}$ und $10 \mathrm{nM}$ bei allen Inkubationszeitpunkten einen hoch signifikanten Unterschied ( $p \leq 0,001$ [***]) zur DMSO-Kontrolle. Rapamycin: $1 \mathrm{nM}=150,7 \%$ (24 h), 179,3 \% (48 h), 252,9 \% (72 h). Rapamycin: $10 \mathrm{nM}=146,7 \%$ (24 h), 167,4 \% (48 h), 227,5 \% (72 h) (Abbildung 10F). 
3.1.3 Hemmung von AKT (Proteinkinase B)

3.1.3.1 MK-2206

Die Proteinkinase B ist ebenfalls eine Serin/Threoninkinase und ist direkt in der PI3KSignalkaskade hinter PI3K nachgeschaltet.

Die nachfolgende Abbildung 11 zeigt die Ergebnisse der sechs untersuchten LECs mit dem AKT-Inhibitor MK-2206 in den Konzentrationen von $10 \mu \mathrm{M}, 25 \mu \mathrm{M}$ und z.T. $50 \mu \mathrm{M}$.

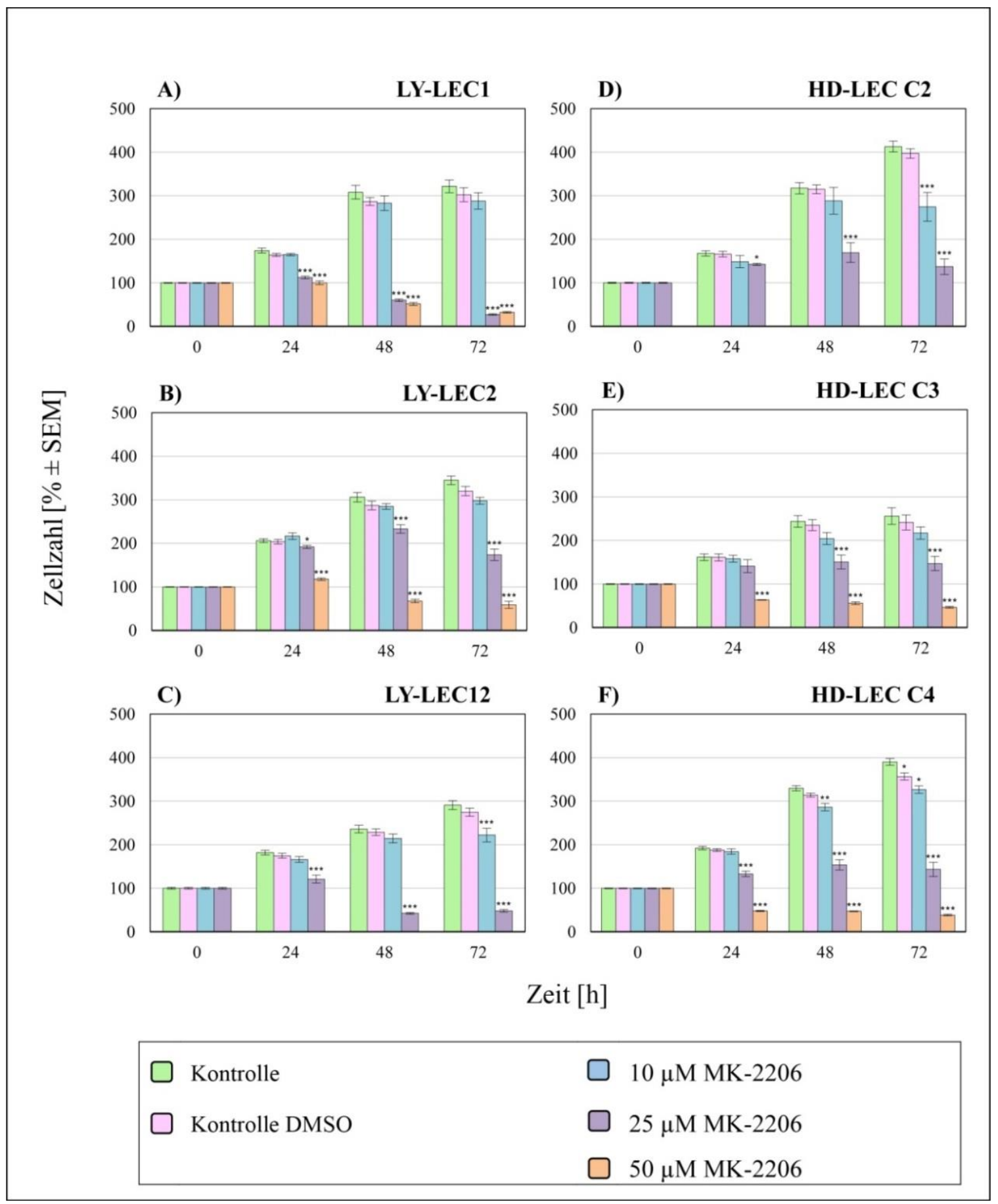

Abbildung 11: Proliferationsassays mit Proteinkinase B(AKT)-Inhibitor MK-2206 
Die Zellzahl der Medium-Kontrolle von Ly-LEC1 stieg nach $24 \mathrm{~h}$ von $100 \%$ auf den Wert $174,1 \%(\hat{=}+74,1 \%)$, nach $48 \mathrm{~h}$ auf $308,2 \%(\hat{=}+77,0 \%)$ und nach $72 \mathrm{~h}$ auf $321,6 \%(\hat{=}$ $+4,3 \%$ ). Die Zellzahl der DMSO-Kontrolle stieg ähnlich wie bei der Medium-Kontrolle an. Es wurde bei $t=24$ h ein Zellzahlwert von $164,2 \%$, bei $t=48$ h $286,8 \%$ und bei $t=72$ h 302,4 \% gemessen. Es wurden keine signifikanten Unterschiede zur Medium-Kontrolle festgestellt. Der AKT-Inhibitor MK-2206 zeigte in der Konzentration von $10 \mu \mathrm{M}$ bei allen Messpunkten keinen signifikanten Unterschied zur DMSO-Kontrolle. MK-2206: $10 \mu \mathrm{M}=$ $165,0 \%(24$ h), 282,8 \% (48 h), 288,0 \% (72 h). In den Konzentrationen von $25 \mu \mathrm{M}$ und $50 \mu \mathrm{M}$ MK-2206 konnte allerdings bei allen Inkubationszeitpunkten ein hoch signifikanter Unterschied ( $\mathrm{p} \leq 0,001[* * *])$ festgestellt werden. MK-2206: $25 \mu \mathrm{M}=112,2 \%(24 \mathrm{~h})$, 60,0 \% (48 h), 27,5\% (72 h). MK-2206: $50 \mu \mathrm{M}=100,1 \%$ (24 h), 51,5\% (48 h), 32,3\% (72 h) (Abbildung 11A).

Für die Zelllinie Ly-LEC2 wuchs die Zellzahl der Medium-Kontrolle in den ersten $24 \mathrm{~h}$ um $+106,2 \%$, in den weiteren $24 \mathrm{~h}$ um $+48,3 \%$ und bis $72 \mathrm{~h}$ nochmal um $+12,6 \%$. Dies entsprach einem Zellzahlwert von aufsteigend $100 \%$, 206,2 \%, 306,0 \% und 344,8 \%. Die Zellzahl der DMSO-Kontrolle stieg in den ersten $24 \mathrm{~h}$ um $+103,9 \%$ an, dann um $+40,7 \%$ und bei 72 h um $+11,5 \%$. Es zeigten sich hierbei keine signifikanten Unterschiede zur Medium-Kontrolle. In der Konzentration von $10 \mu \mathrm{M}$ MK-2206 fanden sich zu keinem Zeitpunkt signifikante Unterschiede zur DMSO-Kontrolle. MK-2206: $10 \mu \mathrm{M}=216,7 \%$ (24 h), 284,7 \% (48 h), 297,7 \% (72 h). In der Konzentration von $25 \mu \mathrm{M}$ MK-2206 ergab

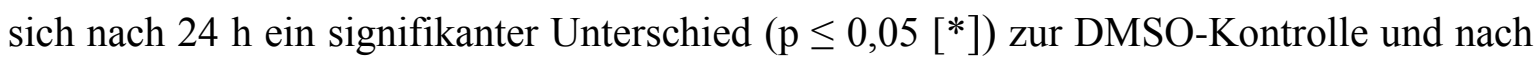
$48 \mathrm{~h}$ und $72 \mathrm{~h}$ ein hoch signifikanter Unterschied $(\mathrm{p} \leq 0,001[* * *])$. MK-2206: $25 \mu \mathrm{M}=$ $192,0 \%$ (24 h), 233,1 \% (48 h), 173,8 \% (72 h). In der Konzentration von $50 \mu \mathrm{M} \mathrm{MK}-$ 2206 konnte bei allen Inkubationszeitpunkten ein hoch signifikanter Unterschied $(\mathrm{p} \leq$ $0,001[* * *])$ zur DMSO-Kontrolle gemessen werden. MK-2206: $50 \mu \mathrm{M}=117,7 \%$ (24 h), $67,5 \%$ (48 h), 58,8\% (72 h) (Abbildung 11B).

Die prozentualen Zellzahlwerte der Medium-Kontrolle von Ly-LEC12 erhöhten sich von $100 \%$ auf $182,0 \%$, nach $48 \mathrm{~h}$ auf 235,8 \% und nach $72 \mathrm{~h}$ auf 291,1\%. Die Zellzahl der DMSO-Kontrolle wuchs von 100,0 \% aufsteigend auf 174,8\%, dann auf 228,8 \% und lag bei $72 \mathrm{~h}$ bei $274,8 \%$. Signifikante Unterschiede zur Medium-Kontrolle wurden nicht festgestellt. Bei MK-2206 in der Konzentration von $10 \mu \mathrm{M}$ bestanden zu den Zeitpunkten $\mathrm{t}$ $=24 \mathrm{~h}$ und $\mathrm{t}=48 \mathrm{~h}$ keine signifikanten Unterschiede zur DMSO-Kontrolle. Allerdings konnte bei $\mathrm{t}=72 \mathrm{~h}$ ein hoch signifikanter Unterschied $(\mathrm{p} \leq 0,001[* * *])$ zur DMSO- 
Kontrolle gemessen werden. MK-2206: $10 \mu \mathrm{M}=166,2 \%$ (24 h), 214,6 \% (48 h), 222,2 \% (72 h). In der Konzentration von $25 \mu \mathrm{M}$ konnten bei allen drei Inkubationszeitpunkten ein hoch signifikanter Unterschied ( $\mathrm{p} \leq 0,001[* * *])$ zur DMSO-Kontrolle gemessen werden. MK-2206: $25 \mu \mathrm{M}=121,0 \%$ (24 h), 42,4 \% (48 h), 48,2 \% (72 h) (Abbildung 11C).

Für HD-LEC C2 erhöhte sich die Zellzahl der Medium-Kontrolle nach 24 h von $100 \%$ auf den Wert 167,5 \% $(\hat{=}+67,5 \%)$, nach 48 h auf 317,4\% $(\hat{=}+89,4 \%)$ und nach $72 \mathrm{~h}$ auf 413,0\% $(\hat{=}+30,1 \%)$. Die Zellzahl der DMSO-Kontrolle stieg ähnlich wie bei der Medium-Kontrolle an. Es konnten keine signifikanten Unterschiede zur Medium-Kontrolle gefunden werden. DMSO = 166,0 \% (24 h), 314,9\% (48 h), 397,2\% (72 h). In der Konzentration von $10 \mu \mathrm{M}$ MK-2206 wurden $\mathrm{zu}$ den Zeitpunkten $\mathrm{t}=24 \mathrm{~h}$ und $\mathrm{t}=48 \mathrm{~h}$ keine signifikanten Unterschiede zur DMSO-Kontrolle gemessen. Allerdings konnte zum Zeitpunkt $\mathrm{t}=72 \mathrm{~h}$ ein hoch signifikanter Unterschied $(\mathrm{p} \leq 0,001[* * *])$ gemessen werden. MK-2206: $10 \mu \mathrm{M}=148,7$ \% (24 h), 288,4 \% (48 h), 274,6 \% (72 h). In der Konzentration von $25 \mu \mathrm{M}$ MK-2206 konnte bei $\mathrm{t}=24 \mathrm{~h}$ ein signifikanter Unterschied $\left(\mathrm{p} \leq 0,05\left[{ }^{*}\right]\right)$ und bei den Inkubationszeitpunkten $\mathrm{t}=48 \mathrm{~h}$ und $\mathrm{t}=72 \mathrm{~h}$ ein hoch signifikanter Unterschied ( $\mathrm{p}$ $\leq 0,001[* * *]) \quad$ zur DMSO-Kontrolle verzeichnet werden. MK-2206: $25 \mu \mathrm{M}=142,5 \%$ (24 h), 169,4 \% (48 h), 137,2 \% (72 h) (Abbildung 11D).

Die Zellzahl der Medium-Kontrolle von HD-LEC C3 wuchs von $100 \%$ auf 161,7 \% (슨 $+61,7 \%)$, nach $48 \mathrm{~h}$ auf 243,6\% $(\hat{=}+50,6 \%)$ und bei $72 \mathrm{~h}$ auf $255,9 \%(\hat{=}+5,0 \%)$. Zwischen der Medium-Kontrolle und der DMSO-Kontrolle wurden keine signifikanten Unterschiede verzeichnet. Die Zellzahl der DMSO-Kontrolle stieg in den Intervallen von 0 h auf $72 \mathrm{~h}$ von $100 \%$ auf 161,0\%, 235,3\% und 241,4\%. In den Ansätzen MK2206 10 $\mu \mathrm{M}$ ergab sich eine ansteigende Wachstumskurve ohne signifikanten Unterschied zu der DMSO-Kontrolle. MK-2206: $10 \mu \mathrm{M}=158,2 \%$ (24 h), 204,3 \% (48 h), 217,0 \% (72 h). In den Ansätzen MK2206 $25 \mu \mathrm{M}$ konnten bei $\mathrm{t}=24 \mathrm{~h}$ keine signifikanten Unterschiede gegenüber der DMSO-Kontrolle gemessen werden. Allerdings wurden bei $\mathrm{t}=48 \mathrm{~h}$ und $\mathrm{t}=$ $72 \mathrm{~h}$ hoch signifikante Unterschiede $(\mathrm{p} \leq 0,001[* * *])$ zur DMSO-Kontrolle gemessen. MK-220: $25 \mu \mathrm{M}=141,1 \%$ (24 h), 150,7 \% (48 h), 147,1 \% (72 h). In den Ansätzen MK$220650 \mu \mathrm{M}$ konnten zu allen drei Inkubationszeitpunkten hoch signifikante Unterschiede zur DMSO-Kontrolle ( $\left.\mathrm{p} \leq 0,001\left[{ }^{* * *}\right]\right)$ gemessen werden. MK-2206: $50 \mu \mathrm{M}=63,2 \%$ (24 h), 55,9\% (48 h), 46,5\% (72 h) (Abbildung 11E).

Für HD-LEC C4 stieg die Zellzahl der Medium-Kontrolle nach $24 \mathrm{~h}$ von $100 \%$ auf den Wert 192,3\% $(\hat{=}+92,3 \%)$, nach $48 \mathrm{~h}$ auf $330,0 \%(\hat{=}+71,6 \%)$ und nach $72 \mathrm{~h}$ auf 


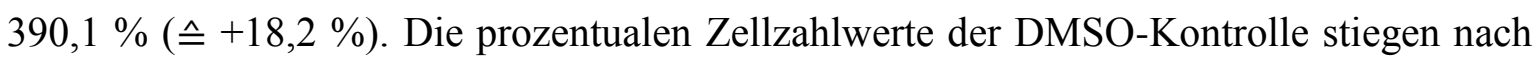
$24 \mathrm{~h}$ auf 188,0 \% $(\hat{=}+88,0 \%)$ an. Nach $48 \mathrm{~h}$ lag der Wert bei 314,1\% $(\hat{=}+67,0 \%)$. Bei beiden Zeitpunkten ergaben sich keine signifikanten Unterschiede, allerdings konnte bei $\mathrm{t}$ $=72 \mathrm{~h}$ ein signifikanter Unterschiede $\left(\mathrm{p} \leq 0,05\left[{ }^{*}\right]\right)$ zur DMSO-Kontrolle gemessen werden. DMSO $=356,7 \%(\hat{=}+13,5 \%)$. Der Proteinkinase B $(\mathrm{AKT})$-Inhibitor MK-2206 zeigte in der Konzentration von $10 \mu \mathrm{M}$ bei $\mathrm{t}=24 \mathrm{~h}$ keinen signifikanten Unterschied zur DMSO-Kontrolle. Allerdings wurde beim Inkubationszeitpunkt $\mathrm{t}=48 \mathrm{~h}$ ein sehr signifikanter Unterschied $(\mathrm{p} \leq 0,01[* *])$ und bei $\mathrm{t}=72 \mathrm{~h}$ ein signifikanter Unterschied ( $\mathrm{p}$ $\leq 0,05[*])$ zur DMSO-Kontrolle gemessen. MK-2206: $10 \mu \mathrm{M}=184,3 \%$ (24 h), 286,2 \% (48 h), 326,7 \% (72 h). In den Konzentrationen von $25 \mu \mathrm{M}$ und $50 \mu \mathrm{M}$ MK2206 wurde bei allen drei Inkubationszeitpunkten ein hoch signifikanter Unterschied ( $\mathrm{p} \leq 0,001$ [***]) zur DMSO-Kontrolle erreicht. MK-2206: $25 \mu \mathrm{M}=133,1 \%$ (24 h), 153,9 \% (48 h), 143,5\% (72 h). MK-2206: $50 \mu \mathrm{M}=48,1 \%$ (24 h), 47,2 \% (48 h), 38,5 \% (72 h) (Abbildung 11F). 


\subsubsection{Hemmung der Tyrosinkinasen}

\subsubsection{Dasatinib}

Dasatinib ist ein Tyrosinkinase-Inhibitor und hemmt die Kinasen der SFK und BCR-ABLFamilie. Die nachfolgende Abbildung 12 zeigt die Ergebnisse der sechs untersuchten LECs mit Dasatinib in der Konzentration von $1 \mu \mathrm{M}$.

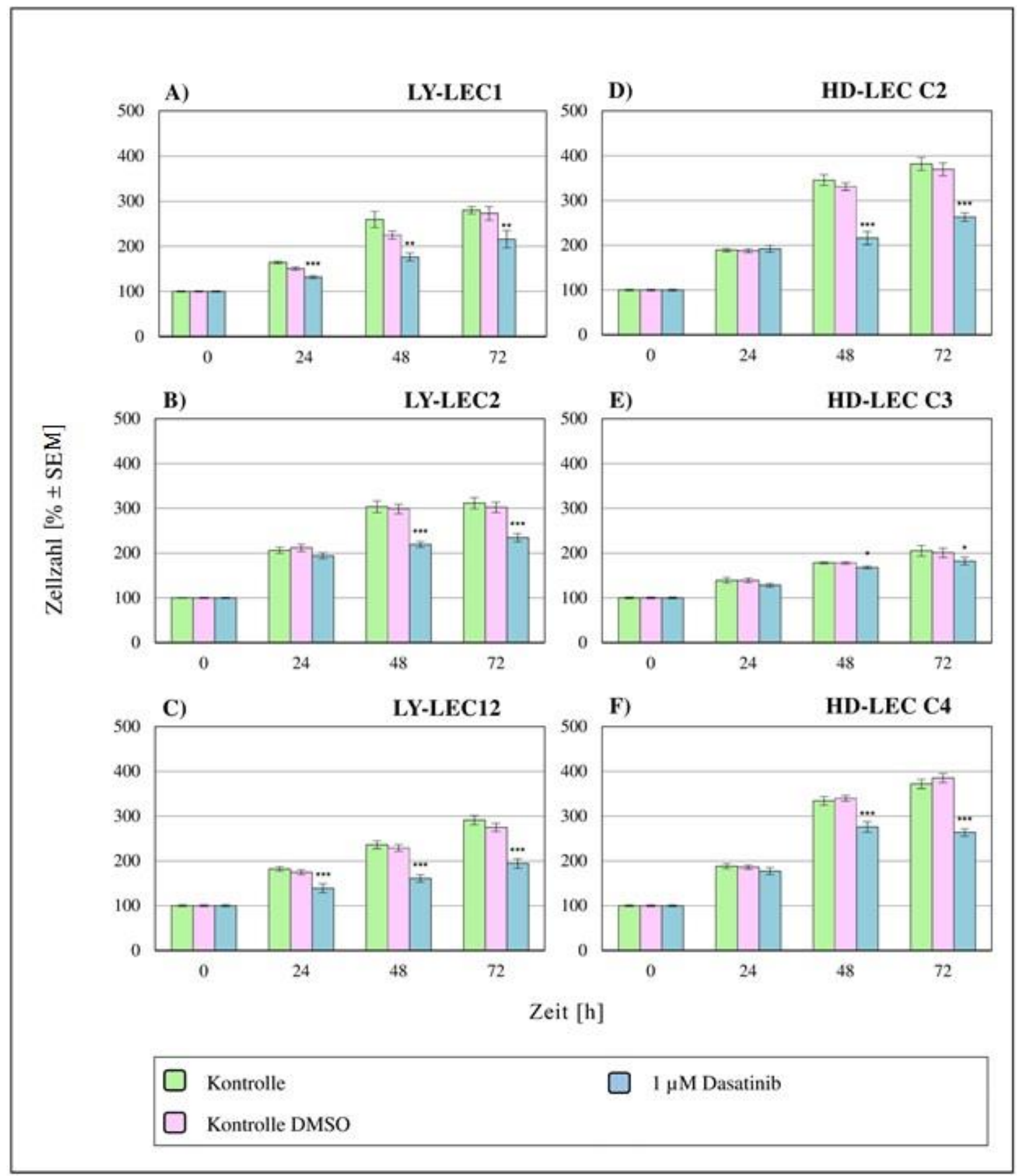

Abbildung 12: Proliferationsassays mit Tyrosinkinase-Inhibitor Dasatinib 
Für Ly-LEC1 stieg die Zellzahl der Medium-Kontrolle nach $24 \mathrm{~h}$ von $100 \%$ auf den Wert $164,3 \%(\hat{=}+64,3 \%)$, nach $48 \mathrm{~h}$ auf $259,5 \%(\hat{=}+57,9 \%)$ und nach $72 \mathrm{~h}$ auf $280,0 \%(\hat{=}$ $+7,8 \%$ ). Die Zellzahl bei der DMSO-Kontrolle stieg ähnlich wie bei der Medium-

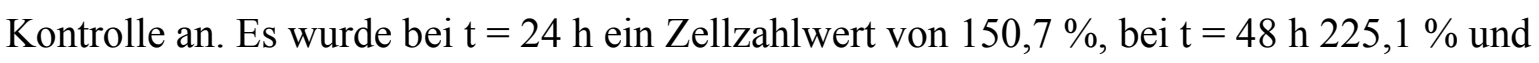
bei 72 h 273,0 \% gemessen. Es konnte kein signifikanter Unterschied zur MediumKontrolle festgestellt werden. Der Inhibitor Dasatinib zeigte in der Konzentration von 1 $\mu \mathrm{M}$ bei Inkubationszeitpunkt $\mathrm{t}=24 \mathrm{~h}$ einen hoch signifikanten Unterschied $(\mathrm{p} \leq 0,001$ $[* * *]$ ) zur DMSO-Kontrolle. Bei den Zeitpunkten $\mathrm{t}=48 \mathrm{~h}$ und $\mathrm{t}=72 \mathrm{~h}$ wurden sehr signifikante Unterschiede ( $\leq 0,01[* *])$ zur DMSO-Kontrolle festgestellt. Dasatinib: 1 $\mu \mathrm{M}=131,8 \%$ (24 h), 176,3 \% (48 h), 215,9 \% (72 h) (Abbildung 12A).

Die Zellzahl der Medium-Kontrolle von Ly-LEC2 wuchs aufsteigend von $100 \%$, auf $206,3 \%(\hat{=}+106,3 \%), 303,5 \%(\hat{=}+47,1 \%)$ und 311,5\% $(\hat{=}+2,6 \%)$. Die Zellzahl der DMSO-Kontrolle stieg von $100 \%$ auf 211,8 \% $(\hat{=}+111,8 \%), 289,6 \%(\hat{=}+40,9 \%)$ und $302,1 \%(\hat{=}+2,6 \%)$. Es zeigten sich hierbei keine signifikanten Unterschiede zur MediumKontrolle. Dasatinib zeigte in der Konzentration von $1 \mu \mathrm{M}$ bei $24 \mathrm{~h}$ keinen signifikanten Unterschied gegenüber der DMSO-Kontrolle. Allerdings wurde bei $48 \mathrm{~h}$ und $72 \mathrm{~h}$ ein hoch signifikanter Unterschied ( $\left.\mathrm{p} \leq 0,001\left[{ }^{* * *}\right]\right)$ zur DMSO-Kontrolle gemessen. Dasatinib: 1 $\mu \mathrm{M}=193,9 \%$ (24 h), 219,2 \% (48 h), 234,5 \% (72 h) (Abbildung 12B).

Die prozentualen Zellzahlwerte der Medium-Kontrolle von Ly-LEC12 erhöhten sich von $100 \%$ auf 182,0 \%, nach $48 \mathrm{~h}$ auf 235,8 \% und nach $72 \mathrm{~h}$ auf 291,1\%. Die Zellzahl der DMSO-Kontrolle wuchs von 100,0 \% aufsteigend auf 174,8 \%, dann auf 228,8 \% und lag bei $72 \mathrm{~h}$ bei $274,8 \%$. Signifikante Unterschiede zur Medium-Kontrolle wurden nicht festgestellt. Bei Dasatinib in der Konzentration von $1 \mu \mathrm{M}$ bestand $\mathrm{zu}$ allen drei Inkubationszeitpunkten ein hoch signifikanter Unterschied $\left(\mathrm{p} \leq 0,001\left[{ }^{* *}\right]\right)$. Dasatinib: 1 $\mu \mathrm{M}=139,0 \%$ (24 h), 160,8 \% (48 h), 194,2 \% (72 h) (Abbildung 12C).

Für HD-LEC C2 erhöhte sich die Zellzahl der Medium-Kontrolle nach 24 h von 100 \% auf den Wert 189,5\% $(\hat{=}+89,5 \%)$, nach $48 \mathrm{~h}$ auf $345,7 \%(\hat{=}+82,4 \%)$ und nach $72 \mathrm{~h}$ auf $381,8 \%(\hat{=}+10,4 \%)$. Die Zellzahl der DMSO-Kontrolle stieg ähnlich wie bei der Medium-Kontrolle an. Es konnten keine signifikanten Unterschiede zur Medium-Kontrolle gefunden werden. DMSO = 187,8 \% (24 h), 331,1 \% (48 h), 369,8\% (72 h). In der Konzentration von $1 \mu \mathrm{M}$ Dasatinib wurden zu dem Zeitpunkt $\mathrm{t}=24 \mathrm{~h}$ keine signifikanten Unterschiede zur DMSO-Kontrolle gemessen. Allerdings konnten bei den Zeitpunkten $\mathrm{t}=$ 
$48 \mathrm{~h}$ und $\mathrm{t}=72 \mathrm{~h}$ hoch signifikante Unterschiede $(\mathrm{p} \leq 0,001[* * *])$ gemessen werden. Dasatinib: $1 \mu \mathrm{M}=192,2 \%$ (24 h), 216,0 \% (48 h), 263,2 \% (72 h) (Abbildung 12D).

Die Zellzahl der Medium-Kontrolle von HD-LEC C3 wuchs von $100 \%$ auf 139,0 \% (슨 $+39,0 \%)$, nach $48 \mathrm{~h}$ auf 178,3\% $(\hat{=}+28,2 \%)$ und bei $72 \mathrm{~h}$ auf $205,0 \%(\hat{=}+14,9 \%)$. Zwischen der Medium-Kontrolle und der DMSO-Kontrolle konnten keine signifikanten Unterschiede verzeichnet werden. Die Zellzahl der DMSO-Kontrolle stieg in den Intervallen von $0 \mathrm{~h}$ auf $72 \mathrm{~h}$ von $100 \%$ auf $139,1 \%, 177,8 \%$ und 200,7 \%. In den Ansätzen Dasatinib $1 \mu \mathrm{M}$ konnten bei $\mathrm{t}=24 \mathrm{~h}$ keine signifikanten Unterschiede gegenüber der DMSO-Kontrolle gemessen werden. Allerdings wurde bei $\mathrm{t}=48 \mathrm{~h}$ und $\mathrm{t}=72 \mathrm{~h}$ ein signifikanter Unterschied $\left(\mathrm{p} \leq 0,05\left[^{*}\right]\right)$ zur DMSO-Kontrolle festgestellt. Dasatinib: $1 \mu \mathrm{M}$ $=128,5 \%(24 \mathrm{~h}), 167,9 \%$ (48 h), 182,1\% (72 h) (Abbildung 12E).

Für HD-LEC C4 stieg die Zellzahl der Medium-Kontrolle nach $24 \mathrm{~h}$ von $100 \%$ auf den Wert 188,4\% $(\hat{=}+88,4 \%)$, nach $48 \mathrm{~h}$ auf 334,0 \% $(\hat{=}+77,2 \%)$ und nach $72 \mathrm{~h}$ auf $371,9 \%(\hat{=}+11,3 \%)$. Die prozentualen Zellzahlwerte der DMSO-Kontrolle stiegen nach $24 \mathrm{~h}$ auf 185,9\% $(\hat{=}+85,9 \%)$ an. Nach $48 \mathrm{~h}$ lag der Zellzahlwert bei 339,8\% $(\hat{=}+$ $82,7 \%)$ und nach $72 \mathrm{~h}$ bei $385,3 \%(\hat{=}+13,3 \%)$. Es konnten keine signifikanten Unterschiede zur DMSO-Kontrolle gefunden werden. Der Inhibitor Dasatinib zeigte in der Konzentration von $1 \mu \mathrm{M}$ bei $\mathrm{t}=24 \mathrm{~h}$ keinen signifikanten Unterschied zur DMSOKontrolle. Allerdings wurde bei den Inkubationszeitpunkten $\mathrm{t}=48 \mathrm{~h}$ und bei $\mathrm{t}=72 \mathrm{~h}$ ein hoch signifikanter Unterschied $(\mathrm{p} \leq 0,001[* * *])$ zur DMSO-Kontrolle gemessen. Dasatinib: $1 \mu \mathrm{M}=177,4 \%$ (24 h), 276,1\% (48 h), 263,6 \% (72 h) (Abbildung 12F). 


\subsubsection{Sorafenib}

Sorafenib gehört $\mathrm{zu}$ den sogenannten Multikinaseinhibitoren und inhibiert einige downstream liegende Proteine der PIK3-Signalkaskade wie z.B. EIF4E. Die nachfolgende Abbildung 13 zeigt die Ergebnisse der sechs untersuchten LECs mit Sorafenib in den Konzentrationen von $1 \mu \mathrm{M}$ und $5 \mu \mathrm{M}$.

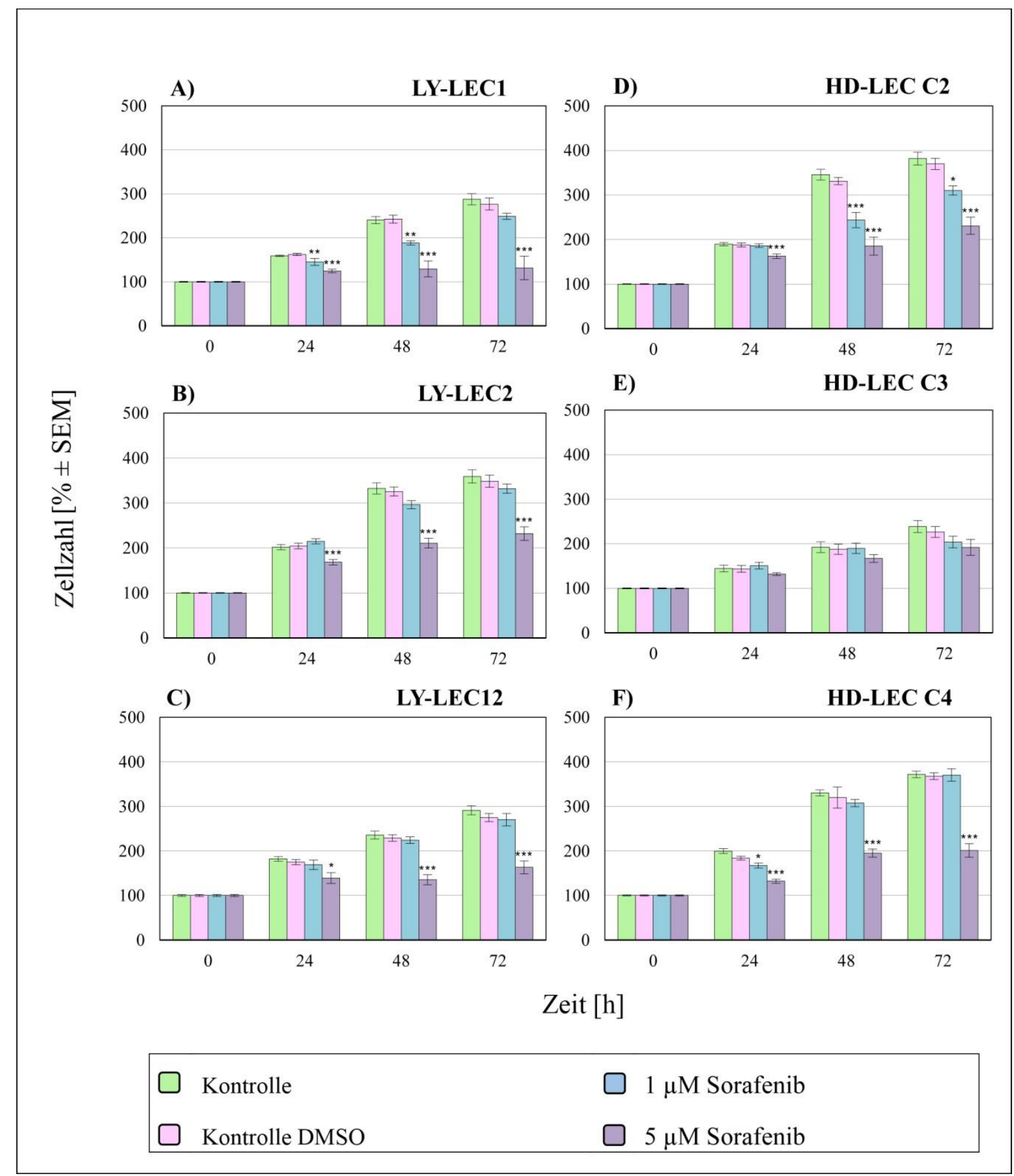

Abbildung 13: Proliferationsassays mit Tyrosinkinase-Inhibitor Sorafenib 
Die Zellzahl der Medium-Kontrolle von Ly-LEC1 stieg nach $24 \mathrm{~h}$ von $100 \%$ auf den Wert $158,9 \%(\hat{=}+58,9 \%)$, nach $48 \mathrm{~h}$ auf $240,1 \%(\hat{=}+51,1 \%)$ und nach $72 \mathrm{~h}$ auf $287,7 \%(\hat{=}$ $+19,8 \%$ ). Die Zellzahl bei DMSO-Behandlung stieg ähnlich wie bei der MediumKontrolle an. Die Zellzahlwerte waren aufsteigend: $100 \%, 162,2 \%$ (스 $+62,2 \%), 242,6 \%$ $(\hat{=}+49,5 \%)$ und $276,7 \%(\hat{=}+14,0 \%)$. Ein signifikanter Unterschied zur MediumKontrolle konnte nicht registriert werden. Der Inhibitor Sorafenib zeigte in der Konzentration von $1 \mu \mathrm{M}$ bei den Inkubationsmesspunkten $\mathrm{t}=24 \mathrm{~h}$ und bei $\mathrm{t}=48 \mathrm{~h}$ einen sehr signifikanten Unterschied ( $\mathrm{p} \leq 0,01[* *])$ zur DMSO-Kontrolle. Beim Messpunkt $\mathrm{t}=$ $72 \mathrm{~h}$ zeigte sich allerdings kein signifikanter Unterschied zur DMSO-Kontrolle. Sorafenib: $1 \mu \mathrm{M}=145,1 \%$ (24 h), 188,3\% (48 h), 248,8 \% (72 h). In der Konzentration von $5 \mu \mathrm{M}$ Sorafenib konnte bei allen drei Inkubationszeitpunkten ein hoch signifikanter Unterschied $(\mathrm{p} \leq 0,001[* * *])$ festgestellt werden. Sorafenib: $5 \mu \mathrm{M}=124,6 \%$ (24 h), 129,1\% (48 h), $131,5 \%$ (72 h) (Abbildung 13A).

Für Ly-LEC2 wuchsen die Zellzahlwerte der Medium-Kontrolle aufsteigend von 100 \%, auf $201,6 \%(\hat{=}+101,6 \%), 332,4 \%(\hat{=}+64,8 \%)$ und $359,1 \%(\hat{=}+8,0 \%)$. Die Zellzahlwerte der DMSO-Kontrolle stiegen von $100 \%$ auf 204,4 \% (스 $+104,4 \%)$, $325,5 \%(\hat{=}+59,2 \%)$ und $348,4 \%(\hat{=}+7,0 \%)$. Es zeigte sich hierbei kein signifikanter Unterschied zur Medium-Kontrolle. Auch in der Konzentration von $1 \mu \mathrm{M}$ Sorafenib fand sich zu keinem gemessenen Inkubationszeitpunkt ein signifikanter Unterschied gegenüber der DMSO-Kontrolle. Sorafenib: $1 \mu \mathrm{M}=214,6$ \% (24 h), 296,2 \% (48 h) und 331,7 \% (72 h). In der Konzentration von $5 \mu \mathrm{M}$ Sorafenib zeigte sich allerdings zu allen drei Inkubationszeitpunkten ein hoch signifikanter Unterschied ( $\leq 50,001[* * *])$ zur DMSOKontrolle. Sorafenib: $5 \mu \mathrm{M}=168,2 \%(24 \mathrm{~h}), 210,4 \%(48 \mathrm{~h})$ und 231,8 \% (72 h) (Abbildung 13B).

Die Zellzahl der Medium-Kontrolle von HD-LEC C2 erhöhte sich in den ersten $24 \mathrm{~h}$ von $100 \%$ auf den Wert 182,0\%, nach $48 \mathrm{~h}$ auf 235,8\% und nach $72 \mathrm{~h}$ auf 291,1\%. Die Zellzahl der DMSO-Kontrolle erhöhte sich von 100,0 \% auf 174,8 \%, dann auf 228,8 \% und bei $72 \mathrm{~h}$ auf 274,8\%. Sorafenib zeigte in der Konzentration von $1 \mu \mathrm{M}$ bei keinem Inkubationszeitpunkt einen signifikanten Unterschied zur DMSO-Kontrolle. Sorafenib: 1 $\mu \mathrm{M}=169,0 \%(24 \mathrm{~h}), 224,2 \%(48 \mathrm{~h})$ und 270,3\% (72 h). In der Konzentration von Sorafenib $5 \mu \mathrm{M}$ konnte zum Zeitpunkt $\mathrm{t}=24 \mathrm{~h}$ ein signifikanter Unterschied $\left(\mathrm{p} \leq 0,05\left[{ }^{*}\right]\right)$ zur DMSO-Kontrolle gemessen werden. Bei den Zeitpunkten $\mathrm{t}=48 \mathrm{~h}$ und $\mathrm{t}=72 \mathrm{~h}$ konnte 
sogar ein hoch signifikanter Unterschied $(\mathrm{p} \leq 0,001[* * *])$ gemessen werden. Sorafenib: 5 $\mu \mathrm{M}=139,1 \%(24 \mathrm{~h}), 135,2 \%(48 \mathrm{~h})$ und 163,1 \% (72 h) (Abbildung 13C).

Die Zellzahl der Medium-Kontrolle von HD-LEC C3 erhöhte sich nach 24 h von $100 \%$ auf den Wert 189,5\% $(\hat{=}+89,5 \%)$, nach $48 \mathrm{~h}$ auf 345,7 \% $(\hat{=}+82,4 \%)$ und nach $72 \mathrm{~h}$ auf $381,8 \%(\hat{=}+10,4 \%)$. Die Zellzahl der DMSO-Kontrolle stieg ähnlich wie bei der Medium-Kontrolle an. Es konnten keine signifikanten Unterschiede zur Medium-Kontrolle gefunden werden. DMSO = 187,8 \% (24 h), 331,1\% (48 h) und 369,8\% (72 h). In den Ansätzen Sorafenib $1 \mu \mathrm{M}$ wurden bei Zeitpunkt $\mathrm{t}=24 \mathrm{~h}$ keine signifikanten Unterschiede zur DMSO-Kontrolle gemessen. Allerdings wurden bei $\mathrm{t}=48 \mathrm{~h}$ ein hoch signifikanter Unterschied $\left(\mathrm{p} \leq 0,001\left[{ }^{* *}\right]\right)$ und bei $\mathrm{t}=72 \mathrm{~h}$ ein signifikanter Unterschied $(\mathrm{p} \leq 0,05[*])$ gemessen. Sorafenib: $1 \mu \mathrm{M}=186,1 \%(24 \mathrm{~h}), 243,6 \%$ (48 h) und 310,0 \% (72 h). In den Ansätzen Sorafenib $5 \mu \mathrm{M}$ traten bei allen drei Inkubationszeitpunkten hoch signifikante Unterschiede auf ( $\mathrm{p} \leq 0,001[* * *])$. Sorafenib: $5 \mu \mathrm{M}=162,7 \%(24 \mathrm{~h}), 185,2 \%$ (48 h) und 230,8\% (72 h) (Abbildung 13D).

Für die Zelllinie HD-LEC C3 wuchs die Zellzahl der Medium-Kontrolle von 100 \% auf $144,3 \%(\hat{=}+44,3 \%)$, nach $48 \mathrm{~h}$ auf 192,2 \% $(\hat{=}+33,1 \%)$ und bei $72 \mathrm{~h}$ auf $238,4 \%(\hat{=}$ $+24,0 \%)$. Zwischen der Medium-Kontrolle und der DMSO-Kontrolle wurden keine signifikanten Unterschiede verzeichnet. Die Zellzahl der DMSO-Kontrolle stieg in den Intervallen von $0 \mathrm{~h}$ auf $72 \mathrm{~h}$ von $100 \%$ auf $143,5 \%, 187,5 \%$ und 226,5\%. In den Ansätzen Sorafenib $1 \mu \mathrm{M}$ und $5 \mu \mathrm{M}$ wurde bei allen Inkubationszeitpunkten kein signifikanter Unterschied zur DMSO-Kontrolle verzeichnet. Sorafenib: $1 \mu \mathrm{M}=150,7 \%$ (24 h), 189,5\% (48 h) und 203,7\% (72 h). Sorafenib: $5 \mu \mathrm{M}=131,8 \%$ (24 h), 166,8\% (48 h) und 191,6\% (72 h) (Abbildung 13E).

Die Zellzahl der Medium-Kontrolle von HD-LEC C4 stieg nach 24 h von $100 \%$ auf den Wert 199,7\% (스 $+99,7 \%)$, nach $48 \mathrm{~h}$ auf 330,4\% $(\hat{=}+65,4 \%)$ und nach $72 \mathrm{~h}$ auf $371,9 \%(\hat{=}+12,5 \%)$. Zwischen der Medium-Kontrolle und der DMSO-Kontrolle ergaben sich keine signifikanten Unterschiede. Die Zellzahl der DMSO-Kontrolle wuchs in den Intervallen von $0 \mathrm{~h}$ auf $72 \mathrm{~h}$ von $100 \%$ auf 183,6\%, 319,9\% und 367,7\% an. Der Inhibitor Sorafenib zeigte in der Konzentration von $1 \mu \mathrm{M}$ bei $\mathrm{t}=24 \mathrm{~h}$ einen signifikanten Unterschied $\left(\mathrm{p} \leq 0,05\left[^{*}\right]\right)$ zur DMSO-Kontrolle. Bei den Zeitpunkten $\mathrm{t}=48 \mathrm{~h}$ und $\mathrm{t}=72 \mathrm{~h}$ konnte allerdings kein signifikanter Unterschied gemessen werden. Sorafenib: $1 \mu \mathrm{M}=$ $167,2 \%$ (24 h), 307,7 \% (48 h) und 370,5\% (72 h). In der Konzentration von Sorafenib 5 $\mu \mathrm{M}$ konnte allerdings bei allen drei Inkubationsmesspunkten ein hoch signifikanter 
Unterschied $(\mathrm{p} \leq 0,001[* * *])$ zur DMSO-Kontrolle gemessen werden. Sorafenib: $5 \mu \mathrm{M}=$ $132,2 \%$ (24 h), 195,0 \% (48 h) und 201,1\% (72 h) (Abbildung 13F).

\subsection{Western Blot}

Mit Hilfe von Western Blots konnte überprüft werden, ob es Unterschiede in der Phosphorylierung von AKT bei den verschiedenen Lymphendothelzelllinien gibt. AKT nimmt in der PI3K Signalkaskade eine zentrale Stellung ein (siehe Kapitel 1.4; Abb. 2). Hierbei wurden Zelllysate von fünf Zelllinien hergestellt (siehe Kapitel 2.2.4).

AKT wurde in phosphorylierter Form (pAKT Serin473, $60 \mathrm{kDa}$ ) und in seiner Gesamtform $(\mathrm{tAKT}=$ total AKT, $60 \mathrm{kDa})$ nachgewiesen. Die Phosphorylierung von AKT an der Aminosäuren Serin (473) lässt darauf schließen, wie stark die PI3K aktiv ist. Zudem wurde das Haushaltsprotein alpha-Tubulin $(57 \mathrm{kDa})$ im gleichen Western Blot dargestellt, um die gleichmäßige Gesamtbeladung der einzelnen Gelspuren zu überprüfen.

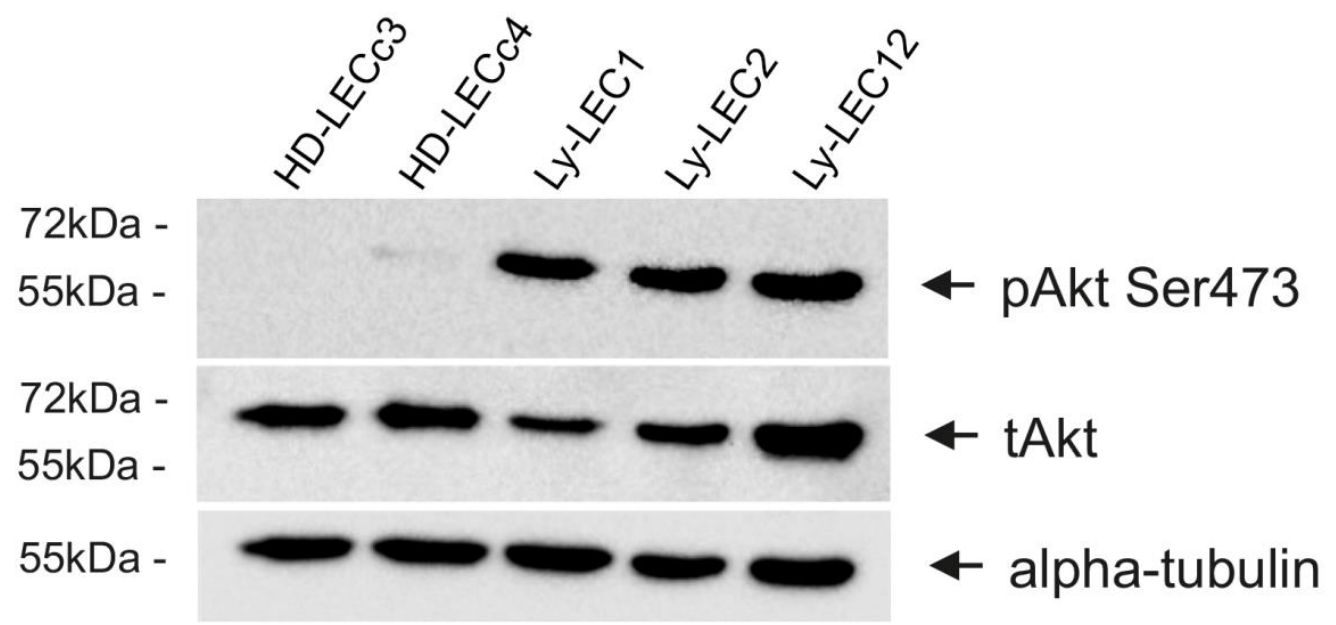

Abbildung 14: Nachweis von pAKT Serin473, tAKT und alpha-Tubulin

Die Abbildung 14 zeigt den durchgeführten Western Blot mit fünf Lymphendothelzelllinien (HD-LEC C3, HD-LEC C4, Ly-LEC1, Ly-LEC2 und LyLEC12). Die obere und mittlere Bande zeigt die Proteinexpression von AKT in der phosphorylierten Form (pAKT Serin473) und in der Gesamtform (tAKT $=$ pAKT + unphosphoryliertes AKT). Bei pAKT Serin473 ist zu erkennen, dass die Proteinexpression bei HD-LEC C3 und HD-LEC C4 deutlich schwächere Signale aufweist als bei den Lymphangiomzelllinien Ly-LEC1, Ly-LEC2 und Ly-LEC12. Das tAKT ist bei allen Zelllinien nachweisbar, jedoch bei Ly-LEC1 und Ly-LEC2 etwas schwächer. In der unteren 
Bande wird das Haushaltsprotein alpha-Tubulin dargestellt, welches in allen Proben als eine nahezu gleichstarke Bande auf Höhe von $57 \mathrm{kDa}$ nachweisbar ist. Dies zeigt, dass in allen Spuren gleich viel Gesamtprotein aufgetragen wurde und dient als Beladungskontrolle. 


\section{Diskussion}

\subsection{Aktivierende PIK3CA-Mutationen in LECs bei LM und Tumoren}

Lange Zeit war die Ätiologie der Lymphgefäßmalformationen unbekannt. Jedoch konnte kürzlich gezeigt werden, dass lymphatische Malformationen (LM), ob isoliert oder in Kombination mit Syndromen, vor allem durch aktivierende Mutationen des PIK3CA-Gens verursacht werden (Luks et al. 2015). Es konnten Mutationen bei 74 \% von 31 Individuen mit isoliertem LM in einer Kohorte des Seattle Children's Hospital gefunden werden. In einer Untersuchungsgruppe des Boston Children's Hospital wurde bei $>90$ \% (16 von 17) der LM-Patienten somatische Mosaike für spezifische PIK3CA-Mutationen entdeckt. Bei der Studie konnte jedoch keine signifikante Korrelation zwischen der Art der Mutation und der Form der LM (makrozystischen oder mikrozystischen) oder dem klinischen Schweregrad der LM beobachtet werden. Es zeigte sich zudem, dass PIK3CA-Mutationen oftmals bei Syndromen mit LM vorkommen. Dabei wiesen 19 von 21 Patienten mit dem Klippel-Trenaunay-Syndrom (KTS), fünf von acht mit FAVA und 31 von 33 mit CLOVES eine PIK3CA-Mutation auf. Bei der Mehrzahl der untersuchten Patienten $(\sim 80 \%)$ handelte es sich um eine der fünf Mutationen: c.1258T> C (p.C420R) (Exon 8), c.1624G> A (p.E542K) (Exon 10), c.1633G> A (p.E545K) (Exon 10), c.3140A> G (p.H1047R) (Exon 21) und c.3140A > T (p.H1047L) (Exon 21).

PIK3CA ist ein $34 \mathrm{~kb}-\mathrm{Gen}$, das auf dem Chromosom 3q26.3 lokalisiert ist und aus 21 Exons besteht. Das Gen kodiert 1068 Aminosäuren, was ein Protein mit einer Größe von $124 \mathrm{kDa}$ ergibt (Karakas et al. 2006). Die PIK3CA kodiert die katalytische UE p110 $\alpha$ der Klasse IA PI3-Kinasen und ist in verschiedenen humanen Krebsarten mutiert (Samuels und Ericson 2006). Der erste wissenschaftliche Bericht über PIK3CA-Mutationsanalysen wurde von Samuels et al. (2004) zusammengefasst. In Studien konnte bei Kolorektal-, Gehirnund Magenkarzinomen eine Häufigkeit der PIK3CA-Genmutationen von 32, 27 bzw. 25 \% festgestellt werden. Maligne Entartungen der Brustdrüse und der Lunge wiesen ein relativ geringes PIK3CA-Mutationsaufkommen auf. Die somatischen Punkt- (Missense-) Mutationen wurden vorwiegend in der Kinase- und helikalen Domäne der PIK3CA-UE gefunden. Dabei konnten Hot-Spots bzw. häufig wiederkehrende Mutationen in den Analysen in Exon 9 (G1624A: E542K) und in Exon 20 (A3140G: H1047R) gefunden werden (Karakas et al. 2006). Genetische Aberrationen im Signalweg der PI3K wurden in vielen menschlichen Krebsarten nachgewiesen (Kang et al. 2005). 
Im „Catalogue of Somatic Mutations in Cancer“ (COSMIC) wird ein Auftreten der PIK3CA-Mutationen bei etwa $30 \%$ der malignen Entartungen, einschließlich des Mammakarzinoms, des Dickdarms, des Endometriums und der Prostata verzeichnet. Dabei enthalten die Zellen meist nur eine einzige p110 $\alpha$-Mutation, wobei $80 \%$ davon eine von drei "Hot-Spot"-Mutationen betreffen (Karakas et al. 2006; Fruman et al. 2017). Zwei dieser „Hot-Spots“ befinden sich in der helikalen Domäne (E545K und E542K, Exon 10 und 9) von p110 $\alpha$, und die dritte befindet sich in der Kinasedomäne (H1047R, Exon 20) (Zhao und Vogt 2008). Bei einer Studie von Kang et al. wurden diese drei Mutationen gezielt in Fibroblasten von Hühnerembryonen eingeführt. Die mutierten Zellen zeigten eine deutliche onkogene Transformation, welche mit einer erhöhten katalytischen Aktivität der PI3K korreliert. Die erhöhte PI3K-Aktivität konnte anhand der konstitutiven Phosphorylierung von AKT, der p70 S6-Kinase und des 4E-BP1 nachgewiesen werden. Die Phosphorylierung der p70 S6-Kinase und des 4E-BP1 wird durch mTOR reguliert und beeinflusst die Proteinsynthese (Kang et al. 2005).

Aktivierende Mutationen des PIK3CA-Gens konnten bei LM Patienten, Patienten mit venösen Malformationen (Castel et al. 2016; Castillo et al. 2016b) und bei CLOVES (Kurek et al. 2012) gefunden werden. In insgesamt 26 von 29 (89 \%) Gewebeproben mit LM und kapillär-venöser-lymphatischer Malformation (CVLM) konnten aktivierende PIK3CA-Mutationen identifiziert werden (Osborn et al. 2015). Bislang wurden aber nie verschiedene Zelltypen aus LM isoliert und verglichen, so dass nicht bekannt war, welche Zelltypen die Mutationen tragen. Daher wurden sowohl LECs als auch Fibroblasten aus LM von sechs Patienten aus der Universitätsklinik Freiburg und dem Universitätsklinikum Regensburg isoliert. Frau Dr. Kaulfuß (Humangenetik, UMG) untersuchte diese Zellen auf häufig vorkommende Mutationen in den Exons 8, 10 und 21 des PIK3CA-Gens und bei den Ly-LEC2 zusätzlich das gesamte Gen. Dabei wurden in fünf von sechs Ly-LECs typische aktivierende PIK3CA-Mutationen identifiziert und in den Ly-LEC2 noch eine Deletion (Glu109del) in Exon 2. In den untersuchten Fibroblasten konnten allerdings keinerlei Mutationen gefunden werden. Dieses Ergebnis zeigt, dass die PIK3CAMutationen in den LM zelltypspezifisch ausschließlich in den LECs vorkommen und ursächlich für die LM sein dürften.

In der Zelllinie Ly-LEC1 konnte eine PIK3CA-Mutation in Exon 8: c.1258T >C (p.C420R) festgestellt werden. Laut NCBI-Datenbank kommt diese PIK3CA-Mutation neben CLOVES (Kurek et al. 2012) und MCAP (Mirzaa et al. 2013) auch bei Ovarialkarzinomen (Jones et al. 2010), Lungenkarzinomen (Plattenepithel-CA), Mamma-CA, kolorektalen 
Neoplasien, adenoidzystischen Karzinomen, Adenokarzinomen des Magens, malignen Entartungen des Uterus und Adenokarzinomen der Prostata vor.

In der Zelllinie Ly-LEC2 konnte eine Mutation in Exon 2 gefunden werden. Es handelt sich dabei um eine 3bp in-frame Deletion von GAA an der Position 109 oder 110 (zwei aufeinanderfolgende Glutaminsäuren). Die Mutation wurde zuvor als Glu109del beschrieben und konnte bei verschiedenen Karzinomen, wie Brustkrebs, nachgewiesen werden (Guo et al. 2013; Desmedt et al. 2015). In dem durchgeführten Western Blot (Abb. 14) konnte gezeigt werden, dass diese Zelllinie eine deutliche AKTHyperphosphorylierung aufweist, somit kann davon ausgegangen werden, dass auch die Glu109del eine aktivierende Mutation darstellt.

In der Zelllinie Ly-LEC10 konnte eine Mutation in Exon 10: c.1636G>A (p.Q546K) nachgewiesen werden, welche zuvor in LM noch nicht gefunden wurde. Diese Mutation konnte jedoch in malignen Entartungen wie Ovarialkarzinom, Glioblastom, Uteruskarzinosarkom und Plattenepithelkarzinom (Janku et al. 2012; Chang et al. 2016) nachgewiesen werden und verursacht höchstwahrscheinlich ebenfalls eine konstitutive Aktivierung der PI3K.

In der Zelllinie Ly-LEC12 wurde eine Mutation in Exon 10: c.1633G>A (p.E545K) gefunden. Diese PIK3CA-Mutation ist laut NCBI-Datenbank bei 36 verschiedenen Erkrankungen gelistet. Beispiele sind Leberzellkrebs, Magenkrebs (Harada et al. 2016), MCAP, malignes Melanom, kleinzelliges Lungen-CA, Plattenepithel-CA der Kopf- und Halsregion, seborrhoische Keratose, Ovialepithelkarzinom, Mamma-CA, Lungenadenokarzinom u.v.m. (Denorme et al. 2018).

In der Zelllinie Ly-LEC14 konnte in Exon 21: c.3140A>T (p.H1047L) eine Mutation nachgewiesen werden. Die Mutation konnte bereits laut NCBI-Datenbank bei 30 verschiedenen Erkrankungen nachgewiesen werden, u.a. Leberzellkrebs, Medulloblastom, malignes Melanom, hepatozelluläres Karzinom, Glioblastom, Lungenadenokarzinom, Ösophagus-CA u.v.m. (Yeung et al. 2017).

Die Identifizierung von Gen-Mutationen hat neue Möglichkeiten für die Behandlung der Erkrankten eröffnet. Der PI3K-AKT-mTOR-Signalweg ist bei menschlichen Krebsarten, wie oben dargestellt, häufig überaktiv. Die PI3K-Hemmung gilt als eine der vielversprechendsten zielgerichteten Therapien für die Krebsbehandlung. Die onkogen transformierende Aktivität der PI3K macht sie zu einem Ziel für pharmakologische 
Inhibitoren, welche zu effektiven und hochspezifischen Antikrebsmedikamenten entwickelt werden könnten (Maira et al. 2009).

Die Zelllinien aus Lymphendothel gesunder Spender (PromoCell, Heidelberg) HD-LEC C2, HD-LEC C3, HD-LEC C4 wurden ebenfalls auf Mutationen in den Exons 8, 10 und 21 untersucht, zeigten jedoch keinerlei Auffälligkeiten, so dass die Substanztestungen an gesunden und erkrankten LECs vergleichend durchführt werden konnten.

\subsection{Aktivierung von AKT und mTOR}

AKT (Proteinkinase B) ist ein zentraler Knotenpunkt in der Signaltransduktion der PI3KSignalkaskade (Manning und Cantley 2007). Bei Säugetieren existieren drei Isoformen: AKT1, AKT2 und AKT3 (codiert als PKB $\alpha$, PKB $\beta$ und PKB $\gamma$ ) (Liu et al. 2009; Scheid und Woodgett 2003). Die drei Formen kommen in allen Geweben und Zelltypen vor (Fouladi et al. 2014). Dabei ist AKT1 immer vorhanden, AKT2 vor allem in insulinresponsiven Gewebe und AKT3 vorwiegend in Gehirn und Hoden (Krycer et al. 2010). Die drei AKTFormen besitzen eine ähnliche Grundstruktur mit einer N-terminalen PH-Domäne, eine zentrale katalytische Serin/Threonindomäne und eine kurze C-terminale regulatorische Domäne (Liu et al. 2009).

Die Proteinkinase B wird in vielen soliden Tumorerkrankungen erheblich aktiviert (Fouladi et al. 2014; Engelman 2009), wie Brustkrebs, Prostatakrebs, Glioblastom, Darmkrebs, Eierstockkrebs, Magenkrebs, nicht-kleinzelligem Lungenkrebs, Pankreaskrebs, malignen rhabdoiden Tumoren, Neuroblastomen, Synovialsarkom, Rhabdomyosarkom, Glioblastom und Medulloblastom.

AKT spielt eine wichtige Rolle in der physiologischen und pathologischen Angiogenese und hat dabei Auswirkungen auf Endothelzellen und auf Zellen, die angiogene Signale produzieren, wie z. B. Tumorzellen. Im weiteren Verlauf wird auf einige durch pAKT aktivierte Prozesse eingegangen (Mayo und Donner 2001; Manning und Cantley 2007):

Durch Blockierung der Funktion von proapoptotischen Proteinen und Prozessen, wie z.B. BAD fördert pAKT das Zellüberleben. Zudem werden FOXO-vermittelte Transkriptionen auf Zielgene, welche eine Apoptose oder Zellzyklusarrest einleiten, inhibiert. Ein weiterer Mechanismus ist die phosphorylierte Aktivierung des Protoonkogen MDM2, welcher die Funktion des Tumorsuppressors p53 inhibiert. Durch Phosphorylierung von S6K1/2 (Aktivierung) und 4E-BP1 (Inhibition), wird die mRNA Translation (Proteinbiosynthese) und die Ribosom-Biogenese aktiviert (Akcakanat et al. 2007). 
Der Zellzyklus kann durch pAKT reguliert werden, indem pAKT das Cdk-InhibitorProtein p27kip1 (Cyclin-abhängige Kinasen-Inhibitor 1B) phosphoryliert und dämpft dadurch dessen inhibitorische Wirkung auf den Zellzyklus. Zudem aktiviert pAKT eNOS (endothelial nitric oxide synthase), welche durch die Freisetzung von Stickstoffoxiden (NO) eine Vasodilatation, vaskuläre Remodellierung und die Angiogenese fördern (Fulton et al. 1999; Olsson et al. 2006).

Es kommt zu einer erhöhten Ausschüttung von den Transkriptionsfaktoren HIF1 $\alpha$ und HIF2 $\alpha$ (hypoxia-inducible factor $\alpha$ ), wodurch eine Expression und anschließende Sekretion von VEGF und anderen angiogenen Faktoren induziert wird.

Die Glukoseaufnahme kann von pAKT gefördert werden, durch die Induktion der Translokation von Glukosetransporter 4 (GLUT4) zur Zellmembran und zudem eine vermehrte Expression von Glukosetransporter 1 (GLUT1) (Kohn et al. 1996; Fruman et al. 2017).

MTOR (mechanistic Target of Rapamycin, früher: mammalian Target of Rapamycin; auch FRAP, RAFT1 oder SEP) ist eine Serin-/Threoninkinase und reguliert die Verfügbarkeit von Nährstoffen, den zellulären Energiespiegel, das Sauerstoffniveau und mitogene Signale (Zhou et al. 2010; Rössler 2015). In Säugetierzellen liegt mTOR als Proteinkomplex mTORC1 und mTORC2 vor (Liu et al. 2009; Völkers und Sussman 2013).

Der mTORC1-Komplex ist Rapamycin-sensitiv und besteht aus den katalytischen UE Raptor, PRAS40 und dem nicht katalytisch aktiven Protein mLST8/GbL (Akcakanat et al. 2007). MTORC1 spielt vor allem eine wichtige Rolle bei der Kontrolle von Zellgröße, Zellzyklus und Zellmetabolismus. Das Zellwachstum wird durch Aktivierung von mTORC1 getriggert (Wullschleger et al. 2006).

MTORC2 ist nicht Rapamycin-sensitiv und besteht aus den katalytischen UE Rictor, mSIN1 und dem nicht katalytisch aktiven Protein GßL. MTORC2 spielt vor allem eine Rolle beim Zellüberleben und der Organisation des Zytoskelettes. 
4.3 PI3K-AKT-mTOR-Inhibitoren und Proliferationsversuche

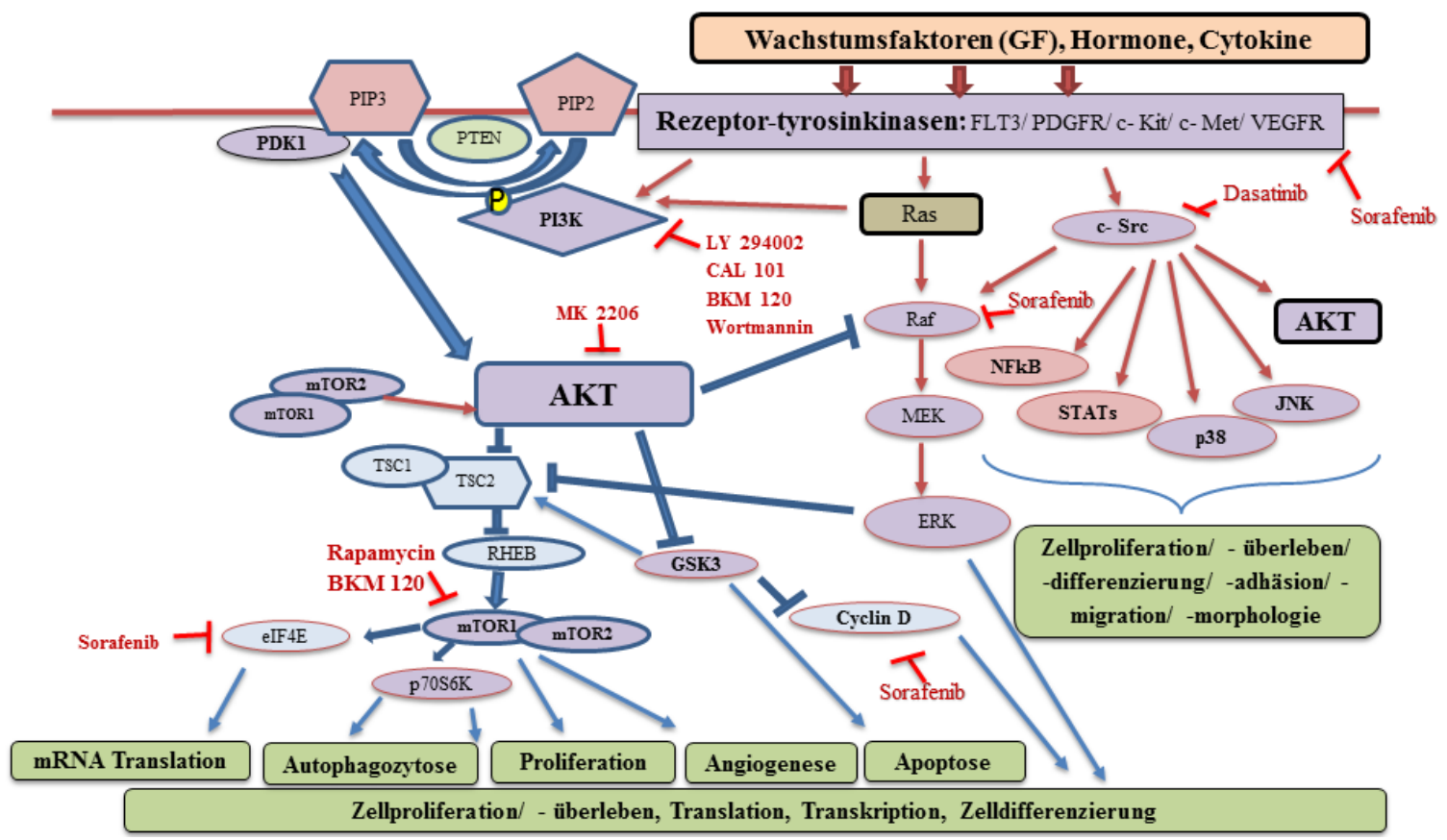

Abbildung 15: PI3K-AKT-mTOR-Signalkaskade mit den getesteten Inhibitoren

Modifiziert nach Selleck Chemicals LLC (Selleck Chemicals 2013), Cell Signaling Technology (Cell Signaling Technology 2008) und Cisbio (Cisbio 2016) in Zusammenarbeit mit Rieke Werner erstellt.

Die erste Generation der PI3K-Inhibitoren waren Wortmannin und LY294002, welche eine In-vitro-Inhibition der PI3K mit einer mittleren inhibitorischen Konzentration (IC50) von ca. $1 \mathrm{nM}$ bis 1,4 mM aufwiesen (Arcado und Wymann 1993; Vlahos et al. 1994). Diese Verbindungen zeigten jedoch in Tierversuchen erhebliche Toxizitäten und kamen aufgrund pharmazeutischer Beschränkung zunächst nicht in die klinische Bewertung (Akinleye et al. 2013). Trotzdem konnten so neue Erkenntnisse über das Potenzial von Inhibitoren des PI3K-AKT-mTOR-Signalweges in Verbindung mit malignen Entartungen gewonnen werden. Es wurde nach weiteren PI3K-AKT-mTOR-Inhibitoren mit verbesserter Verträglichkeit, Wirksamkeit, Pharmakokinetik und Pharmakodynamik geforscht (Janku 2017). Dabei sind mindestens 15 Inhibitoren mit positiven Profilen in verschiedenen Stadien der klinischen Entwicklung (Akinleye et al. 2013).

Die ersten eingesetzten PI3K/mTOR-Inhibitoren bei der Behandlung von Malignomen waren Rapamycin-Analoga (allosterische mTORC1-Inhibitoren) wie Temsirolismus, zugelassen bei fortgeschrittenem Nierenzellkarzinom, und Everolimus, zugelassen bei fortgeschrittenem Mamma- und Nierenzellkarzinom, fortgeschrittenen pankreatischen neuroen- 
dokrinen Tumoren, progressiven gastrointestinalen und lungenneuroendokrinen Tumoren, renalen Angiomyolipomen sowie subependymalem Riesenzellastrozytom (Janku 2017).

In den Proliferationsversuchen an LECs kamen acht verschiedene Inhibitoren zur Anwendung. Im weiteren Verlauf wird auf die verwendeten Inhibitoren und die Ergebnisse der vorliegenden Arbeit eingegangen.

\subsubsection{Hemmung der PI3K durch Wortmannin, BKM120, LY294002 und CAL-101}

Wortmannin ist ein hochpotenter und spezifischer PIK3CA-Inhibitor (p110 $\alpha)$. Aufgrund seiner hohen Lebertoxizität in Tierversuchen kann Wortmannin aber nicht klinisch eingesetzt werden (Arcado und Wymann 1993; Wymann et al. 1996; Wagener und Müller 2010).

In den Versuchen hemmte Wortmannin bei einer Konzentration von $50 \mu \mathrm{M}$ das Zellwachstum sowohl bei den untersuchten Ly-LECs als auch bei den HD-LECs hoch signifikant $(\mathrm{p} \leq 0,001[* * *])$. Bei einer Konzentration von $10 \mu \mathrm{M}$ zeigte Wortmannin nur bei HD-LEC C4 nach $\left.48 \mathrm{~h}\left(\mathrm{p} \leq 0,01{ }^{* *}\right]\right)$ einen signifikanten Unterschied zur DMSOKontrolle. Wortmannin wirkt somit bei $50 \mu \mathrm{M}$ sowohl bei LECs mit als auch ohne aktivierende PI3K-Mutation, nicht jedoch bei einer Konzentration von $10 \mu \mathrm{M}$. Im Gegensatz dazu zeigten Boscolo et al. (2015) für $10 \mu \mathrm{M}$ Wortmannin sowohl bei HD-LEC als auch bei LM-LEC einen signifikanten Unterschied ( $\left.\leq \leq 0,05\left[{ }^{*}\right]\right)$ zur DMSO-Kontrolle (Boscolo et al. 2015). Die Versuchsdurchführungen bei Boscolo et al. und den Versuchen in der vorliegenden Arbeit sind vergleichbar: es wurde das gleiche Medium (Endothelial Cell GM MV2-Medium) verwendet, ähnlich viele Zellen ausplattiert (Boscolo: 10.000 Zellen $/ \mathrm{cm}^{2}$, Versuche in dieser Arbeit umgerechnet: $15.000 / \mathrm{cm}^{2}$ ) und die gleichen Zeiten zum Adhärieren der Zellen bzw. Zellzählung nach Inhibitorzugabe eingehalten. Trotzdem reagieren die Zelllinien von Boscolo et al. (2015) sensibler auf die Zugabe von $10 \mu \mathrm{M}$ Wortmannin. Wortmannin inhibiert die p110 a des PIK3CA-Gens und nach den Ergebnissen zufolge in der Konzentration von $50 \mu \mathrm{M}$ an gesunden und mutierten PIK3CALymphendothelzelllinien.

Buparlisib (BKM120) ist ein potenter selektiver Pan-PI3K-Klasse I-Inhibitor. Durch die Hemmung von PI3K der Klasse I p110 $\alpha, \beta, \gamma$ und $\delta$ mit jeweiligen IC50 von 52, 166, 116 und 262 nM (Janku 2017) wird die Phosphorylierung von AKT und S6R verhindert und die Apoptose von Krebszellen eingeleitet. BKM120 wird schnell resorbiert und hat eine hohe Bioverfügbarkeit ( $\geq 90 \%$ ) (Sirohi et al. 2015). Buparlisib wird derzeit bei Patienten mit 
verschiedenen soliden Tumoren einschließlich Brustkrebs untersucht. Es wurde als vielversprechendes Antikrebsmittel eingestuft, zeigte allerdings in der Monotherapie einen ungenügenden Nutzen. Ergebnisse aus Kombinationsstudien mit verschiedenen Antikrebsmitteln (endokrine Therapie, Anti-HER2-Therapie und die Chemotherapie) zeigten eine variable Wirksamkeit mit Toxizitäten (Criscitiello et al. 2018).

In den Versuchen wurde BKM120 in der Konzentration von $0,2 \mu \mathrm{M}$ und $1 \mu \mathrm{M}$ eingesetzt. Es zeigte bei 0,2 $\mu \mathrm{M}$ keinen Unterschied zur DMSO-Kontrolle in Ly-LEC1, Ly-LEC12, HD-LEC C3 und HD-LEC C4. Lediglich bei den Ly-LEC2, die eine Glu109del aufweisen, konnten signifikante Werte bei einer BKM120-Konzentration von 0,2 $\mu \mathrm{M}$ im Vergleich zur DMSO-Kontrolle gemessen werden (bei $48 \mathrm{~h}: \mathrm{p} \leq 0,05\left[{ }^{*}\right]$ und bei $72 \mathrm{~h}: \mathrm{p} \leq 0,001\left[{ }^{* * *}\right]$ ). Bei HD-LEC C2 konnten ebenfalls signifikante Werte zur DMSO-Kontrolle gemessen

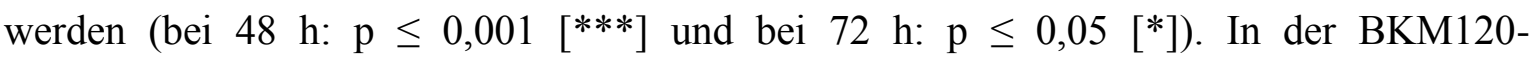
Konzentration von $1 \mu \mathrm{M}$ konnten bei allen untersuchten Zelllinien hoch signifikante Werte verzeichnet werden.

Buparlisib wurde schon in vielen In-vitro und In-vivo (Maira et al. 2012; Rodon et al. 2014) Studien an verschiedenen Zelllinien und „Krebs-Xenograftmodellen“ getestet. Dabei zeigte Buparlisib eine antiproliferative, proapoptotische und antitumoröse Aktivität. Umfassende Untersuchungen wurden schon bei vielen Tumorerkrankungen (Geuna et al. 2015), vor allem aber bei Mammakarzinomen (Studie BELLE-2) durchgeführt (Colwell 2016; Fruman et al. 2017).

Der PI3K-Klasse IA-Inhibitor LY294002 wurde in der Konzentration von 0,5 $\mu \mathrm{M}$ und 5 $\mu \mathrm{M}$ in Proliferationsversuchen getestet. Dabei zeigte sich in allen untersuchten Zelllinien keine signifikante Wirkung bei einer Konzentration von $0,5 \mu \mathrm{M}$. Bei der Konzentration von $5 \mu \mathrm{M}$ zeigten sich bei allen Zelllinien unterschiedlich starke Signifikanzen zu der DMSO-Kontrolle. Ly-LEC2 zeigte einen signifikanten Unterschied zur DMSO-Kontrolle bei $72 \mathrm{~h}\left(\mathrm{p} \leq 0,05\left[^{*}\right]\right)$. Für alle anderen Zelllinien (Ly-LEC1, Ly-LEC12, HD-LEC C2, HD-LEC C3 und HD-LEC C4) wurde mindestens ein signifikanter Unterschied zur DMSO-Kontrolle $\left(\mathrm{p} \leq 0,05\left[^{*}\right]\right)$ ab dem Zeitpunkt $\mathrm{t}=48 \mathrm{~h}$ gemessen. Proliferationsversuche mit LY294002 in der Studie von Boscolo et al. 2015 wurden in den Konzentrationen von $50 \mu \mathrm{M}$ und $100 \mu \mathrm{M}$ durchgeführt. Die Ergebnisse zeigten einen signifikanten Unterschied zur DMSO-Kontrolle bei beiden Konzentrationen $\left(\mathrm{p} \leq 0,05\left[^{*}\right]\right)$ und bei beiden Zelllinien (HD-LEC, LM-LEC). LY294002 zeigt somit in dieser Studie und auch in der Studie von Boscolo eine konzentrationsabhängige Hemmung der Proliferation sowohl bei 
den Ly-LECs als auch bei den HD-LECs. LY294002 wurde schon in einigen In-vitroStudien an neuronalen, kardiovaskulären, immunologischen und Diabetes-Modellen angewandt (El-Kholy et al. 2003). Der IC50 beträgt 1,4 $\mu \mathrm{M}$ (Vlahos et al. 1994).

CAL-101 (Idelalisib) ist ein potenter PI3K $\delta$-Inhibitor. In lymphatischen Zelllinien und anderen Gewebeproben hemmt CAL-101 PI3K und fördert dadurch die Zellapoptose. In einer Studie wurde CAL-101 bei 54 Patienten mit stark vorbehandelter chronischer lymphatischer Leukämie untersucht, dabei zeigte die orale Therapie bei der Mehrzahl der Patienten eine sichere und schnell induzierte dauerhafte Krankheitsbekämpfung (Brown et al. 2014). Zudem konnte eine induzierte Zytotoxizität beim Multiplen Myelom durch CAL-101 festgestellt werden (Ikeda et al. 2010).

In den Versuchen wurde CAL-101 in der Konzentration von $5 \mu \mathrm{M}$ und $50 \mu \mathrm{M}$ eingesetzt. In der Konzentration von $5 \mu \mathrm{M}$ zeigte CAL-101 bei allen Zelllinien keinen signifikanten Proliferationseinfluss. Mit $50 \mu \mathrm{M}$ CAL-101 konnte bei den Zelllinien Ly-LEC1, LyLEC12, HD-LEC C3, HD-LEC C4 mindestens signifikante ( $\left.\leq \leq 0,05\left[^{*}\right]\right)$ Werte im Vergleich zur DMSO-Kontrolle gemessen werden. Obwohl CAL-101 nur die PI3K $\delta$ inhibiert, zeigen sich bei einer hohen Konzentration Auswirkungen auf die Proliferation von LECs.

CAL-101 wurde schon in einigen Studien zur Behandlung bei chronischer lymphatischer Leukämie (CLL) und Non-Hodgkin-Lymphomen erfolgreich untersucht (Brown et al. 2014; Lannutti et al. 2011; Byrd et al. 2012; Fruman et al. 2017).

Zusammenfassend kann gesagt werden, dass eine deutliche hemmende Wirkung der verwendeten PI3K-Inhibitoren auf alle Zelllinien bei höherer Konzentration festzustellen ist (Ausnahme CAL-101 bei Ly-LEC2 und HD-LEC C2). Bei den niedrigeren Konzentrationen ist keine signifikante Inhibition zu verzeichnen (Ausnahme BKM120 bei Ly-LEC2 und HD-LEC C2).

\subsubsection{Hemmung von mTOR durch Rapamycin}

Rapamycin (Sirolimus) ist ein mTOR-Inhibitor, welcher Einfluss auf den zellulären Metabolismus, die Zellmotilität, die Angiogenese und das Zellwachstum hat (Rössler et al. 2014). Die zytostatische Wirkung von Rapamycin wird durch die Hemmung der Zellteilung durch den Stopp der G1-Phase (G1-Arrest) ausgelöst (Hosoi et al. 1998). Zudem unterdrückt Rapamycin In-vitro die Hypoxie-induzierte Angiogenese und die Endothelzellproliferation (Humar et al. 2002). Bei Mäusen wirkt Rapamycin stark inhibitorisch auf das 
Tumorwachstum, die Angiogenese sowie die Produktion von VEGF (Guba et al. 2002; Zhou et al. 2010). In mehreren Studien konnte eine Inhibition der Lymphangiogenese und Lymphknotenmetastasen durch Rapamycin gezeigt werden (Huber et al. 2007; Patel et al. 2011; Kobayashi et al. 2007).

Rapamycin wurde in den Proliferationsversuchen in der Konzentration von $1 \mathrm{nM}$ und 10 $\mathrm{nM}$ getestet. Es zeigten sich bei beiden Konzentrationen in allen untersuchten Zelllinien hoch signifikante $(\mathrm{p} \leq 0,001[* * *])$ Unterschiede zur DMSO-Kontrolle.

In vielen Studien wurde Rapamycin an murinen und auch an humanen Krebszelllinien getestet (Zhou et al. 2010). Dabei konnte gezeigt werden, dass Rapamycin das Wachstum von Rhabdomyosarkomen, Neuroblastomen, Glioblastomen, kleinzelligen Lungenkarzinomen (SCLC), Osteosarkomen, Pankreaskarzinomen, Mammakarzinomen, Prostatakarzinomen, B16-Melanomen und B-Zell-Lymphomen inhibieren kann.

Bei einer In-vitro-Studie von Hammill et al. wurde bei sechs Patienten mit vaskulären Malformationen Sirolimus über einen bestimmten Zeitraum verabreicht. Alle Patienten hatten vor der Behandlung mit Rapamycin verschiedene andere Therapien ohne Erfolg erhalten. Auf Rapamycin zeigten alle Patienten signifikante Reaktionen mit einer Verbesserung der Symptome. Allerdings wurden auch Nebenwirkungen wie Mukositis, Hypercholesterinämie, Kopfschmerzen, Erhöhung der Leberwerte AST / ALT und Neutropenie festgestellt (Hammill et al. 2011).

In einer Übersichtsarbeit wurden 20 Studien mit Patienten, die Sirolimus erhielten, überprüft (Wiegand et al. 2018). Darunter waren 45 LM-Patienten, acht Patienten mit lymphatisch-venöser Fehlbildung und 19 Patienten wiesen eine kapillär-lymphatischvenöse Fehlbildung auf. Die Behandlung mit Sirolimus führte bei 60 Patienten zu einer teilweisen Remission, bei drei Patienten kam es zur Progression der Erkrankung, und bei den restlichen Patienten konnte kein Ergebnis notiert werden. Dabei unterschieden sich die Dosierung, Talspiegel und Behandlungsdauer der untersuchten Studien. Die Ergebnisse zeigen, dass eine Sirolimus-Therapie bei Patienten mit LM und kombinierten LMErkrankungen wirksam sein könnte.

Boscolo et al. (2015) untersuchten Rapamycin auch in Proliferationsversuchen mit den gleichen Konzentrationen wie in den vorliegenden Versuchen. Dabei wurden jedoch keine signifikanten Werte bei HD-LECs und sehr signifikante Werte $(\mathrm{p}<0,01$ [**]) bei den LMLECs gemessen (Boscolo et al. 2015). Die Ergebnisse in dieser Arbeit zeigten hingegen eine eindeutige Hemmung der Proliferation durch Rapamycin (1 nM und $10 \mathrm{nM}$ ) sowohl 
auf gesunde als auch auf LECs aus lymphatischen Malformationen. Der Einsatz von Rapamycin bei LM ist nach den Untersuchungen streng zu kontrollieren bzw. sollte überdacht werden, da Rapamycin auch auf gesunde Lymphendothelzellen eine stark inhibitorische Wirkung zeigt. Allerdings bleibt auch offen, ob die In-vitro-Versuche unmittelbar auf die In-vivo-Situation übertragbar sind, denn es ist zu vermuten, dass auch die gesunden LECs In-vitro deutlich schneller proliferieren, als es die Zellen In-vivo tun.

\subsubsection{Hemmung von AKT durch MK-2206}

MK-2206 ist ein oralverträglicher AKT-Inhibitor. In Studien mit hepatozellulären Karzinomen (HCC) konnte eine antitumoröse Aktivität festgestellt werden (Wilson et al. 2014). In einer Phase-I-Studie von 2012 zeigte MK-2206 eine gute dosisabhängige Verträglichkeit bei Kindern mit rezidivierenden soliden Tumoren (Fouladi et al. 2014). Allerdings zeigte jedoch eine Phase-II-Studie mit dem MEK-Inhibitor Selumetinib bei Erwachsenen mit fortgeschrittenem kolorektalen Karzinom häufig Toxizitäten und die gewünschte Hemmung konnte nicht erreicht werden (Do et al. 2015).

MK-2206 zeigte in den Versuchen ab dem Zeitpunkt von $48 \mathrm{~h}$ bei der Konzentration von $25 \mu \mathrm{M}$ und $50 \mu \mathrm{M}$ immer hoch signifikante Unterschiede zur DMSO-Kontrolle ( $\leq 50,001$ $[* * *])$. Bei $10 \mu \mathrm{M}$ wurden für die Zelllinien Ly-LEC1, Ly-LEC2 und HD-LEC C3 keine signifikanten Unterschiede zur DMSO-Kontrolle festgestellt, jedoch konnten bei LyLEC12, HD-LEC C2 und HD-LEC C4 signifikante ( $\left.\leq \leq 0,05\left[{ }^{*}\right]\right)$ bis hoch signifikante ( $p$ $\leq 0,001[* * *])$ Unterschiede zur Kontrolle verzeichnet werden. MK-2206 scheint dabei aber mit $50 \mu \mathrm{M}$ überdosiert zu sein, da die Zellen massiv abstarben. Bei $25 \mu \mathrm{M}$ zeigte sich eine Proliferationshemmung bei allen gesunden LECs. Bei den kranken LECs kam es dagegen zu einer Verminderung der Ausgangszellzahl bei den Ly-LEC1 und Ly-LEC12. Nur die Ly-LEC2, welche die Glu109del in Exon 2 aufweisen, verhielten sich so wie die gesunden LECs. Möglicherweise zeigt dies, dass MK-2206 bei LECs, welche die typischen PI3K Mutationen aufweisen, einen stärkeren Effekt besitzt als bei gesunden LECs. Da MK-2206 schon einmal bei Kindern getestet worden ist, könnte sich hier eine neue Therapieoption auftun.

\subsubsection{Hemmung der Tyrosinkinasen durch Dasatinib und Sorafenib}

Der Tyrosinkinase-Inhibitor Dasatinib wurde in den Versuchen in der Konzentration von 1 $\mu \mathrm{M}$ getestet. Es zeigten sich bei allen untersuchten Zelllinien mindestens signifikante $(\mathrm{p} \leq$ 
$\left.0,05\left[^{*}\right]\right)$ Unterschiede zur DMSO-Kontrolle. Bei den Zelllinien Ly-LEC1, Ly-LEC2, LyLEC12, HD-LEC C2 und HD-LEC C4 sogar hoch signifikante ( $\leq \leq 0,001[* * *])$ Unterschiede zur DMSO-Kontrolle. Dasatinib ist zugelassen für die Behandlung von chronischer myeloischer Leukämie (CML; alle Phasen) und für die Behandlung von Philadelphia-Chromosom-positiver akuter lymphoblastischer Leukämie ( $\mathrm{Ph}+\mathrm{ALL}$; resistent oder intolerant gegenüber vorheriger Imatinib-Behandlungen) (Lindauer und Hochhaus 2014). Beide Erkrankungen sind durch eine konstitutiv aktive Tyrosinkinase (BCR-ABL) gekennzeichnet. Dasatinib zeigte zudem Wirkungen im Einsatz gegen epitheliale Tumorzellen, einschließlich humane Prostata- und Mamma-karzinomzellen (Lombardo et al. 2004).

Sorafenib ist ein oral verfügbarer Multikinaseinhibitor mit antiproliferativer und antiangiogener Wirkung. Studien zeigten, dass Sorafenib Raf, PDGF, VEGF, FLT3, c-Kit und den MAPK-Signalweg blockiert (Hahn und Stadler 2006). Es wird angenommen, dass der zugrundeliegende Mechanismus eine kompetitive Hemmung der ATP-Bindung an die katalytischen Domänen der verschiedenen Kinasen beinhaltet (Wilhelm und Du Chien 2002).

Sorafenib wurde in den Versuchen in den Konzentrationen von $1 \mu \mathrm{M}$ und $5 \mu \mathrm{M}$ getestet. Bei der Konzentration von $5 \mu \mathrm{M}$ zeigten sich direkt nach $24 \mathrm{~h}$ mindestens signifikante Unterschiede zur DMSO-Kontrollgruppe (nur HD-LEC C3 zeigte keine Signifikanzen). In der Konzentration von $1 \mu \mathrm{M}$ zeigten sich in der Zelllinie Ly-LEC2, Ly-LEC12 und HDLEC C3 keine signifikanten Unterschiede zur DMSO-Kontrollgruppe. In den Zelllinien Ly-LEC1 zeigten sich an den Zeitpunkten $\mathrm{t}=24 \mathrm{~h}$ und $\mathrm{t}=48 \mathrm{~h}$ sehr signifikante $(\mathrm{p}<0,01$ $[* *])$ Unterschiede zur DMSO-Kontrollgruppe. Bei HD-LEC C2 und HD-LEC C4 zeigten sich auch an mindestens einem Zeitpunkt signifikante ( $\left.\leq 0,05\left[{ }^{*}\right]\right)$ Werte zur DMSOGruppe. Die Ergebnisse zeigen, dass Sorafenib in höherer Konzentration auf gesunde und erkrankte Lymphendothelzellen wirkt. Interessant ist, dass Sorafenib in der Konzentration von $1 \mu \mathrm{M}$ sehr stark auf die mutierten Ly-LEC1-Zellen wirkt, allerdings nicht auf LyLEC2 (Glu109del in Exon 2) und Ly-LEC12 (Mutation in Exon 10). Bei den gesunden Zellen HD-LEC C3 wirkt Sorafenib in der Konzentration von 1 und $5 \mu \mathrm{M}$ nicht, allerdings ist auch eine generell langsamere Proliferation von HD-LEC C3 im Vergleich zu den anderen Zelllinien zu vermerken. Es konnte bei den zwei anderen gesunden Zelllinien jedoch signifikante Unterschiede zur DMSO-Kontrollgruppe gemessen werden. 
Sorafenib ist zugelassen und hat sich als wirksam gegenüber mehreren soliden Tumoren, wie Nierenzellkarzinom und differenzierter Schilddrüsenkarzinome (DTC) erwiesen und ist inzwischen eine Standardtherapie für hepatozelluläre Karzinome (HCC) (Lang 2008). In einer klinischen Studie mit HCC zeigte Sorafenib herausragende Ergebnisse, insbesondere bei inoperablem HCC (Bruix und Sherman 2011).

\subsection{Western Blot-Versuche zur Darstellung der Aktivierung von AKT}

Es wurden Western Blot-Versuche an fünf Lymphendothelzelllinien (Ly-LEC1, Ly-LEC2, Ly-LEC12, HD-LEC C3 und HD-LEC C4) durchgeführt. Dabei wurde geprüft, ob es Unterschiede in der Phosphorylierung von AKT zwischen gesunden LECs und den LECs aus LM gibt.

Die Serin/Threoninkinase AKT (Proteinkinase B), welche sich unterhalb der PI3K in der Signalkaskade befindet, wurde in phosphorylierter Form (pAKT Serin473, $60 \mathrm{kDa}$ ) und in ihrer gesamten Form (tAKT $=$ total AKT, $60 \mathrm{kDa}$ ) nachgewiesen. Die Phosphorylierung von AKT an Serin (Ser473) und Threonin (Thr308) lässt darauf schließen, wie stark die PI3K aktiv ist. Zudem wurde das Haushaltsprotein alpha-Tubulin $(57 \mathrm{kDa})$ im gleichen Western Blot dargestellt, um die gleichmäßige Beladung des Gels zu überprüfen.

Das Ergebnis des Western Blots zeigt die verstärkte Aktivierung von pAKT an Ser473 in den LM-Zelllinien Ly-LEC1, Ly-LEC2 und Ly-LEC12. Im Gegensatz dazu konnte in den gesunden Zelllinien HD-LEC C3 und HD-LEC C4 keine deutliche Aktivität von pAKT festgestellt werden. Die Menge von tAKT und $\alpha$-Tubulin ist dagegen bei allen Proben ähnlich bzw. nahezu gleich.

\subsection{Ausblick der In-vitro-Daten auf eine klinische Therapie}

Können die In-vitro-Daten direkt auf die Situation bei Patienten, Säuglingen oder Erwachsenen übertragen werden? Es ist bekannt, dass sich Blutgefäßendothelzellen bei Erwachsenen kaum vermehren (Folkman und Cotran 1976). Allerdings gibt es zu Proliferation von Blutendothel und lymphatischen Endothelzellen bei Kindern geringe Studienlagen. Es ist davon auszugehen, dass in den kindlichen Wachstumsphasen die Proliferationsrate der Endothelzellen signifikant höher ist als bei einem Erwachsenen.

Dennoch ist der Umsatz von LECs bei Kleinkindern wahrscheinlich signifikant niedriger als die Proliferation dieser Zellen In-vitro. Daher sind die dargestellten Ergebnisse der In- 
vitro-Versuche möglicherweise nicht direkt auf die In-vivo-Situation übertragbar, und ein therapeutisches Fenster für Kinase-Inhibitoren könnte vorhanden sein.

Eine Hemmung der Proliferation der Lymphendothelzellen konnte bei der Verwendung der einzelnen Inhibitoren konzentrationsabhängig gemessen werden. Allerdings kam es zur Inhibition sowohl der kranken als auch der gesunden LECs in den In-vitro-Versuchen. Eine Behandlung von Kindern mit den verwendeten Kinase-Inhibitoren sollte genau und engmaschig überwacht werden. Weitere potenzielle Inhibitoren wie der selektive PI3K $\alpha$ Inhibitor Alpelisib (BYL719) wurde in Versuchen an PIK3CA-mutierten Mauszelllinien (Mutation: E545K und H1047R) mit gutem Erfolg untersucht (Fritsch et al. 2014). Alpelisib befindet sich nun in klinischen Phase II-Studien (Massacesi et al. 2016). Zudem versprechen die neuen Inhibitoren WX-554 (MEK-Inhibitor) und WX-037 (PI3K $\alpha, \delta$ Inhibitor) synergetische Wachstumshemmungen bei In-vitro-Studien und In-vivoMausmodellen mit HCT116 und HT29 Zelllinien (Haagensen et al. 2016). Eine Möglichkeit wäre, diese Inhibitoren auch in Proliferationsversuchen mit Lymphendothelzellen zu testen. 


\section{Zusammenfassung}

Lymphatische Malformationen (LM; Lymphangiome) sind gutartige kongenitale Fehlbildungsstörungen des Lymphgefäßsystems und zeichnen sich durch zystische Lymphgefäßerweiterungen aus. Dabei unterscheidet man die makrozystische, mikrozystische und gemischte Form der LM. Die LM treten vor allem im Kopf-, Mundund Halsbereich auf, sind aber auch an Rumpf, Extremitäten und im Mediastinum zu finden. Die Zysten sind dabei mit Lymphendothelzellen (LEC) ausgekleidet, welche typische Endothel- (CD31, VE-Cadherin) und Lymphendothelzellmarker (Podoplanin, PROX1, LYVE-1) exprimieren. Die Therapiemöglichkeiten umfassen vor allem die chirurgische Resektion und Sklerosierung der betroffenen Stellen. Eine kausale Standardtherapie gibt es bislang noch nicht. Allerdings haben kürzlich durchgeführte Studien gezeigt, dass sich in LM-Proben aktivierende Mutationen der katalytischen $\alpha$-UE des PIK3CA-Gens (Phosphatidylinositol-4,5-bisphosphate 3-kinase catalytic subunit alpha) befinden. Im Seattle Children's Hospital wurde LM-Gewebe von 31 Patienten auf aktivierende PIK3CA-Mutationen untersucht. Dabei zeigten sich bei $74 \%$ der Betroffenen spezifische Mutationen, typischerweise in Exon 8, 10 oder 21. Der genaue Zelltyp, in dem die Mutationen vorkamen, wurde aber nicht bestimmt.

Am Institut für Anatomie und Zellbiologie der UMG wurde LM-Gewebe von fünf Patienten in Kultur genommen. Aus dem LM-Gewebe wurden LECs und Fibroblasten isoliert und getrennt kultiviert. Frau Dr. S. Kaulfuß aus dem Institut für Humangenetik der UMG untersuchte die Zellen auf PIK3CA-Mutationen in den Exons 8, 10 und 21. Es zeigten sich bei vier von fünf LEC-Proben typische aktivierende, monoallelische PIK3CAMutationen; in den Fibroblasten waren keine Mutationen nachweisbar. In einer Zelllinie (Ly-LEC2) fand sich eine Deletion in Exon 2 (Glu109del), nicht jedoch in den Fibroblasten des Patienten. Neben dem LM-Gewebe wurden auch Lymphendothelzellen von juvenilen Spendern (PromoCell, Heidelberg) untersucht. Es fanden sich keine Mutationen in den Exons 8, 10 und 21 der PIK3CA.

In den durchgeführten Proteinnachweisversuchen (Western Blot) konnte eine deutlich verstärkte Expression von pAKT in den Zelllinien Ly-LEC1, Ly-LEC2 und Ly-LEC12 im Gegensatz zu den gesunden Zelllinien HD-LEC C3 und HD-LEC C4 nachweisen werden. Dies zeigt, dass der PI3K-AKT-mTOR-Signalweg in den mutierten LECs hoch aktiviert ist. 
Um die Proliferation der gesunden HD-LECs und der mutierten Ly-LECs zu bestimmen und den Einfluss von Inhibitoren zu testen, wurden Proliferationsassays an sechs LECLinien (drei gesunde vs. drei kranke) über $72 \mathrm{~h}$ durchgeführt. Dabei wurde durch spezifische Inhibitoren der PIK3CA und der downstream liegenden Kinasen mTOR und AKT, sowie weiterer Tyrosinkinasen versucht, die Proliferation der Ly-LEC spezifisch zu hemmen. Ziel ist es, mit Inhibitoren, die das Wachstum und die Angiogenese der Ly-LEC In-vitro inhibieren, ein therapeutisches Fenster für die Behandlung der LM-Patienten zu finden.

Die Proliferationsversuche zeigen zum Teil unterschiedliche und zum Teil gleichartige Wirkungen der acht verschiedenen Inhibitoren auf die gesunden LECs und die LM-LECs. Folgende Inhibitoren wurden in der vorliegenden Arbeit getestet: PI3K-Inhibitoren Wortmannin, BKM120, LY294002, CAL-101; mTOR-Inhibitor - Rapamycin; AKTInhibitor - MK-2206 und die Kinase-Inhibitoren - Dasatinib und Sorafenib.

Rapamycin hemmt das Zellwachstum als einziger Inhibitor in beiden verwendeten Konzentrationen im Nanomolarbereich stets hoch signifikant im Vergleich zur Lösungsmittel-Kontrolle (DMSO). Bei den anderen Inhibitoren hemmt die höher verwendete Konzentration (im Mikromolarbereich) in fast allen Fällen die Zelllinien signifikant im Vergleich zur DMSO-Kontrolle (Ausnahme LY294002 bei Ly-LEC2; CAL101 bei Ly-LEC2 und HD-LEC C2, Sorafenib bei HD-LEC C3). Bei der geringeren Konzentration kommt es zu keiner signifikanten Inhibition (Ausnahme BKM120 bei LyLEC12 und HD-LEC C2; MK-2206 bei Ly-LEC12, HD-LEC C2 und HD-LEC C4; Sorafenib bei Ly-LEC1 und HD-LEC C2).

Es zeigte sich im Allgemeinen keine eindeutig spezifische Inhibition der LM-LECs (LyLECs) ohne die Beeinflussung der gesunden HD-LECs. Einzig bei MK-2206 war eine Reduktion der mutierten LECs unter den Ausgangswert zu beobachten, was bei den gesunden LECs nicht der Fall war. Eine Inhibition der Proliferation der Lymphendothelzellen durch PI3K-/ mTOR-/ AKT- bzw. Tyrosinkinaseinhibitoren ist in einer gewissen Konzentration möglich. Allerdings beeinflussen die Inhibitoren die Proliferation von sowohl LM-LECs als auch gesunden LECs. Ob die Befunde der Untersuchungen direkt auf die In-vivo-Situation übertragen werden können, wird diskutiert. Eine Behandlung von LM-Patienten, wie sie mit Rapamycin nun bereits stattfindet, sollte auf jeden Fall streng und engmaschig kontrolliert werden. 


\section{Literaturverzeichnis}

Abernethy LJ (2003): Classification and imaging of vascular malformations in children. Eur Radiol 13, 2483-2497

Akcakanat A, Singh G, Hung MC, Meric-Bernstam F (2007): Rapamycin regulates the phosphorylation of rictor. Biochem Biophys Res Commun 362, 330-333

Akinleye A, Avvaru P, Furqan M, Song Y, Liu D (2013): Phosphatidylinositol 3-kinase (PI3K) inhibitors as cancer therapeutics. J Hematol Oncol $\underline{6}, 88$

Albuquerque RJC, Hayashi T, Cho WG, Kleinman ME, Dridi S, Takeda A, Baffi JZ, Yamada K, Kaneko H, Green MG et al. (2009): Alternatively spliced vascular endothelial growth factor receptor-2 is an essential endogenous inhibitor of lymphatic vessel growth. Nat Med 15, 1023-1030

Alcaraz C, Diego M, Pastor MJ, Escribano JM (1990): Comparison of a radioimmunoprecipitation assay to immunoblotting and ELISA for detection of antibody to African swine fever virus. J Vet Diagn Invest 2, 191-196

Alitalo K, Tammela T, Petrova TV (2005): Lymphangiogenesis in development and human disease. Nature $\underline{438}, 946-953$

Anderson KE, Coadwell J, Stephens LR, Hawkins PT (1998): Translocation of PDK-1 to the plasma membrane is important in allowing PDK-1 to activate protein kinase B. Current Biol 모 684-691

Arcado A, Wymann MP (1993): Wortmannin is a potent phosphatidylinositol 3-kinase inhibitor: the role of phosphatidylinositol 3,4,5-trisphosphate in neutrophil responses. Biochem J 296, 297-301

Ardelean MA, Bauer J, Schulz U, Schimpl G (2008): Lymphangiome: Der aktuelle Stellenwert der Therapie mit OK-432. pädiatrie \& pädologie $\underline{5}, 32-35$

Aumüller G, Aust G, Doll A, Engele J, Kirsch J, Mense S, Reißig D, Salvetter J, Schmidt W, Schmitz F et al.: Duale Reihe Anatomie. 2., überarb. Auflage. Thieme, Stuttgart 2010

Bachman KE, Argani P, Samuels Y, Silliman N, Ptak J, Szabo S, Konishi H, Karakas B, Blair BG, Lin C et al. (2004): The PIK3CA gene is mutated with high frequency in human breast cancers. Cancer Biol Ther $\underline{3}, 772-775$

Banerji S, Ni J, Wang SX, Clasper S, Su J, Tammi R, Jones M, Jackson DG (1999): LYVE1, a New Homologue of the CD44 Glycoprotein, Is a Lymph-specific Receptor for Hyaluronan. J Cell Biol 144, 789-801

Bazigou E, Xie S, Chen C, Weston A, Miura N, Sorokin L, Adams R, Muro AF, Sheppard $\mathrm{D}$, Makinen T (2009): Integrin-alpha9 is required for fibronectin matrix assembly during lymphatic valve morphogenesis. Dev Cell 17, 175-186

Boscolo E, Coma S, Luks VL, Greene AK, Klagsbrun M, Warman ML, Bischoff J (2015): AKT hyper-phosphorylation associated with PI3K mutations in lymphatic endothelial cells from a patient with lymphatic malformation. Angiogenesis $\underline{18}, 151-162$

Broderick DK, Di C, Parrett TJ, Samuels YR, Cummins JM, McLendon RE, Fults DW, Velculescu VE, Bigner DD, Yan H (2004): Mutations of PIK3CA in anaplastic oligodendrogliomas, high-grade astrocytomas, and medulloblastomas. Cancer Res $\underline{64}$, $5048-5050$

Brown JR, Byrd JC, Coutre SE, Benson DM, Flinn IW, Wagner-Johnston ND, Spurgeon SE, Kahl BS, Bello C, Webb HK et al. (2014): Idelalisib, an inhibitor of 
phosphatidylinositol 3-kinase p1108, for relapsed/refractory chronic lymphocytic leukemia. Blood 123, 3390-3397

Bruix J, Sherman M (2011): Management of hepatocellular carcinoma: An update. Hepatology $\underline{53}, 1020-1022$

Buckmiller LM, Richter GT, Suen JY (2010): Diagnosis and management of hemangiomas and vascular malformations of the head and neck. Oral Dis $\underline{16}, 405-418$

Butler MG, Isogai S, Weinstein BM (2009): Lymphatic development. Birth Defects Res C Embryo Today $\underline{\text { 87, 222-231 }}$

Byrd JC, Woyach JA, Johnson AJ (2012): Translating PI3K-Delta Inhibitors to the Clinic in Chronic Lymphocytic Leukemia: The Story of CAL-101 (GS1101). Am Soc Clin Oncol Educ Book 10, 691-694

Castellano E, Downward J (2011): RAS Interaction with PI3K: More Than Just Another Effector Pathway. Genes Cancer 2, 261-274

Castel P, Carmona FJ, Grego-Bessa J, Berger MF, Viale A, Anderson KV, Bague S, Scaltriti M, Antonescu CR, Baselga E et al. (2016): Somatic PIK3CA mutations as a driver of sporadic venous malformations. Sci Transl Med $\underline{8}$, 332-342

Castillo SD, Vanhaesebroeck B, Sebire NJ (2016a): Phosphoinositide 3-kinase: A new kid on the block in vascular anomalies. J Pathol 240, 387-396

Castillo SD, Tzouanacou E, Zaw-Thin M, Berenjeno IM, Parker VER, Chivite I, MilàGuasch M, Pearce W, Solomon I, Angulo-Urarte A et al. (2016b): Somatic activating mutations in Pik3ca cause sporadic venous malformations in mice and humans. Sci Transl Med $\underline{8}, 332-343$

Cell Signaling Technology (2008): Interaktiver Signalweg mTOR. Online verfügbar unter https://www.cellsignal.de/contents/science-cst-pathways-pi3k-akt-signaling-

resources/mtor-signaling-interactive-pathway/pathways-mtor-signaling. Zuletzt geprüft am 25.06.2019

Chang MT, Asthana S, Gao SP, Lee BH, Chapman JS, Kandoth C, Gao J, Socci ND, Solit $\mathrm{DB}$, Olshen $\mathrm{AB}$ et al. (2016): Identifying recurrent mutations in cancer reveals widespread lineage diversity and mutational specificity. Nat Biotechnol $\underline{34}, 155-163$

Cisbio (2016): C-Src Simpified Pathway. Online verfügbar unter

https://www.cisbio.eu/phospho-c-src-tyr419-cellular-kit-40624. Zuletzt geprüft am 24.06.2019

Clemens RK, Pfammatter T, Meier TO, Alomari AI, Amann-Vesti BR (2015a): Vascular malformations revisited. Vasa $\underline{44}, 5-22$

Clemens RK, Pfammatter T, Meier TO, Alomari AI, Amann-Vesti BR (2015b): Combined and complex vascular malformations. Vasa $\underline{44}, 92-105$

Colwell J (2016): PI3K Inhibitor Improves PFS in BELLE-2 Trial. Cancer Discov $\underline{6}, 115-$ 116

Criscitiello C, Viale G, Curigliano G, Goldhirsch A (2018): Profile of buparlisib and its potential in the treatment of breast cancer: Evidence to date. Breast Cancer (Dove Med Press) $\underline{10}, 23-29$

Croonen EA, Nillesen WM, Stuurman KE, Yntema HG (2013): Prenatal diagnostic testing of the Noonan syndrome genes in fetuses with abnormal ultrasound findings. Eur J Hum Genet 21, 936-942 
Denorme P, Morren M-A, Hollants S, Spaepen M, Suaer K, Zutterman N, Labarque V, Legius E, Brems H (2018): Phosphatidylinositol-4,5-bisphosphate 3-kinase catalytic subunit alpha (PIK3CA)-related overgrowth spectrum: A brief report. Pediatr Dermatol $\underline{35}$, 186-188

Desmedt C, Fumagalli D, Pietri E, Zoppoli G, Brown D, Nik-Zainal S, Gundem G, Rothé F, Majjaj S, Garuti A et al. (2015): Uncovering the genomic heterogeneity of multifocal breast cancer. J Pathol 236, 457-466

Do K, Speranza G, Bishop R, Khin S, Rubinstein L, Kinders RJ, Datiles M, Eugeni M, Lam MH, Doyle LA et al. (2015): Biomarker-driven phase 2 study of MK-2206 and selumetinib (AZD6244, ARRY-142886) in patients with colorectal cancer. Invest New Drugs $\underline{33}, 720-728$

Dorsey JF, Jove R, Kraker AJ, Wu J (2000): The pyrido[2,3-d]pyrimidine derivative PD180970 inhibits p210 Bcr-Abl tyrosine kinase and induces apoptosis of K562 leukemic cells. Cancer Res $\underline{60}, 3127-3131$

El-Kholy W, Macdonald PE, Lin JH, Wang J, Fox JM, Light PE, Wang Q, Tsushima RG, Wheeler MB (2003): The phosphatidylinositol 3-kinase inhibitor LY294002 potently blocks $\mathrm{K}(\mathrm{V})$ currents via a direct mechanism. FASEB J 17, 720-722

Engelman JA (2009): Targeting PI3K signalling in cancer: Opportunities, challenges and limitations. Nat Rev Cancer 9, 550-562

Folkman J, Cotran R (1976): Relation of vascular proliferation to tumor growth. Int Rev Exp Pathol 16, 207-248

Fouladi M, Perentesis JP, Phillips CL, Leary S, Reid JM, McGovern RM, Ingle AM, Ahern $\mathrm{CH}$, Ames MM, Houghton P et al. (2014): A phase I trial of MK-2206 in children with refractory malignancies: A Children's Oncology Group study. Pediatr Blood Cancer $\underline{61}$, 1246-1251

Fritsch C, Huang A, Chatenay-Rivauday C, Schnell C, Reddy A, Liu M, Kauffmann A, Guthy D, Erdmann D, Pover A et al. (2014): Characterization of the novel and specific PI3K $\alpha$ inhibitor NVP-BYL719 and development of the patient stratification strategy for clinical trials. Mol Cancer Ther 13 , 1117-1129

Fritz-Niggli, H., Jung, E. G., Klunker, W., Korn-Heydt, G. E., Niermann, H., Curth, H. O., Šalamon, T., Schnyder, U. W., Sohar, E., Wendt, G. G. et al. (Hrsg.): Vererbung von Hautkrankheiten. Springer, Berlin 1966

Fruman DA, Chiu H, Hopkins BD, Bagrodia S, Cantley LC, Abraham RT (2017): The PI3K Pathway in Human Disease. Cell 170, 605-635

Fulton D, Gratton JP, McCabe TJ, Fontana J, Fujio Y, Walsh K, Franke TF, Papapetropoulos A, Sessa WC (1999): Regulation of endothelium-derived nitric oxide production by the protein kinase Akt. Nature 399, 597-601

Geuna E, Milani A, Martinello R, Aversa C, Valabrega G, Scaltriti M, Montemurro F (2015): Buparlisib an oral pan-PI3K inhibitor for the treatment of breast cancer. Expert Opin Investig Drugs 24, 421-431

Grasso DL, Pelizzo G, Zocconi E, Schleef J (2008): Lymphangiomas of the head and neck in children. Acta Otorhinolaryngologica Ital $\underline{28}, 17-20$

Guba M, Breitenbuch P von, Steinbauer M, Koehl G, Flegel S, Hornung M, Bruns CJ, Zuelke C, Farkas S, Anthuber M et al. (2002): Rapamycin inhibits primary and metastatic 
tumor growth by antiangiogenesis: Involvement of vascular endothelial growth factor. Nat Med $\underline{8}, 128-135$

Guo G, Sun X, Chen C, Wu S, Huang P, Li Z, Dean M, Huang Y, Jia W, Zhou Q et al. (2013): Whole-genome and whole-exome sequencing of bladder cancer identifies frequent alterations in genes involved in sister chromatid cohesion and segregation. Nat Genet $\underline{45}$, 1459-1463

Haagensen EJ, Thomas HD, Schmalix WA, Payne AC, Kevorkian L, Allen RA, Bevan P, Maxwell RJ, Newell DR (2016): Enhanced anti-tumour activity of the combination of the novel MEK inhibitor WX-554 and the novel PI3K inhibitor WX-037. Cancer Chemother Pharmacol 78, 1269-1281

Hahn O, Stadler W (2006): Sorafenib. Curr Opin Oncol 18, 615-621

Ha J, Yu Y-C, Lannigan F (2014): A Review of the Management of Lymphangiomas. CPR $\underline{10}, 238-248$

Hammill AM, Wentzel M, Gupta A, Nelson S, Lucky A, Elluru R, Dasgupta R, Azizkhan RG, Adams DM (2011): Sirolimus for the treatment of complicated vascular anomalies in children. Pediatr Blood Cancer 57, 1018-1024

Harada K, Baba Y, Shigaki H, Ishimoto T, Miyake K, Kosumi K, Tokunaga R, Izumi D, Ohuchi M, Nakamura K et al. (2016): Prognostic and clinical impact of PIK3CA mutation in gastric cancer: Pyrosequencing technology and literature review. BMC Cancer 16, 400

Harms V: Physik für Mediziner und Pharmazeuten: Ein kurz gefasstes Lehrbuch. 15., überarb. Auflage. Harms, Lindhöft 2000

Hasselhof V, Sperling A, Buttler K, Ströbel P, Becker J, Aung T, Felmerer G, Wilting J (2016): Morphological and Molecular Characterization of Human Dermal Lymphatic Collectors. PLoS ONE $\underline{11}$, e0164964

Hosoi H, Dilling MB, Liu LN, Danks MK, Shikata T, Sekulic A, Abraham RT, Lawrence JC, Houghton PJ (1998): Studies on the mechanism of resistance to rapamycin in human cancer cells. Mol pharmacol 54, 815-824

Huber S, Bruns CJ, Schmid G, Hermann PC, Conrad C, Niess H, Huss R, Graeb C, Jauch $\mathrm{KW}$, Heeschen $\mathrm{C}$ et al. (2007): Inhibition of the mammalian target of rapamycin impedes lymphangiogenesis. Kidney Int 71, 771-777

Humar R, Kiefer FN, Berns H, Resink TJ, Battegay EJ (2002): Hypoxia enhances vascular cell proliferation and angiogenesis in vitro via rapamycin (mTOR)-dependent signaling. FASEB J $\underline{16}, 771-780$

Ikeda H, Hideshima T, Fulciniti M, Perrone G, Miura N, Yasui H, Okawa Y, Kiziltepe T, Santo L, Vallet S et al. (2010): PI3K/p110\{delta $\}$ is a novel therapeutic target in multiple myeloma. Blood 116, 1460-1468

Janku F, Wheler JJ, Westin SN, Moulder SL, Naing A, Tsimberidou AM, Fu S, Falchook GS, Hong DS, Garrido-Laguna I et al. (2012): PI3K/AKT/mTOR inhibitors in patients with breast and gynecologic malignancies harboring PIK3CA mutations. J Clin Oncol $\underline{30}$, 777-782

Janku F (2017): Phosphoinositide 3-kinase (PI3K) pathway inhibitors in solid tumors: From laboratory to patients. Cancer Treat Rev $\underline{59}, 93-101$

Jeltsch M, Tammela T, Alitalo K, Wilting J (2003): Genesis and pathogenesis of lymphatic vessels. Cell Tissue Res $\underline{314}$, 69-84 
Jones S, Wang TL, Shih IM, Mao TL, Nakayama K, Roden R, Glas R, Slamon D, Diaz LA, Vogelstein B et al. (2010): Frequent mutations of chromatin remodeling gene ARID1A in ovarian clear cell carcinoma. Science 330, 228-231

Joukov V, Kaipainen A, Jeltsch M, Pajusola K, Olofsson B, Kumar V, Eriksson U, Alitalo K (1997): Vascular endothelial growth factors VEGF-B and VEGF-C. Cell Physiol $\underline{173}$, $211-215$

Kang S, Bader AG, Vogt PK (2005): Phosphatidylinositol 3-kinase mutations identified in human cancer are oncogenic. Proc Nat Acad Sci USA $\underline{102}$, 802-807

Karakas B, Bachman KE, Park BH (2006): Mutation of the PIK3CA oncogene in human cancers. Br J Cancer 94, 455-459

Kärpänen T, Heckman CA, Keskitalo S, Jeltsch M, Ollila H, Neufeld G, Tamagnone L, Alitalo K (2006): Functional interaction of VEGF-C and VEGF-D with neuropilin receptors. FASEB J 20, 1462-1472

Kobayashi S, Kishimoto T, Kamata S, Otsuka M, Miyazaki M, Ishikura H (2007): Rapamycin, a specific inhibitor of the mammalian target of rapamycin, suppresses lymphangiogenesis and lymphatic metastasis. Cancer Sci $\underline{98}$, 726-733

Kohn AD, Summers SA, Birnbaum MJ, Roth RA (1996): Expression of a Constitutively Active Akt Ser/Thr Kinase in 3T3-L1 Adipocytes Stimulates Glucose Uptake and Glucose Transporter 4 Translocation. J Biol Chem 271, 31372-31378

Krycer JR, Sharpe LJ, Luu W, Brown AJ (2010): The Akt-SREBP nexus: Cell signaling meets lipid metabolism. Trends Endocrinol Metab 21, 268-276

Kurek KC, Luks VL, Ayturk UM, Alomari AI, Fishman SJ, Spencer SA, Mulliken JB, Bowen ME, Yamamoto GL, Kozakewich HPW et al. (2012): Somatic mosaic activating mutations in PIK3CA cause CLOVES syndrome. Am J Hum Genet 90, 1108-1115

Laemmli UK (1970): Cleavage of structural proteins during the assembly of the head of bacteriophage T4. Nature 227, 680-685

Lang L (2008): FDA approves sorafenib for patients with inoperable liver cancer. Gastroenterology 134, 379

Lannutti BJ, Meadows SA, Herman SEM, Kashishian A, Steiner B, Johnson AJ, Byrd JC, Tyner JW, Loriaux MM, Deininger M et al. (2011): CAL-101, a p110delta selective phosphatidylinositol-3-kinase inhibitor for the treatment of B-cell malignancies, inhibits PI3K signaling and cellular viability. Blood 117, 591-594

Limaye N, Vikkula M: Molecular and Genetic Aspects of Hemangiomas and Vascular Malformations. In: Mattassi R, Loose DA, Vaghi M (Hrsg.): Hemangiomas and Vascular Malformations: An Atlas of Diagnosis and Treatment. 2. Auflage; Springer, Mailand 2015, $21-38$

Lindauer M, Hochhaus A (2014): Dasatinib. Recent Results Cancer Res 201, 27-65

Liu P, Cheng H, Roberts TM, Zhao JJ (2009): Targeting the phosphoinositide 3-kinase pathway in cancer. Nat Rev Drug Discov $\underline{8}, 627-644$

Lombardo LJ, Lee FY, Chen P, Norris D, Barrish JC, Behnia K, Castaneda S, Cornelius LAM, Das J, Doweyko AM et al. (2004): Discovery of N-(2-chloro-6-methyl- phenyl)-2(6-(4-(2-hydroxyethyl)- piperazin-1-yl)-2-methylpyrimidin-4- ylamino)thiazole-5carboxamide (BMS-354825), a dual Src/Abl kinase inhibitor with potent antitumor activity in preclinical assays. J Med Chem $\underline{47}, 6658-6661$ 
Luks VL, Kamitaki N, Vivero MP, Uller W, Rab R, Bovée JVMG, Rialon KL, Guevara CJ, Alomari AI, Greene AK et al. (2015): Lymphatic and other vascular malformative/overgrowth disorders are caused by somatic mutations in PIK3CA. J Pediatr $\underline{166}, 1048-1054$

Maby-El Hajjami H, Petrova TV (2008): Developmental and pathological lymphangiogenesis: From models to human disease. Histochem Cell Biol 130, 1063-1078

Maira SM, Stauffer F, Schnell C, García-Echeverría C (2009): PI3K inhibitors for cancer treatment: Where do we stand? Biochem Soc Trans $\underline{37}, 265-272$

Maira SM, Pecchi S, Huang A, Burger M, Knapp M, Sterker D, Schnell C, Guthy D, Nagel T, Wiesmann $\mathrm{M}$ et al. (2012): Identification and characterization of NVP-BKM120, an orally available pan-class I PI3-kinase inhibitor. Mol Cancer Ther 11, 317-328

Manning BD, Cantley LC (2007): AKT/PKB signaling: Navigating downstream. Cell $\underline{129}$, $1261-1274$

Manning SC, Perkins J (2013): Lymphatic malformations. Curr Opin Otolaryngol Head Neck Surg 21, 571-575

Massacesi C, Di Tomaso E, Urban P, Germa C, Quadt C, Trandafir L, Aimone P, Fretault N, Dharan B, Tavorath R et al. (2016): PI3K inhibitors as new cancer therapeutics: Implications for clinical trial design. Onco Targets Ther $\underline{9}, 203-210$

Mayo LD, Donner DB (2001): A phosphatidylinositol 3-kinase/Akt pathway promotes translocation of Mdm2 from the cytoplasm to the nucleus. Proc Natl Acad Sci U S A $\underline{98}$, 11598-11603

Menendez-Castro C, Zapke M, Fahlbusch F, Goessel H, Rascher W, Jüngert J (2017): Microbubbles in macrocysts - Contrast-enhanced ultrasound assisted sclerosant therapy of a congenital macrocystic lymphangioma: A case report. BMC Med Imaging 17, 39

Miceli A, Stewart KM (2017): Lymphangioma. StatPearls Publishing LLC 12, 1235-1237

Mirzaa G, Conway R, Graham JM, Dobyns (2013): PIK3CA -Related Segmental Overgrowth. GeneReviews ${ }^{\circledR}, 1-50$

Norgall S, Papoutsi M, Rössler J, Schweigerer L, Wilting J, Weich HA (2007): Elevated expression of VEGFR-3 in lymphatic endothelial cells from lymphangiomas. BMC Cancer $\underline{7}$

Norrmén C, Tammela T, Petrova TV, Alitalo K (2011): Biological basis of therapeutic lymphangiogenesis. Circulation $\underline{123}, 1335-1351$

Novus Biologicals (2019): Western Blot Protocol. Online verfügbar unter https://images.novusbio.com/design/westernBlotBenchtopProtocol.pdf. Zuletzt geprüft am 24.06.2019

Ogita S, Tsuto T, Nakamura K, Deguchi E, Iwai N (1994): OK-432 Therapy in 64 Patients with Lymphangioma. Jourmal of Pediatric Surgery 29, 784-785

Olsson AK, Dimberg A, Kreuger J, Claesson-Welsh L (2006): VEGF receptor signalling in control of vascular function. Nat Rev Mol Cell Biol ㄱ, 359-371

Osborn AJ, Dickie P, Neilson DE, Glaser K, Lynch KA, Gupta A, Dickie BH (2015):

Activating PIK3CA alleles and lymphangiogenic phenotype of lymphatic endothelial cells isolated from lymphatic malformations. Hum Mol Genet 24, 926-938

Patel V, Marsh CA, Dorsam RT, Mikelis CM, Masedunskas A, Amornphimoltham P, Nathan CAO, Nathan CA, Singh B, Weigert R et al. (2011): Decreased lymphangiogenesis 
and lymph node metastasis by mTOR inhibition in head and neck cancer. Cancer Research $\underline{71}, 7103-7112$

Perkins JA, Manning SC, Tempero RM, Cunningham MJ, Edmonds JL, Hoffer FA, Egbert MA (2010): Lymphatic malformations: Review of current treatment. Otolaryngol Head Neck Surg $\underline{142}, 795-803$

Petrova TV, Mäkinen T, Mäkelä TP, Saarela J, Virtanen I, Ferrell RE, Finegold DN, Kerjascki D, Ylä-Herttuala SY, Alitalo K (2002): Lymphatic endothelial reprogramming of vascular endothelial cells by the Prox-1 homeobox transcription factor. EMBO J 21, 45934599

Rautio R, Keski-Nisula L, Laranne J, Laasonen E (2003): Treatment of lymphangiomas with OK-432 (Picibanil). Cardiovasc Intervent Radiol 26, 31-36

Rengier F: Basics Anatomie - Leitungsbahnen. Elsevier Urban \& Fischer, München 2009

Rodon J, Braña I, Siu LL, Jonge MJ de, Homji N, Mills D, Di Tomaso E, Sarr C, Trandafir L, Massacesi C et al. (2014): Phase I dose-escalation and -expansion study of buparlisib (BKM120), an oral pan-Class I PI3K inhibitor, in patients with advanced solid tumors. Invest New Drugs $\underline{32}, 670-681$

Rössler J, Braunschweiger F, Schill T (2014): Medikamentöse Behandlungsansätze für infantile Hämangiome und lymphatische Malformationen. HNO $\underline{62}, 12-18$

Rössler J (2015): Neuigkeiten bei der Behandlung von lymphatischen Malformationen. padiatr hautnah $\underline{27}, 58-61$

Saharinen P, Tammela T, Karkkainen MJ, Alitalo K (2004): Lymphatic vasculature: Development, molecular regulation and role in tumor metastasis and inflammation. Trends Immunol 25, 387-395

Samedi VM, Elsharkawy A (2017): Rare lymphatic malformation in an extreme premature infant: answer. J Pediatr Neonat Individual Med $\underline{6}, 1-3$

Samuels Y, Wang Z, Bardelli A, Silliman N, Ptak J, Szabo S, Yan H, Gazdar A, Powell SM, Riggins GJ et al. (2004): High frequency of mutations of the PIK3CA gene in human cancers. Science $\underline{304}, 554$

Samuels Y, Velculescu VE (2004): Oncogenic mutations of PIK3CA in human cancers. Cell Cycle $\underline{3}, 1221-1224$

Samuels Y, Ericson K (2006): Oncogenic PI3K and its role in cancer. Curr Opin Oncol $\underline{18}$, $77-82$

Schacht V, Ramirez MI, Hong Y-K, Hirakawa S, Feng D, Harvey N, Williams M, Dvorak AM, Dvorak HF, Oliver G et al. (2003): T1alpha/podoplanin deficiency disrupts normal lymphatic vasculature formation and causes lymphedema. EMBO J 22, 3546-3556

Scheid MP, Woodgett JR (2003): Unravelling the activation mechanisms of protein kinase B/Akt. FEBS Letters 546, 108-112

Selleck Chemicals (2013): PI3K. Online verfügbar unter Www.selleckchem.com/PI3K.html. Zuletzt geprüft am 25.06.2019

Shah NP, Tran C, Lee FY, Chen P, Norris D, Sawyers CL (2004): Overriding imatinib resistance with a novel ABL kinase inhibitor. Science 305, 399-401

Sirohi B, Rastogi S, Dawood S (2015): Buparlisib in breast cancer. Future Oncol 11, $1463-$ 1470 
Stadler F, Iro H, Werner JA: Handbuch HNO 2009(HNO UP DATE). Springer, Berlin, Heidelberg 2010

Tammela T, Petrova TV, Alitalo K (2005): Molecular lymphangiogenesis: New players. Trends Cell Biol 15, 434-441

Tammela T, Alitalo K (2010): Lymphangiogenesis: Molecular mechanisms and future promise. Cell $\underline{140}, 460-476$

Vanhaesebroeck B, Leevers SJ, Panayotou G, Waterfield MD (1997): Phosphoinositide 3kinases: A conserved family of signal transducers. Trends Biochem Sci 22, 267-272

Vanhaesebroeck B, Waterfield MD (1999): Signaling by distinct classes of phosphoinositide 3-kinases. Exp Cell Res 253, 239-254

Vanhaesebroeck B, Guillermet-Guibert J, Graupera M, Bilanges B (2010): The emerging mechanisms of isoform-specific PI3K signalling. Nat Rev Mol Cell Biol 11, 329-341

Vlahos CJ, Matter WF, Hui KY, Brown RF (1994): A specific inhibitor of phosphatidylinositol 3-kinase, 2-(4-morpholinyl)-8-phenyl-4H-1-benzopyran-4-one (LY294002). J Biol Chem 269, 5241-5248

Völkers M, Sussman M (2013): mTOR/PRAS40 interaction: Hypertrophy or proliferation. Cell Cycle 12, 3579-3580

Wagener C, Müller O: Molekulare Onkologie: Entstehung, Progression, klinische Aspekte ; 95 Tabellen. 3., komplett aktualisierte und erweiterte Auflage. Thieme, Stuttgart 2010

Wick N, Saharinen P, Saharinen J, Gurnhofer E, Steiner CW, Raab I, Stokic D, Giovanoli P, Buchsbaum S, Burchard A et al. (2007): Transcriptomal comparison of human dermal lymphatic endothelial cells ex vivo and in vitro. Physiol Genomics $\underline{28}$, 179-192

Wiegand S, Wichmann G, Dietz A (2018): Treatment of Lymphatic Malformations with the mTOR Inhibitor Sirolimus: A Systematic Review. Lymphat Res Biol 16, 330-339

Wilhelm S, Du Chien S (2002): BAY 43-9006: Preclinical data. Curr Pharm Des $\underline{8}$, 22552257

Wilson JM, Kunnimalaiyaan S, Gamblin TC, Kunnimalaiyaan M (2014): MK2206 inhibits hepatocellular carcinoma cellular proliferation via induction of apoptosis and cell cycle arrest. J Surg Res 191, 280-285

Wilting J, Papoutsi M, Christ B, Nicolaides KH, Kaisenberg CS von, Borges J, Stark GB, Alitalo K, Tomarev SI, Niemeyer C et al. (2002): The transcription factor Prox1 is a marker for lymphatic endothelial cells in normal and diseased human tissues. FASEB J $\underline{16}$, $1271-1273$

Wilting J, Christ B, Yuan L, Eichmann A (2003a): Cellular and molecular mechanisms of embryonic haemangiogenesis and lymphangiogenesis. Naturwissenschaften $\underline{90}, 433-448$

Wilting J, Tomarev SI, Christ B, Schweigerer L (2003b): Lymphangioblasts in embryonic lymphangiogenesis. Lymphat Res Biol $1,33-40$

Wilting J, Aref Y, Huang R, Tomarev SI, Schweigerer L, Christ B, Valasek P, Papoutsi M (2006): Dual origin of avian lymphatics. Dev Biol 292, 165-173

Wullschleger S, Loewith R, Hall MN (2006): TOR signaling in growth and metabolism. Cell $\underline{124}, 471-484$

Wymann MP, Bulgarelli-Leva G, Zvelebil MJ, Pirola L, Vanhaesebroeck B, Waterfield MD, Panayotou G (1996): Wortmannin inactivates phosphoinositide 3-kinase by covalent 
modification of Lys-802, a residue involved in the phosphate transfer reaction. Mol Cell Biol 16, 1722-1733

Yeung KS, Ip JJK, Chow CP, Kuong EYL, Tam PK-H, Chan GC-F, Chung BH-Y (2017):

Somatic PIK3CA mutations in seven patients with PIK3CA-related overgrowth spectrum. Am J Med Genet A $\underline{173}$, 978-984

Zadvinskis DP, Benson M, Kerr HH, Mancuso AA, Cacciarelli AA, Madrazo BL, Mafee MF, Dalen K (1992): Congenital Malformations of the Cervicothoracic Lymphatic System: Embryology and Pathogenesis. RadioGraphics 12, 1175-1189

Zhao L, Vogt PK (2008): Class I PI3K in oncogenic cellular transformation. Oncogene 27, 5486-5496

Zhou H, Luo Y, Huang S (2010): Updates of mTOR inhibitors. Anticancer Agents Med Chem $\underline{10}, 571-581$ 


\section{Danksagung}

Ich möchte an dieser Stelle meinem betreuenden Doktorvater, Herrn Prof. Dr. rer. nat. Jörg Wilting meinen Dank für die Vergabe des spannenden Dissertationsthemas und seine stetige Unterstützung aussprechen. Für die Möglichkeit der Teilnahme und Vorstellung meiner Arbeit bei der Lymphologica 2017 in Bad Soden möchte ich mich sehr bedanken.

Herrn PD Dr. rer. nat. Jürgen Becker möchte ich ganz herzlich danken für die praktische Einführung in die Zellbiologie und die engagierte und intensive Betreuung meiner Arbeit.

Zudem möchte ich mich bei meiner Zweitbetreuerin Frau PD Dr. rer. nat. Silke Kaulfuß für die Unterstützung meiner Arbeit bedanken.

Für die Einführung in die Zellkultur und die Western Blot Technik möchte ich mich besonders bei Sonja Schwoch bedanken. Auch möchte ich mich bei Frau Dr. rer. nat. Martina Vockerodt und bei Melanie Lohrberg für ihre Diskussionsbereitschaft bedanken. 